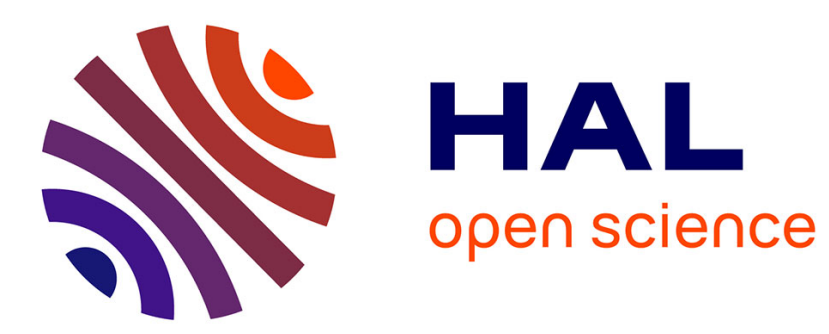

\title{
High resolution reconstructions of the Southwest Indian Ridge, 52 Ma to present: implications for the breakup and absolute motion of the Africa plate
}

C Demets, S Merkouriev, D Sauter

\section{- To cite this version: \\ C Demets, S Merkouriev, D Sauter. High resolution reconstructions of the Southwest Indian Ridge, $52 \mathrm{Ma}$ to present: implications for the breakup and absolute motion of the Africa plate. Geophysical Journal International, 2021, 226 (3), pp.1461-1497. 10.1093/gji/ggab107 . hal-03551495}

\author{
HAL Id: hal-03551495 \\ https://hal.science/hal-03551495
}

Submitted on 1 Feb 2022

HAL is a multi-disciplinary open access archive for the deposit and dissemination of scientific research documents, whether they are published or not. The documents may come from teaching and research institutions in France or abroad, or from public or private research centers.
L'archive ouverte pluridisciplinaire HAL, est destinée au dépôt et à la diffusion de documents scientifiques de niveau recherche, publiés ou non, émanant des établissements d'enseignement et de recherche français ou étrangers, des laboratoires publics ou privés. 


\title{
High resolution reconstructions of the Southwest Indian Ridge, 52 Ma to present: implications for the breakup and absolute motion of the Africa plate
}

\author{
C. DeMets ${ }^{\oplus},{ }^{1}$ S. Merkouriev ${ }^{2,3}$ and D. Sauter ${ }^{\oplus 4}$ \\ ${ }^{1}$ Department of Geoscience, University of Wisconsin-Madison, Madison, WI 53706,USA. E-mail: dcdemets@wisc.edu \\ ${ }^{2}$ Pushkov Institute of Terrestrial Magnetism of the Russian Academy of Sciences, St Petersburg Filial, 1 Mendeleevskaya Liniya, St Petersburg 199034, Russia \\ ${ }^{3}$ Saint Petersburg State University, Institute of Earth Sciences Universitetskaya nab., 7-9, St. Petersburg 199034, Russia \\ ${ }^{4}$ Institut Terre et Environnement de Strasbourg Universite de Strasbourg CNRS UMR 70635 rue Descartes, Strasbourg F-67084, France
}

Accepted 2021 March 15. Received 2021 March 2; in original form 2020 September 1

\begin{abstract}
SUMMAR Y
We reconstruct the post-52 Ma seafloor spreading history of the Southwest Indian Ridge at 44 distinct times from inversions of $\approx 20000$ magnetic reversal, fracture zone and transform fault crossings, spanning major regional tectonic events such as the Arabia-Eurasia continental collision, the Arabia Peninsula's detachment from Africa, the arrival of the Afar mantle plume below eastern Africa and the initiation of rifting in eastern Africa. Best-fitting and noise-reduced rotation sequences for the Nubia-Antarctic, Lwandle-Antarctic and Somalia-Antarctic Plate pairs indicate that spreading rates everywhere along the ridge declined gradually by $\approx 50$ per cent from $\approx 31$ to $19-18 \mathrm{Ma}$. A concurrent similar-magnitude slowdown in the component of the Africa Plate's absolute motion parallel to Southwest Indian Ridge spreading suggests that both were caused by a 31-18 Ma change in the forces that drove and resisted Africa's absolute motion. Possible causes for this change include the effects of the Afar mantle plume on eastern Africa or the Arabia Peninsula's detachment from the Somalia Plate, which culminated at 20-18 Ma with the onset of seafloor spreading in the Gulf of Aden. At earlier times, an apparently robust but previously unknown $\approx 6$-Myr-long period of rapid kinematic change occurred from 43 to $37 \mathrm{Ma}$, consisting of a $\approx 50$ per cent spreading rate slowdown from 43 to $40 \mathrm{Ma}$ followed by a full spreading rate recovery and $30-40^{\circ}$ clockwise rotation of the plate slip direction from 40 to $37 \mathrm{Ma}$. Although these kinematic changes coincided with a reconfiguration of the palaeoridge geometry, their underlying cause is unknown. Southwest Indian Ridge abyssal hill azimuths are consistent with the slip directions estimated with our newly derived Somalia-Antarctic and Lwandle-Antarctic angular velocities, adding confidence in their reliability. Lwandle-Antarctica Plate motion has closely tracked Somalia-Antarctic Plate motion since $50 \mathrm{Ma}$, consistent with slow-to-no motion between the Lwandle and Somalia plates for much of that time. In contrast, Nubia-Somalia rotations estimated from our new Southwest Indian Ridge rotations indicate that $189 \pm 34 \mathrm{~km}$ of WNW-ESE divergence between Nubia and Somalia has occurred in northern Africa since $40 \mathrm{Ma}$, including 70-80 km of WNW-ESE divergence since 17-16 Ma, slow to no motion from 26 to $17 \mathrm{Ma}$, and $109 \pm$ $38 \mathrm{~km}$ of WNW-ESE divergence from 40 to $\approx 26 \mathrm{Ma}$ absent any deformation within eastern Antarctica before $26 \mathrm{Ma}$.
\end{abstract}

Key words: Plate motions; Africa; Antarctica.

\section{INTRODUCTION AND BACKGROUND}

The Southwest Indian Ridge (hereafter SWIR) has accommodated motion between the Africa and Antarctic plates since the breakup of Gondwanaland at $160 \mathrm{Ma}$ (Lawver \& Scotese 1987). Due to its central location in the global plate circuit (Fig. 1), accurate recon- structions of the ridge's seafloor spreading history are critical for reconstructing the movements of the tectonic plates in the Atlantic, Pacific and Indian Ocean basins and the palaeogeography of nearly all of the major continents since the Late Cretaceous. Since the ridge also indirectly records tectonic events along the Africa Plate's boundaries, changes in its seafloor spreading rates and directions 


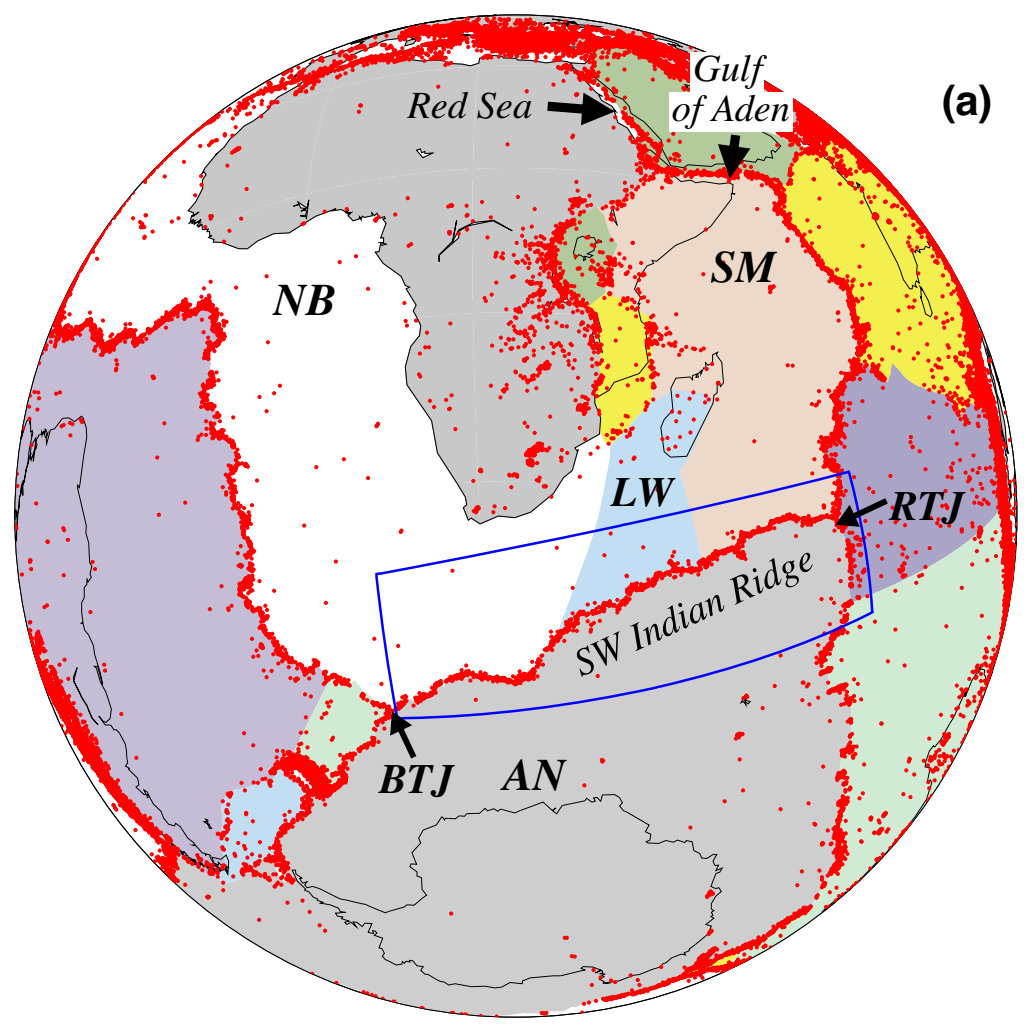

(b)

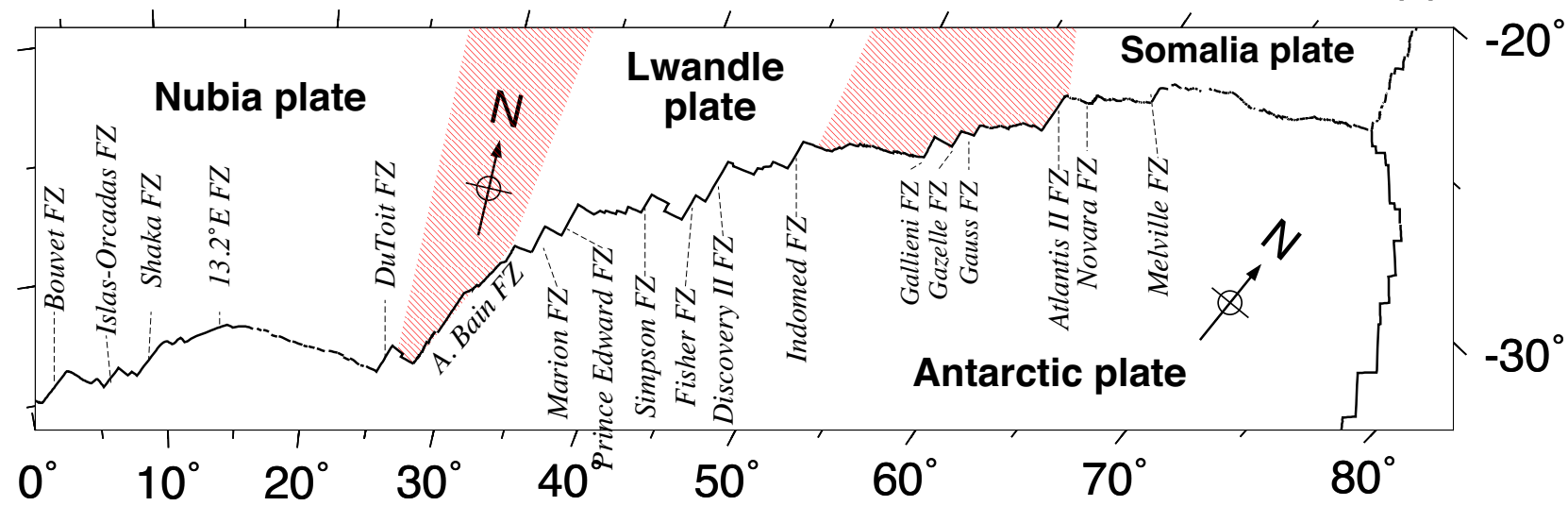

Figure 1. Southwest Indian Ridge Plate tectonic setting. The red circles are 1964-2013 $M>3.5$ earthquakes shallower than $60 \mathrm{~km}$. The blue rectangle delimits the region of the lower map. (b) Oblique Mercator projection of the Southwest Indian Ridge. The pink patterned areas approximate the diffuse boundaries that separate the Lwandle Plate from the Nubia and Somalia plates. Prominent transform faults are labelled. AN, Antarctic Plate; BTJ, Bouvet triple junction; LW, Lwandle Plate; NB, Nubia Plate; RTJ, Rodrigues triple junction; SM, Somalia Plate.

indirectly record how the forces that drive and resist Africa Plate motion have evolved through time.

Numerous previous studies have gradually refined the rotations that reconstruct Africa-Antarctic Plate motion, thereby identifying most of its major kinematic changes and their ages (e.g. Patriat et al. 1985, 2008; Royer et al. 1988; Bernard et al. 2005; Cande et al. 2010; Cande \& Patriat 2015; DeMets et al. 2015). In recent years, several studies have focused in particular on reconstructions that span the past $80 \mathrm{Myr}$, a period of rapid plate kinematic changes in the Indian Ocean basin that are variously attributed to India's collision with Eurasia (e.g. Copley et al. 2010) and the arrival of the Reunion hotspot plume head (Cande \& Stegman 2011; van Hinsbergen et al. 2011). Reconstructions of magnetic reversals C34-C20 now constrain the Southwest Indian Ridge opening history at $\approx 2$ Myr intervals from 84 to $43 \mathrm{Ma}$ (Cande et al. 2010; Cande \& Patriat 2015) and $\approx 1$ Myr intervals from 20 Ma (C6) to the present (DeMets et al. 2015). The only period without a high resolution spreading history is 43-20 Ma, when continental Arabia collided with Eurasia (McQuarrie \& van Hinsbergen 2013), the Arabia peninsula detached from the Africa Plate, the Afar mantle plume arrived at the base of eastern Africa (e.g. George et al. 1997), and Africa and its surrounding seafloor fragmented into Nubia, Somalia and other smaller plates.

We reconstruct the SWIR seafloor spreading history at 1-2-Myr intervals from $52 \mathrm{Ma}$ (Chron 23) to the present, thereby closing the gap left by previous studies. One of our objectives is to investigate 
an apparent 50 per cent slowdown in SWIR seafloor spreading rates at $\approx 24$ Ma identified by Patriat et al. (2008) from modelling of several long SWIR magnetic profiles and reconstructions of magnetic reversals C6, C8 and $\mathrm{C} 13$ along the eastern third of the SWIR. A second objective is to better quantify the nature and timing of a major but poorly understood change in SWIR plate motion at the time of C18, whose existence has been inferred from seafloor morphology (Bernard et al. 2005; Baines et al. 2007). We also seek to better understand the fragmentation of the formerly coherent Africa plate into the Nubia, Somalia and Lwandle subplates (Hartnady 2002), a topic of wide inherent importance due to its relevance to global plate reconstructions and to research about rifting in eastern Africa and the opening histories of the Gulf of Aden and Red Sea. Because reconstructions of Africa onto Antarctica for times before $20 \mathrm{Ma}$ approximate Africa as a single undeformed plate despite clear evidence for significant movement between Somalia and Nubia during the past $20 \mathrm{Myr}$ (e.g. Bernard et al. 2005; Cande et al. 2010; Cande \& Patriat 2015), global plate reconstructions that pass through the Southwest Indian Ridge for times before 20 Ma must either approximate and correct for Nubia-Somalia Plate motion (e.g. Molnar \& Stock 2009; Iaffaldano et al. 2013) or suffer degraded accuracy. Movement between East and West Antarctica before 26 Ma appears to have affected areas of Antarctica south of the Pacific-Antarctic Rise (Granot \& Dyment 2018) and thus does not affect our analysis.

\section{DATA}

We estimate rotations from inversions of numerous magnetic anomaly identifications that we made from along-track shipboard and airborne magnetic anomalies and crossings of fracture zones and transform faults that we digitized from seafloor bathymetric and gravimetric data (Fig. 2).

\subsection{Magnetic reversal identifications}

Many of the magnetic data that are used for this analysis were originally compiled, interpreted, and used in our previous study of SWIR plate motions between C6 and the present (DeMets et al. 2015). These include data from American, French, Italian, Japanese and South African cruises (tracks for these cruises are shown in grey in Fig. 2a). For this study, we additionally incorporate data from French cruises that were previously unavailable to us, consisting mostly of transit tracks from the R/V Marion Dufresne (blue lines in Fig. 2a).

Table 1 identifies and provides ages for all 44 magnetic polarity reversals that are used in this analysis. These consist of all 21 reversals from our previous study (DeMets et al. 2015) and 23 older reversals from $\mathrm{C} 6 \mathrm{~B}$ through $\mathrm{C} 23$. A synthetic magnetic profile displays all 44 of the reversal tie points (Fig. S1). All the reversal ages used here are adopted from the astronomically tuned GTS20 geomagnetic reversal timescale (Ogg 2020). All the seafloor spreading rates that are estimated from our own and previously published rotations are normalized to GTS20 reversal ages.

We identified magnetic reversals via visual correlations of observed magnetic anomaly profiles to synthetic magnetic profiles that were created using spreading rates and anomaly phase shifts suitable for the western, central and eastern SWIR. Fig. 2(b) locates all 6973 reversal identifications that are used for our study, including $\approx 4800$ identifications of C1n through C6 from DeMets et al. (2015), several dozen new identifications of $\mathrm{C} 1 \mathrm{n}$ through $\mathrm{C} 6$, and $\approx 2200$ new identifications of C6B through C23. Twelve large-scale supplemental maps that overlay all of the reversal identifications on the along-track magnetic anomaly data and seafloor bathymetry are provided for readers who are interested in the details of our interpretation. All 6973 reversal crossings that are used in our inversions are accessible at www.marine-geo.org (doi: 10.26022/IEDA/330177).

We assigned all of the reversal crossings initial $1 \sigma$ uncertainties of \pm 1 or $\pm 2 \mathrm{~km}$ based on 1-2 km misfits that we reported for reconstructions of $\mathrm{C} 1-\mathrm{C} 13$ for slow spreading centres in the Arctic, Atlantic and Indian Ocean basins (Merkouriev \& DeMets 2006, 2014a,b; DeMets et al. 2015; DeMets \& Merkouriev 2019; DeMets et al. 2020). Our methods for estimating rotation covariances (Section 3.2) are relatively insensitive to the uncertainties that are assigned to the individual data.

Our reversal identifications are consistent with but more numerous and geographically widespread than those of Cannat et al. (2006), Patriat et al. (2008), Cande et al. (2010) and Cande \& Patriat (2015). The number of reversal identifications diminishes rapidly with seafloor age (Table 1), reflecting sparser survey coverage of older seafloor (Fig. 2a).

All the reversal crossings and other data are grouped into subsets that separately record the movements of the Nubia, Lwandle and Somalia plates relative to Antarctica. The locations we adopted for the diffuse Nubia-Lwandle and Somalia-Lwandle Plate boundaries (Fig. 1) are consistent with those estimated by DeMets et al. (2015). The approximations of the Nubia-Antarctic-Lwandle and SomaliaAntarctica-Lwandle triple junctions as discrete rather than diffuse is a possible source of error and/or bias in our estimated rotations.

\subsection{Fracture zone flow lines and transform faults}

We digitized 18 transform faults and 37 fracture zones to constrain the present and past slip directions along the SWIR (red lines in Fig. $2 \mathrm{a}$ and $\mathrm{S} 10-\mathrm{S} 21$ ). East of $54^{\circ} \mathrm{E}$, where the ridge and flanking seafloor have been surveyed extensively with multibeam systems (e.g. Dick et al. 1991; Mendel et al. 1997; Patriat et al. 1997; Sauter et al. 2001; Hosford et al. 2003; Cannat et al. 2006), our fracture zone and abyssal hill interpretations are based mostly on French bathymetric grids that incorporate data from these cruises. Readers interested in the details of our interpretations can view these bathymetric data at their full $100-\mathrm{m}$ resolution in Fig. S9. For seafloor that is located west of $54^{\circ} \mathrm{E}$, we digitized fracture zone and transform fault locations from a Marine Geoscience Data System bathymetric grid, which combines multibeam, single-beam, and altimetrically derived measurements (www.geomapapp.org and Carbotte et al. 2004). All of the transform fault and fracture zone crossings that are used in our inversions are accessible at www.ma rine-geo.org (doi: 10.26022/IEDA/330177).

In areas with multibeam survey coverage, we digitized fracture zone crossings every $\sim 0.5 \mathrm{~km}$. Elsewhere, we spaced the fracture zone crossings by $\sim 2.0 \mathrm{~km}$. Nominal $1 \sigma$ uncertainties of \pm 0.8 to $\pm 5 \mathrm{~km}$ were assigned to all the transform fault and fracture zone crossings by equating fracture zone valley half-widths to a 95 percent location uncertainty and halving each 95 percent uncertainty to find the $1 \sigma$ uncertainty. Fracture zone valley widths are as narrow as $3 \mathrm{~km}$ in areas where conventional or multibeam data clearly define the zone of present or past faulting and as wide as $20 \mathrm{~km}$ where the locus of faulting is only loosely constrained by the available data.

We omitted the traces of the Atlantis II and Discovery II fracture zones from our data because trial inversions with both of these long-offset fracture zones indicate that portions of their traces are 

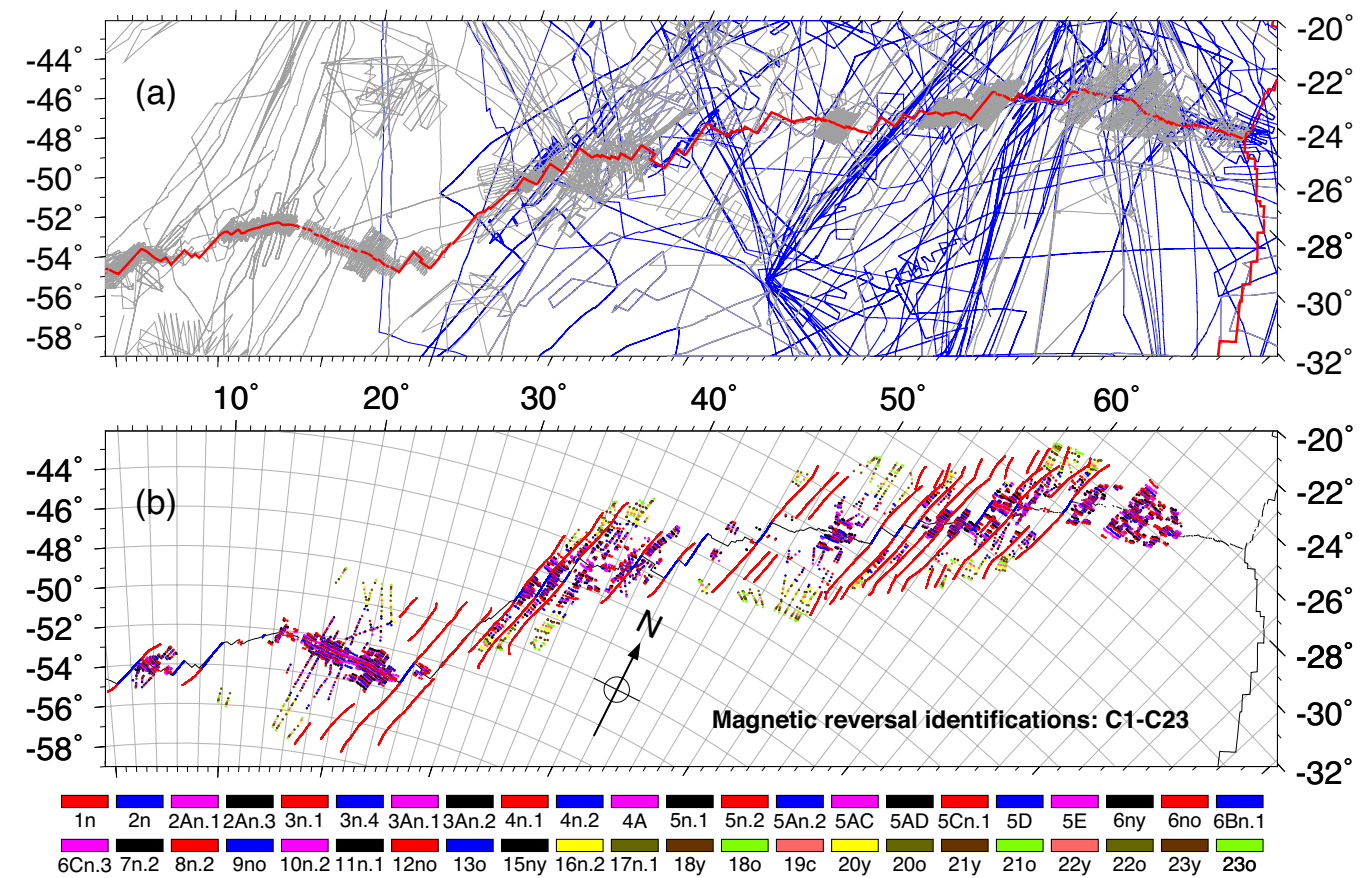

Figure 2. (a) Tracks of all the shipboard and airborne magnetic data that were used for this analysis. Magnetic data from the tracks shown by the grey lines were used for our previous high-resolution study of C1n to C6 (DeMets et al. 2015) and for this study. Additional tracks used for the present study are indicated by the blue lines. The red line marks the present ridge axis. (b) All 6937 crossings of magnetic reversals $1 \mathrm{n}$ through $23 \mathrm{o}$ and fracture zones (red circles) that are used to estimate the rotation sequences described in the text. Both maps are oblique Mercator projections.

anomalous with respect to flow lines that are estimated using other nearby fracture zones. We suspect that the 15-Myr seafloor age offset across the Atlantis II fracture zone, which is the largest along the Somalia-Antarctic segment of the ridge, is responsible for the inconsistency. Other contributing factors may include the effects of palaeo-ridge propagators or ridge jumps on the fracture zone geometries. Misinterpretations of their flow line traces may also contribute to the larger-than-expected flow-line inconsistencies.

\section{METHODS AND CONSTRAINTS}

Two sequences of finite rotations are estimated for each plate pair, the first of which is derived from an inversion of the plate kinematic data and the second of which is determined from the first via a Bayesian noise-mitigation methodology described below. Their fits are compared in order to verify whether the latter noise-reduced rotations faithfully reproduce the plate motion history. Unless noted otherwise, the noise-reduced rotations and stage angular velocities always constitute our preferred estimates since they describe simpler (i.e. less noisy) seafloor spreading histories without increasing the data misfits enough to alter any of our interpretations or conclusions.

\subsection{Best-fitting rotations, data fitting functions and uncertainties}

The methods and fitting functions that are used here to estimate best-fitting rotations are the same as those that are described by Merkouriev \& DeMets (2014a). Crossings of magnetic reversals, transform faults, and fracture zones are fit using great-circle, smallcircle and flow line fitting functions, respectively. All the data for a given plate pair were inverted simultaneously to find the sequence of finite rotations that minimizes the cumulative weighted leastsquares misfit. A priori corrections were applied to all the rotations to compensate for outward displacement (DeMets \& Wilson 2008), consisting of a 5-km correction for the Nubia-Antarctic rotations and 2-km corrections to the Lwandle-Antarctic and SomaliaAntarctic rotations (DeMets et al. 2015).

Weighted root-mean-square (WRMS) misfits to individual data types and per reconstructed time are used as our primary means of tracking and comparing misfits. WRMS misfits account for the number of parameters that are adjusted to fit the data and the data uncertainties.

Covariances were estimated for each best-fitting finite rotation using one of two methods. Most covariances were estimated using a previously described bootstrap resampling method (e.g. DeMets \& Merkouriev 2019), whereby each conjugate spreading segment, fracture zone flow line and transform fault is assigned a unique integer code and the segment integer codes are sampled randomly in order to create 1000 alternative data sets, each consisting of the same number of fracture zones, transform faults and spreading segments as the original data. Via this method, the integer codes for some spreading segments, fracture zones, or transform faults (and hence all the data for those segments) are omitted entirely from some samples, thereby eliminating their influence on the solution. Other segments may be sampled more than once, thereby increasing their weight in the solution. The 1000 bootstrap data sets thus sample a wide range of possible segment-based data weights.

When data from too few conjugate spreading segments are available, typically four or fewer segments, the segment-based bootstrapping method may underestimate or misrepresent the true rotation uncertainties, which become increasingly sensitive to the relative weights that are assigned to the individual data as the number of reconstructed segments approaches one. In such cases, we used 
Table 1. Data summary.

\begin{tabular}{|c|c|c|c|c|c|c|c|}
\hline \multirow{3}{*}{$\begin{array}{l}\text { Magnetic } \\
\text { reversal }\end{array}$} & \multirow{3}{*}{$\begin{array}{l}\text { Age } \\
\text { (Ma) }\end{array}$} & \multicolumn{2}{|c|}{ Nubia-Antarctic $\dagger$} & \multicolumn{2}{|c|}{ Lwandle-Antarctic $\dagger$} & \multicolumn{2}{|c|}{ Somalia-Antarctic $\dagger$} \\
\hline & & \multicolumn{2}{|c|}{ \# data : WRMS (km) } & \multicolumn{2}{|c|}{ \# data : WRMS (km) } & \multicolumn{2}{|c|}{ \# data : WRMS (km) } \\
\hline & & Anom & $\mathrm{FZ}$ & Anom & FZ & Anom & $\mathrm{FZ}$ \\
\hline 1no & 0.773 & $250: 1.63$ & $57: 0.36$ & $128: 1.34$ & $50: 0.26$ & $236: 1.40$ & $51: 0.12$ \\
\hline 2ny & 1.775 & $181: 1.41$ & $70: 0.59$ & $102: 1.41$ & $44: 0.53$ & $152: 1.14$ & $60: 0.36$ \\
\hline 2An.1y & 2.595 & $195: 1.51$ & $44: 0.75$ & $104: 1.42$ & $51: 0.85$ & $206: 1.46$ & $37: 0.65$ \\
\hline $2 A n .3 o$ & 3.596 & $152: 1.53$ & $60: 0.96$ & $83: 1.23$ & $46: 1.08$ & $147: 1.40$ & $52: 0.89$ \\
\hline $3 n .1 y$ & 4.187 & $125: 1.57$ & $38: 1.19$ & $61: 1.34$ & $24: 1.02$ & $113: 1.82$ & $32: 1.04$ \\
\hline $3 n .40$ & 5.235 & $117: 1.74$ & $56: 1.14$ & $59: 1.33$ & $57: 1.16$ & $89: 1.82$ & $44: 1.16$ \\
\hline 3An.1y & 6.023 & $104: 1.50$ & $46: 1.02$ & $47: 1.78$ & $54: 1.11$ & $78: 1.68$ & $49: 1.39$ \\
\hline 3 An.2o & 6.727 & $90: 1.42$ & $46: 1.01$ & $47: 1.49$ & $30: 1.19$ & $58: 1.59$ & $29: 1.58$ \\
\hline $4 n .1 y$ & 7.537 & $78: 1.60$ & $50: 1.05$ & $26: 2.14$ & $45: 1.61$ & $52: 1.32$ & $46: 1.86$ \\
\hline $4 n .20$ & 8.125 & $53: 1.27$ & $27: 1.21$ & $29: 2.41$ & $29: 1.86$ & $61: 1.43$ & $33: 1.84$ \\
\hline 4Ao & 9.105 & $26: 2.13$ & $74: 1.34$ & $83: 1.55$ & $52: 2.30$ & $122: 1.64$ & $71: 1.94$ \\
\hline $5 \mathrm{n} .1 \mathrm{y}$ & 9.786 & $48: 2.43$ & $65: 1.52$ & $110: 2.27$ & $47: 2.58$ & $155: 1.35$ & $39: 1.72$ \\
\hline $5 n .20$ & 11.056 & $54: 1.89$ & $75: 1.89$ & $121: 2.15$ & $68: 2.79$ & $163: 1.34$ & $103: 1.42$ \\
\hline $5 \mathrm{An} .2 \mathrm{o}$ & 12.474 & $35: 1.99$ & $66: 1.51$ & $83: 2.11$ & $101: 3.22$ & $78: 1.57$ & $105: 1.64$ \\
\hline $5 \mathrm{ACy}$ & 13.739 & $43: 2.32$ & $81: 1.16$ & $65: 1.84$ & $84: 3.73$ & $76: 1.49$ & $91: 2.10$ \\
\hline 5ADo & 14.609 & $40: 1.94$ & $38: 1.19$ & $44: 2.47$ & $52: 4.15$ & $64: 1.67$ & $68: 2.19$ \\
\hline $5 \mathrm{Cn} .1 \mathrm{y}$ & 15.974 & $23: 2.38$ & $86: 1.35$ & $25: 3.05$ & $73: 3.39$ & $65: 1.94$ & $136: 2.35$ \\
\hline $5 \mathrm{Dy}$ & 17.235 & $12: 4.68$ & $96: 1.89$ & $36: 1.70$ & $77: 3.01$ & $44: 1.97$ & $93: 2.38$ \\
\hline 5Ey & 18.007 & $8: 5.35$ & $50: 2.80$ & $55: 1.40$ & $61: 3.06$ & $66: 1.77$ & $79: 2.42$ \\
\hline 6ny & 18.636 & $9: 3.23$ & $49: 3.12$ & $52: 1.80$ & $42: 2.85$ & $87: 2.26$ & $50: 2.25$ \\
\hline 6no & 19.535 & $11: 1.54$ & $54: 3.31$ & $46: 1.84$ & $88: 2.64$ & $98: 1.91$ & $104: 2.38$ \\
\hline 6Bn.1y & 21.806 & $9: 2.83$ & $81: 2.06$ & $49: 2.81$ & $152: 3.16$ & $63: 2.21$ & $189: 2.34$ \\
\hline $6 \mathrm{Cn} .300$ & 23.318 & $10: 3.31$ & $97: 2.03$ & $45: 2.84$ & $132: 3.15$ & $68: 2.12$ & $190: 3.02$ \\
\hline $7 \mathrm{n} .200$ & 24.459 & $7: 1.88$ & $54: 1.97$ & $37: 2.16$ & $98: 3.35$ & $36: 2.40$ & $129: 3.06$ \\
\hline $8 n .20$ & 25.987 & $9: 4.35$ & $58: 2.06$ & $57: 2.97$ & $117: 3.64$ & $56: 2.55$ & $207: 2.75$ \\
\hline 9no & 27.439 & $7: 2.79$ & $54: 2.66$ & $54: 3.41$ & $87: 3.84$ & $39: 2.27$ & $171: 2.66$ \\
\hline $10 \mathrm{n} .2 \mathrm{o}$ & 28.278 & $6: 2.14$ & $30: 3.63$ & $30: 2.42$ & $55: 3.98$ & $29: 1.95$ & $96: 2.63$ \\
\hline $11 \mathrm{n} .1 \mathrm{y}$ & 29.183 & $8: 4.38$ & $34: 4.79$ & $35: 2.44$ & $79: 3.94$ & $42: 2.56$ & $103: 2.89$ \\
\hline 12 no & 30.977 & $6: 3.98$ & $108: 3.63$ & $33: 2.60$ & $107: 4.16$ & $29: 2.20$ & $247: 3.39$ \\
\hline 130 & 33.726 & $9: 3.69$ & $171: 2.85$ & $39: 3.97$ & $172: 4.54$ & $25: 2.02$ & $383: 4.62$ \\
\hline 15 ny & 35.102 & $8: 4.21$ & $69: 3.82$ & $18: 4.09$ & $68: 4.80$ & $15: 2.80$ & $147: 6.44$ \\
\hline $16 \mathrm{n} .2 \mathrm{y}$ & 35.774 & $7: 2.37$ & $54: 4.61$ & $28: 4.33$ & $59: 4.94$ & $20: 2.40$ & $103: 6.10$ \\
\hline $17 \mathrm{n} .1 \mathrm{y}$ & 36.573 & $7: 4.50$ & $63: 5.32$ & $15: 3.69$ & $59: 4.79$ & $8: 1.81$ & $115: 6.44$ \\
\hline $18 \mathrm{n} .1 \mathrm{y}$ & 38.398 & $6: 2.21$ & $58: 5.87$ & $43: 2.94$ & $49: 4.64$ & $29: 2.76$ & $55: 6.73$ \\
\hline $18 \mathrm{n} .2 \mathrm{o}$ & 40.073 & $7: 1.57$ & $68: 4.69$ & $42: 3.64$ & $55: 4.69$ & $36: 1.75$ & $92: 6.85$ \\
\hline $19 \mathrm{c}$ & 41.105 & $7: 2.39$ & $47: 4.45$ & $42: 3.89$ & $45: 5.61$ & $28: 1.93$ & $234: 3.01$ \\
\hline $20 y$ & 42.196 & $7: 2.51$ & $40: 4.70$ & $45: 2.49$ & $52: 7.24$ & $31: 2.52$ & $263: 3.74$ \\
\hline $20 \mathrm{o}$ & 43.450 & $10: 4.51$ & $62: 4.75$ & $52: 2.91$ & $37: 3.07$ & $36: 2.32$ & $299: 4.86$ \\
\hline $21 y$ & 46.235 & $9: 1.87$ & $88: 5.39$ & $36: 3.42$ & $31: 2.14$ & $17: 1.79$ & $442: 5.86$ \\
\hline 210 & 47.760 & $9: 2.56$ & $39: 7.36$ & $33: 2.96$ & $14: 0.99$ & $18: 3.63$ & $155: 8.02$ \\
\hline $22 y$ & 48.878 & $7: 1.06$ & $33: 8.22$ & $24: 2.17$ & $10: 3.23$ & $7: 2.18$ & $110: 7.60$ \\
\hline 220 & 49.666 & $7: 2.36$ & $20: 7.07$ & $27: 2.76$ & $7: 5.45$ & $7: 1.78$ & $49: 7.62$ \\
\hline $23 n .1 y$ & 50.767 & $7: 0.40$ & $18: 8.46$ & $26: 2.03$ & $10: 7.83$ & $6: 2.32$ & $47: 7.04$ \\
\hline $23 n .20$ & 51.724 & $7: 1.54$ & $14: 9.77$ & $28: 4.73$ & $8: 9.31$ & $8: 3.19$ & $21: 7.73$ \\
\hline
\end{tabular}

$\dagger$ The rotations for $\mathrm{C} 1 \mathrm{n}$ are also constrained by transform fault crossings, as follows: 580 crossings for Nubia-Antarctica with a WRMS misfit of $0.90 \mathrm{~km} ; 611$ crossings for Lwandle-Antarctica with a WRMS misfit of $1.03 \mathrm{~km} ; 397$ crossings for Somalia-Antarctica with a WRMS misfit of $1.04 \mathrm{~km}$. Chron designators followed by a ' $y$ ' or 'o', respectively indicate the young or old edge of the chron. The ages for all the reversals are from the astronomically tuned GTS20 timescale of Ogg (2020). Anom and, respectively, indicate the number of magnetic anomaly and fracture zone crossings that were used to estimate the finite rotations in Tables 2, 5 and 8. Ages estimated for the fracture zone crossings are approximated based on their position along their respective flow lines, but are not used for the inversion. Instead, each fracture zone crossing contributes information to the finite rotation estimates for all ages. WRMS is the weighted rootmean-square misfit in $\mathrm{km}$ of a best-fitting rotation adjusted for the number of parameters that were estimated to fit the data.

Monte Carlo sampling to assign individualized reversal crossing uncertainties between \pm 1.0 and $\pm 2.5 \mathrm{~km}$ for each bootstrap sample. The rotation covariances for those times thus implicitly incorporate the influence of variations in the relative weights of the individual data on the solution.
Inversions of the 1000 data sets described above yielded 1000 trial sequences of 44 rotations for each of the Nubia-Antarctic, Lwandle-Antarctic and Somalia-Antarctic Plate pairs. The bestfitting rotations and covariances given herein are the mean values and scatter of the 1000 bootstrap rotation sequences. The bootstrap 
covariances are invariant to the plate that is held fixed in an inversion and may thus be combined with the finite rotation covariances for other plate pairs without concern for which plate was fixed when the covariances were estimated.

\subsection{Noise-reduced rotations and stage angular velocities}

Stage rotations that are derived by differentiating a sequence of closely spaced finite rotations may predict rapid, implausibly large variations in stage velocities (Iaffaldano et al. 2012). In order to mitigate these variations, which are largely attributable to noise in finite rotations, we use REDBACK software (Iaffaldano et al. 2014), which applies a trans-dimensional, hierarchical Bayesian algorithm to sequences of best-fitting rotations such as those produced in this analysis to identify optimal, less-noisy sequences of finite rotations and stage angular velocities that are consistent with the original rotations within their estimated uncertainties. REDBACK also estimates when discrete changes in plate motion are most likely to have occurred, which we exploit for our analysis.

The stage angular velocities that are estimated with REDBACK are based on differentiating the time progression of finite rotations and thus sample the maximum temporal resolution of our data. Due to REDBACK's methodology, the stage angular velocity covariances cannot be derived directly from the REDBACK finite rotation covariances. All of the noise-reduced stage angular velocities are thus tabulated herein.

\subsection{Stage rotations}

We also estimated stage rotations and their uncertainties directly from the best-fitting finite rotations and covariances using the standard method, that is given finite rotations $\hat{A}_{t_{2}}^{B \rightarrow A}$ and $\hat{A}_{t_{1}}^{B \rightarrow A}$ that reconstruct Plate $\mathrm{B}$ onto Plate A for times $t_{2}$ and $t_{1}$, the stage rotation $\hat{A}_{t_{2} \rightarrow t_{1}}^{B \rightarrow A}$ that reconstructs the motion of Plate $\mathrm{B}$ relative to Plate A from $t_{2}$ to $t_{1}$ is given by $\hat{A}_{t_{1}}{ }^{T} \hat{A}_{t_{2}}$. None of the best-fitting stage rotations are tabulated given that they can be derived from the best-fitting rotations.

Our best-fitting stage rotations span overlapping time intervals of 2-3 Myr, longer than the $\approx 1$ Myr spacing between many of our finite rotations, but useful for improving the signal-to-noise ratio. All of the finite rotations for a given plate pair incorporate the same correction for outward displacement. Consequently, the stage rotations and angular velocities that are estimated herein are insensitive to the corrections that are applied to the finite rotations for outward displacement, which cancel out when any two finite rotations are combined to estimate a stage rotation. Any error in our corrections for outward displacement will however introduce a systematic bias of $\approx 1.3 \mathrm{~mm} \mathrm{yr}^{-1}$ per $1-\mathrm{km}$ of error into our stage spreading rate estimates between the present and old edge of Chron 1, which spans the past $773000 \mathrm{yr}$.

\section{RESULTS}

\subsection{Nubia-Antarctic Plate motion}

\subsubsection{Best-fitting and noise-reduced rotations and poles}

The best-fitting Nubia-Antarctic rotations (Table 2) were determined from 1830 magnetic reversal crossings, 2588 fracture zone crossings and 580 transform fault crossings, all located between the Bouvet Triple Junction and the Andrew Bain transform fault (Fig. 2b). The rotations are constrained by as many as 250 reversal crossings (C1n) to as few as 7 for $\mathrm{C} 23$ o (Table 1). The degrees of freedom for the individual rotations range from 840 for $\mathrm{C} 1 \mathrm{n}$ to only 14 for C23 (Tables 1 and 2), reflecting the sparser survey coverage away from the ridge (Fig. 2a). The rotations for C5D, C5E, C6ny and C6no are less reliable than the others due to the difficulty in identifying those reversals. The noise-reduced rotations and angular velocities that we derived from our REDBACK analysis of the best-fitting rotations and their covariances are given in Tables 3 and 4.

The best-fitting poles have migrated south-southeastward by $\approx 20$ angular degrees since 52 Ma (Fig. 3a). The noise-reduced poles also reproduce this pattern but describe a smoother migration path (Fig. 3b). The finite opening angles (Fig. 3c) define a complex opening rate history, with multiple inflections that are indicative of spreading rate changes. These are described in more detail in Sections 4.1.4 and 4.5.

\subsubsection{Magnetic reversal reconstructions and misfits}

Best-fitting reconstructions of selected magnetic reversals and flow lines for the Nubia-Antarctic Plate boundary (Fig. 4; see Figs S10S13 for reconstructions of all 44 magnetic reversals) reveal only modest changes in the ridge configuration and flow line trajectories since $52 \mathrm{Ma}$. The plate boundary geometry has thus been relatively stable during this period. Cande \& Patriat (2015) document evidence for an abrupt clockwise change in the relative slip direction at anomaly 24 (53 Ma), earlier than the time period considered in this study.

The WRMS misfits of the 44 best-fitting rotations to the 1830 reversal crossings range from 0.4 to $5.35 \mathrm{~km}$ (Table 1 and Fig. S2), nearly the same as WRMS misfits of $1.1-4.1 \mathrm{~km}$ for reconstructions of $\mathrm{C} 1 \mathrm{n}$ to $\mathrm{C} 13 \mathrm{n}$ in the southern Atlantic basin (DeMets \& Merkouriev 2019), where seafloor spreading rates are similar to the SWIR. The WRMS reversal misfits for the noise-reduced NubiaAntarctic rotations in Table 3 are only $0-1000 \mathrm{~m}$ larger than the best-fitting rotation misfits for 36 of the 44 reconstructed reversals, too small to affect any of our subsequent results or interpretations. Larger fitting penalties of $1.1-4.9 \mathrm{~km}$ for the other eight noise-reduced rotations, all for times older than $\mathrm{C} 6$, are a result of several factors. The best-fitting rotations for older reversals are typically less reliable because they are often estimated from fewer reversal identifications and the palaeoridge segmentation that is necessary for identifying conjugate magnetic lineations is usually less well known. The differences in the fits of the best-fitting and noise-reduced rotations may thus increase with reversal age. The WRMS misfits of noise-reduced rotations may also increase more rapidly with age than for the best-fitting rotations because the REDBACK algorithm requires accurate magnetic reversal ages as a basis for minimizing plate motion variations. If the errors in the GTS20 reversal age determinations increase with reversal age, as seems likely, this implies progressively larger WRMS misfits for the noise-reduced rotations with reversal age than for the best-fitting rotations.

\subsubsection{Transform fault and fracture zone flow line fits}

Small circles around the C1n best-fitting and noise-reduced opening poles misfit the six Nubia-Antarctic transform fault traces 
Table 2. Nubia-Antarctic best-fitting finite rotations

\begin{tabular}{|c|c|c|c|c|c|c|c|c|c|c|}
\hline \multirow[t]{2}{*}{ Chron } & \multirow[t]{2}{*}{ DOF } & \multirow{2}{*}{$\begin{array}{l}\text { Lat. } \\
\left({ }^{\circ} \mathrm{N}\right)\end{array}$} & \multirow{2}{*}{$\begin{array}{l}\text { Long. } \\
\left({ }^{\circ} \mathrm{E}\right)\end{array}$} & \multirow{2}{*}{$\begin{array}{l}\Omega \\
\left({ }^{\circ}\right)\end{array}$} & \multicolumn{6}{|c|}{ Rotation covariances } \\
\hline & & & & & $\mathrm{a}$ & $\mathrm{b}$ & $\mathrm{c}$ & d & $\mathrm{e}$ & $\mathrm{f}$ \\
\hline 1n & 840 & -2.93 & 324.09 & -0.103 & 2.2 & -1.4 & -0.2 & 2.1 & -1.1 & 2.3 \\
\hline $2 n$ & 212 & -5.11 & 328.04 & -0.260 & 13.3 & 3.8 & -13.5 & 4.3 & -3.2 & 36.4 \\
\hline 2An.1 & 200 & -10.45 & 331.18 & -0.377 & 16.7 & 3.3 & -11.9 & 7.4 & 2.8 & 37.1 \\
\hline 2An.3 & 183 & -14.94 & 332.51 & -0.551 & 26.2 & 3.9 & -11.6 & 12.9 & 5.7 & 52.2 \\
\hline $3 n .1$ & 130 & -15.92 & 333.51 & -0.663 & 29.7 & 9.3 & -10.0 & 16.5 & 5.8 & 51.0 \\
\hline $3 n .4$ & 146 & -11.31 & 330.49 & -0.759 & 37.9 & -0.7 & -19.2 & 13.7 & 3.2 & 73.7 \\
\hline 3An.1 & 123 & -10.00 & 330.21 & -0.865 & 40.8 & 2.2 & -14.2 & 20.9 & -2.4 & 46.8 \\
\hline $3 \mathrm{An} .2$ & 111 & -5.88 & 327.95 & -0.926 & 41.3 & -4.7 & -22.8 & 20.0 & -6.8 & 67.7 \\
\hline $4 n .1$ & 107 & -6.61 & 328.77 & -1.049 & 46.0 & -4.0 & -13.7 & 22.4 & -5.2 & 68.0 \\
\hline $4 n .2$ & 63 & -6.35 & 329.06 & -1.108 & 41.2 & -3.6 & -22.7 & 28.9 & -14.3 & 103.1 \\
\hline $4 \mathrm{~A}$ & 89 & -8.08 & 330.60 & -1.317 & 61.7 & 16.4 & -29.2 & 26.1 & -6.9 & 93.5 \\
\hline $5 \mathrm{n} .1$ & 96 & -6.07 & 330.10 & -1.431 & 99.1 & -14.2 & -21.3 & 49.1 & -28.5 & 114.6 \\
\hline $5 \mathrm{n} .2$ & 110 & -4.08 & 329.26 & -1.607 & 79.1 & 8.2 & -46.5 & 30.3 & -15.8 & 101.0 \\
\hline $5 \mathrm{An} .2$ & 86 & -4.67 & 330.12 & -1.802 & 73.1 & 6.0 & -43.6 & 37.5 & -23.8 & 96.4 \\
\hline $5 \mathrm{AC}$ & 109 & -6.47 & 331.61 & -2.073 & 75.0 & -0.9 & -43.2 & 27.6 & -21.2 & 84.0 \\
\hline $5 \mathrm{AD}$ & 65 & -5.93 & 331.61 & -2.183 & 92.5 & 2.2 & -59.9 & 30.2 & -26.6 & 101.7 \\
\hline $5 \mathrm{Cn} .1$ & 98 & -6.78 & 332.53 & -2.484 & 93.3 & 23.4 & -66.5 & 26.1 & -22.8 & 92.0 \\
\hline $5 \mathrm{D}$ & 101 & -4.59 & 331.80 & -2.738 & 116.5 & 12.9 & -41.3 & 69.1 & 6.6 & 151.7 \\
\hline $5 \mathrm{E}$ & 51 & -4.91 & 332.23 & -2.908 & 185.1 & -7.5 & -19.7 & 107.2 & -15.4 & 146.9 \\
\hline 6ny & 51 & -4.06 & 331.73 & -3.031 & 172.3 & 7.2 & 7.9 & 92.4 & -10.2 & 143.9 \\
\hline 6 no & 56 & 2.01 & 327.56 & -3.002 & 260.6 & 103.9 & 0.3 & 174.7 & 25.6 & 220.4 \\
\hline 6Bn.1 & 85 & 0.98 & 327.97 & -3.267 & 111.1 & 31.4 & -68.0 & 44.7 & -37.8 & 176.3 \\
\hline $6 \mathrm{Cn} .3$ & 102 & 1.27 & 327.77 & -3.559 & 143.1 & 37.5 & -109.4 & 45.4 & -33.9 & 260.7 \\
\hline $7 \mathrm{n} .2$ & 54 & 1.40 & 327.75 & -3.769 & 155.7 & 42.8 & -82.9 & 45.4 & -46.3 & 221.2 \\
\hline $8 \mathrm{n} .2$ & 62 & 1.31 & 327.92 & -4.100 & 245.6 & 62.0 & -104.3 & 67.8 & -51.4 & 365.3 \\
\hline 9no & 56 & 1.01 & 328.09 & -4.423 & 202.7 & 80.2 & -36.5 & 85.7 & -8.5 & 472.7 \\
\hline 10n.2 & 31 & 0.94 & 327.98 & -4.608 & 291.0 & 128.7 & 18.6 & 123.3 & 51.3 & 641.4 \\
\hline $11 \mathrm{n} .1$ & 37 & 0.96 & 327.60 & -4.791 & 433.1 & 208.9 & 225.6 & 209.5 & 176.9 & 695.9 \\
\hline 12 no & 109 & 1.01 & 328.17 & -5.244 & 258.2 & 82.9 & -112.9 & 100.4 & -41.8 & 409.5 \\
\hline 130 & 175 & 0.11 & 328.97 & -6.127 & 303.4 & 111.4 & -254.8 & 92.6 & -120.1 & 344.2 \\
\hline 15 ny & 72 & 1.03 & 328.50 & -6.421 & 244.0 & 96.1 & -212.4 & 95.7 & -102.1 & 358.0 \\
\hline 16n.2 & 56 & 1.43 & 328.23 & -6.652 & 265.0 & 121.2 & -243.7 & 104.6 & -127.2 & 413.1 \\
\hline $17 \mathrm{n} .1$ & 65 & 1.27 & 328.19 & -6.933 & 285.3 & 106.1 & -237.4 & 116.9 & -128.6 & 358.3 \\
\hline $18 y$ & 59 & 1.16 & 327.97 & -7.172 & 341.5 & 157.2 & -110.6 & 155.8 & -52.8 & 527.5 \\
\hline 180 & 70 & 1.05 & 328.01 & -7.538 & 286.2 & 160.5 & -202.4 & 164.7 & -63.7 & 595.9 \\
\hline $19 \mathrm{c}$ & 49 & 1.21 & 327.76 & -7.776 & 351.4 & 181.2 & -238.4 & 187.3 & -91.5 & 618.9 \\
\hline $20 y$ & 42 & 0.52 & 327.99 & -8.034 & 370.3 & 162.5 & -219.2 & 160.1 & -94.1 & 623.2 \\
\hline $20 \mathrm{o}$ & 65 & 0.14 & 327.89 & -8.383 & 395.3 & 146.3 & -194.3 & 143.4 & -74.6 & 632.6 \\
\hline $21 y$ & 90 & 3.99 & 325.01 & -8.676 & 443.6 & 283.1 & -80.2 & 316.1 & 225.8 & 1202.9 \\
\hline 210 & 41 & 10.36 & 320.40 & -8.708 & 786.3 & 251.7 & -33.3 & 1570.6 & 1209.8 & 2509.4 \\
\hline $22 y$ & 33 & 10.40 & 320.39 & -8.956 & 615.8 & 401.7 & 60.3 & 458.4 & 439.9 & 1781.5 \\
\hline 220 & 20 & 9.93 & 319.78 & -9.172 & 811.4 & 23.6 & -268.9 & 894.1 & -18.5 & 1382.6 \\
\hline $23 y$ & 18 & 9.75 & 320.09 & -9.304 & 847.2 & 435.9 & 77.7 & 366.2 & 309.5 & 2904.4 \\
\hline $23 \mathrm{o}$ & 14 & 9.40 & 319.40 & -9.437 & 383.7 & 155.1 & -375.9 & 87.2 & -175.7 & 403.6 \\
\hline
\end{tabular}

Notes: These finite rotations reconstruct movement of the Nubia Plate relative to the Antarctic Plate and include corrections for $5 \mathrm{~km}$ of outward displacement described in the text. The rotation angles $\Omega$ are positive CCW. Each rotation is the mean of 1000 bootstrap solutions (see text). DOF, the degrees of freedom, equals the total number of anomaly, transform fault and fracture zone flow-line crossings that are used to estimate the rotation for a given time reduced by the number of estimated parameters. The weighted RMS misfits for these rotations are given in Table 1. The Cartesian rotation covariances are calculated in a Nubia-fixed reference frame and have units of $10^{-9}$ radians $^{2}$. Covariances are determined from the bootstrapping procedure described in the text. Elements $a, d$ and $f$ are the variances of the $\left(0^{\circ} \mathrm{N}, 0^{\circ} \mathrm{E}\right),\left(0^{\circ} \mathrm{N}, 90^{\circ} \mathrm{E}\right)$ and $90^{\circ} \mathrm{N}$ components of the rotation. The covariance matrices are reconstructed as follows: $\left(\begin{array}{lll}a & b & c \\ b & d & e \\ c & e & f\end{array}\right)$

with respective WRMS values of 900 and $1300 \mathrm{~m}$. The larger noise-reduced misfit is an outcome of the REDBACK criteria for minimizing plate motion variations, which gives rise to more strongly clustered noise-reduced poles for $\mathrm{C} 1 \mathrm{n}$ and other young reversals than for the best-fitting poles (Fig. 3). DeMets et al. (2015) report a similar 920-m WRMS misfit to the same transform fault crossings for their $\mathrm{C} 1 \mathrm{n}$ best-fitting pole.

The synthetic fracture zone flow lines that are estimated with our best-fitting and noise-reduced Nubia-Antarctic rotations match the bathymetrically defined fracture zone valleys well at most locations (Figs 4 and S10-S13), with WRMS misfits that increase from just 
Table 3. Nubia-Antarctic noise-reduced finite rotations.

\begin{tabular}{|c|c|c|c|c|c|c|c|c|c|}
\hline \multirow[t]{2}{*}{ Chron } & \multirow{2}{*}{$\begin{array}{l}\text { Lat. } \\
\left({ }^{\circ} \mathrm{N}\right)\end{array}$} & \multirow{2}{*}{$\begin{array}{l}\text { Long. } \\
\left({ }^{\circ} \mathrm{E}\right)\end{array}$} & \multirow{2}{*}{$\begin{array}{l}\Omega \\
\left({ }^{\circ}\right)\end{array}$} & \multicolumn{6}{|c|}{ Covariances } \\
\hline & & & & $\mathrm{a}$ & $\mathrm{b}$ & $\mathrm{c}$ & d & $\mathrm{e}$ & $\mathrm{f}$ \\
\hline $1 \mathrm{n}$ & -5.06 & 326.72 & -0.111 & 43.7 & -23.3 & 26.0 & 17.8 & -22.2 & 28.6 \\
\hline $2 n$ & -8.09 & 328.70 & -0.257 & 64.4 & -24.4 & 23.6 & 22.4 & -28.8 & 38.6 \\
\hline 2An.1 & -10.37 & 330.15 & -0.376 & 86.6 & -26.5 & 23.3 & 28.2 & -36.6 & 49.5 \\
\hline 2 An. 3 & -11.98 & 331.20 & -0.523 & 138.1 & -30.1 & 20.5 & 43.3 & -57.4 & 79.4 \\
\hline $3 \mathrm{n} .1$ & -11.72 & 331.16 & -0.609 & 169.0 & -35.3 & 23.2 & 53.3 & -70.7 & 97.9 \\
\hline $3 n .4$ & -9.98 & 330.41 & -0.755 & 148.6 & -31.9 & 21.1 & 48.0 & -64.0 & 89.1 \\
\hline 3An.1 & -8.62 & 329.85 & -0.863 & 159.2 & -34.3 & 22.5 & 52.8 & -70.7 & 98.8 \\
\hline 3 An. 2 & -7.62 & 329.51 & -0.958 & 214.7 & -47.1 & 31.1 & 71.7 & -96.2 & 134.7 \\
\hline $4 n .1$ & -7.00 & 329.45 & -1.072 & 259.2 & -60.7 & 43.4 & 87.7 & -117.1 & 162.8 \\
\hline $4 n .2$ & -6.73 & 329.52 & -1.158 & 268.8 & -61.6 & 43.4 & 91.1 & -121.7 & 169.2 \\
\hline $4 \mathrm{~A}$ & -6.41 & 329.72 & -1.306 & 263.0 & -50.5 & 28.7 & 88.4 & -119.3 & 167.8 \\
\hline $5 n .1$ & -6.23 & 329.88 & -1.409 & 276.3 & -50.3 & 26.6 & 92.3 & -124.7 & 175.6 \\
\hline $5 n .2$ & -5.97 & 330.21 & -1.605 & 338.8 & -66.8 & 40.5 & 111.8 & -149.8 & 209.1 \\
\hline 5 An. 2 & -5.80 & 330.65 & -1.836 & 420.1 & -91.0 & 62.7 & 136.8 & -181.5 & 250.2 \\
\hline $5 \mathrm{AC}$ & -5.69 & 331.06 & -2.058 & 445.8 & -57.2 & 10.8 & 145.6 & -199.0 & 282.9 \\
\hline $5 \mathrm{AD}$ & -5.60 & 331.32 & -2.215 & 537.4 & -39.8 & -27.8 & 176.1 & -244.8 & 353.7 \\
\hline $5 \mathrm{Cn} .1$ & -5.38 & 331.68 & -2.466 & 871.4 & -56.8 & -53.8 & 281.6 & -391.2 & 564.6 \\
\hline $5 \mathrm{D}$ & -4.87 & 331.77 & -2.698 & 1423.8 & -142.1 & -15.5 & 449.6 & -615.9 & 876.4 \\
\hline $5 \mathrm{E}$ & -4.19 & 331.56 & -2.833 & 1841.1 & -159.0 & -53.3 & 592.1 & -814.1 & 1161.6 \\
\hline 6ny & -2.97 & 330.88 & -2.931 & 1987.8 & -134.7 & -115.6 & 659.0 & -915.4 & 1319.6 \\
\hline 6 no & -0.05 & 329.00 & -3.039 & 2028.5 & -37.5 & -314.4 & 661.0 & -962.9 & 1472.2 \\
\hline $6 \mathrm{Bn} .1$ & 1.17 & 328.21 & -3.341 & 1307.1 & -174.4 & 17.0 & 451.1 & -631.1 & 925.7 \\
\hline $6 \mathrm{Cn} .3$ & 1.24 & 328.14 & -3.608 & 1276.2 & -139.2 & -31.4 & 437.2 & -618.3 & 917.9 \\
\hline $7 \mathrm{n} .2$ & 1.23 & 328.12 & -3.820 & 1358.0 & -150.5 & -32.7 & 461.6 & -653.8 & 973.2 \\
\hline $8 \mathrm{n} .2$ & 1.20 & 328.10 & -4.118 & 1571.6 & -209.7 & 9.6 & 529.7 & -746.1 & 1107.0 \\
\hline 9no & 1.17 & 328.09 & -4.429 & 1751.8 & -221.3 & -14.7 & 580.2 & -822.3 & 1231.4 \\
\hline $10 \mathrm{n} .2$ & 1.15 & 328.08 & -4.619 & 1897.2 & -236.6 & -25.5 & 621.9 & -883.9 & 1330.2 \\
\hline $11 \mathrm{n} .1$ & 1.13 & 328.07 & -4.831 & 2149.9 & -295.6 & 6.2 & 699.8 & -991.8 & 1491.7 \\
\hline 12 no & 1.09 & 328.04 & -5.296 & 2405.2 & -188.6 & -224.2 & 744.8 & -1089.0 & 1700.8 \\
\hline 130 & 1.02 & 328.00 & -6.093 & 2752.2 & 236.3 & -985.4 & 739.2 & -1188.5 & 2051.5 \\
\hline 15 ny & 0.99 & 327.98 & -6.442 & 3007.0 & 475.9 & -1438.3 & 746.1 & -1263.9 & 2293.4 \\
\hline $16 \mathrm{n} .2$ & 0.98 & 327.97 & -6.607 & 3245.8 & 549.2 & -1621.6 & 784.9 & -1346.8 & 2477.1 \\
\hline $17 n .1$ & 0.96 & 327.95 & -6.795 & 3606.0 & 614.4 & -1826.5 & 851.9 & -1473.9 & 2739.6 \\
\hline $18 \mathrm{y}$ & 0.92 & 327.92 & -7.201 & 4289.5 & 961.4 & -2585.0 & 911.7 & -1671.0 & 3276.2 \\
\hline 180 & 0.88 & 327.89 & -7.573 & 5213.1 & 1273.5 & -3365.1 & 1027.7 & -1953.8 & 3967.5 \\
\hline $19 \mathrm{c}$ & 0.85 & 327.87 & -7.802 & 5910.8 & 1489.5 & -3927.6 & 1115.4 & -2163.4 & 4480.2 \\
\hline $20 y$ & 0.82 & 327.84 & -8.039 & 6760.2 & 1742.1 & -4600.5 & 1220.4 & -2414.2 & 5098.1 \\
\hline $20 \mathrm{o}$ & 0.78 & 327.82 & -8.286 & 7895.6 & 2034.4 & -5434.4 & 1373.8 & -2759.6 & 5927.5 \\
\hline $21 y$ & 4.64 & 324.85 & -8.649 & 5548.3 & 1278.1 & -3832.6 & 812.1 & -1730.0 & 4047.8 \\
\hline 210 & 9.47 & 321.11 & -8.838 & 5483.8 & 942.1 & -3632.2 & 649.7 & -1463.5 & 3859.8 \\
\hline $22 y$ & 9.51 & 320.64 & -9.002 & 2966.8 & 389.3 & -1849.6 & 341.3 & -754.5 & 2058.3 \\
\hline 220 & 9.46 & 320.36 & -9.121 & 1709.9 & 142.6 & -960.5 & 215.5 & -445.2 & 1194.9 \\
\hline $23 y$ & 9.38 & 319.96 & -9.291 & 533.5 & 15.0 & -261.7 & 74.6 & -142.9 & 376.2 \\
\hline 230 & 9.32 & 319.62 & -9.437 & 268.0 & -21.7 & -78.7 & 56.8 & -94.4 & 207.6 \\
\hline
\end{tabular}

Notes: These noise-reduced rotations were determined from a REDBACK analysis of the best-fitting Nubia-Antarctica finite rotations and covariances in Table 2. They reconstruct movement of the Nubia Plate relative to the Antarctic Plate and include corrections for $5 \mathrm{~km}$ of outward displacement described in the text. The rotation angles $\Omega$ are positive anticlockwise. The Cartesian rotation covariances are calculated in a Nubia-fixed reference frame and have units of $10^{-9}$ radians $^{2}$.

a few hundred meters at young ages to $\approx 8 \mathrm{~km}$ at $50 \mathrm{Ma}$ (Table 1 and Fig. S2b). The flow line misfits are similar to misfits reported by DeMets \& Merkouriev (2019) for reconstructions of southern Atlantic basin fracture zones (Fig. S2b).

The flow lines that are estimated with the noise-reduced rotations are nearly always located within their corresponding fracture zone valleys (Figs S10-S13). For seafloor ages younger than 20 $\mathrm{Ma}$, the WRMS misfits for the noise-reduced rotations are an insignificant 300-m-or-less greater than for the best-fitting rotations. The differences between the best-fitting and noise-reduced WRMS fracture zone misfits at seafloor ages greater than $20 \mathrm{Ma}$ increase to $1-9 \mathrm{~km}$ (Figs S12 and S13). Given the ambiguities in identifying the location of palaeo-slip within a given fracture zone valley, these differences in fit are likely smaller than our resolution threshold.

\subsubsection{Spreading history: displacements, rates, directions and GPS}

From the best-fitting and noise-reduced rotations and angular velocities in Tables 2-4, we reconstructed Nubia-Antarctic displacements (Fig. 5) and spreading rate and slip direction histories (Fig. 6) for a flow line that originates on the ridge at $20^{\circ} \mathrm{E}$, where our 
Table 4. Nubia-Antarctic noise-reduced stage angular velocities.

\begin{tabular}{|c|c|c|c|c|c|c|c|c|c|}
\hline \multirow{2}{*}{$\begin{array}{l}\text { Interval } \\
\text { (Ma) }\end{array}$} & \multirow{2}{*}{$\begin{array}{l}\text { Lat. } \\
\left({ }^{\circ} \mathrm{N}\right)\end{array}$} & \multirow{2}{*}{$\begin{array}{l}\text { Long. } \\
\left({ }^{\circ} \mathrm{E}\right)\end{array}$} & \multirow{2}{*}{$\begin{array}{c}\dot{\omega} \\
\left({ }^{\circ} \mathrm{Myr}^{-1}\right)\end{array}$} & \multicolumn{6}{|c|}{ Covariances } \\
\hline & & & & $\mathrm{a}$ & $\mathrm{b}$ & $\mathrm{c}$ & $\mathrm{d}$ & $\mathrm{e}$ & $\mathrm{f}$ \\
\hline $0.773-0.00$ & -5.06 & 326.72 & -0.144 & 28.52 & -12.58 & 2.27 & 16.60 & -5.36 & 21.68 \\
\hline $1.775-0.773$ & -10.39 & 330.23 & -0.146 & 16.21 & -4.10 & -4.73 & 9.16 & -3.78 & 25.06 \\
\hline $2.595-1.775$ & -15.23 & 333.28 & -0.147 & 26.77 & -1.28 & -15.55 & 15.84 & -13.44 & 53.75 \\
\hline $3.596-2.595$ & -16.06 & 333.94 & -0.148 & 42.07 & -4.12 & -22.20 & 24.75 & -24.93 & 84.30 \\
\hline $4.187-3.596$ & -10.15 & 330.91 & -0.145 & 43.27 & -2.93 & -24.80 & 27.98 & -32.21 & 97.51 \\
\hline $5.235-4.187$ & -2.75 & 327.43 & -0.141 & 48.17 & -8.69 & -14.75 & 27.12 & -22.93 & 63.72 \\
\hline $6.023-5.235$ & 0.88 & 326.12 & -0.139 & 85.89 & -17.98 & -25.67 & 44.43 & -38.33 & 107.15 \\
\hline $6.727-6.023$ & 1.31 & 326.59 & -0.138 & 108.59 & -31.61 & -21.42 & 50.81 & -39.12 & 111.92 \\
\hline $7.537-6.727$ & -1.77 & 329.02 & -0.142 & 52.17 & -10.74 & -14.77 & 26.07 & -19.21 & 62.02 \\
\hline $8.125-7.537$ & -3.39 & 330.44 & -0.146 & 43.34 & -12.43 & -6.63 & 21.01 & -13.21 & 42.74 \\
\hline $9.105-8.125$ & -3.97 & 331.31 & -0.151 & 43.38 & -17.05 & -0.20 & 18.89 & -11.17 & 29.66 \\
\hline $9.786-9.105$ & -3.99 & 331.88 & -0.153 & 45.31 & -17.48 & -0.53 & 19.58 & -11.89 & 32.30 \\
\hline $11.056-9.786$ & -4.09 & 332.59 & -0.155 & 41.20 & -15.79 & 0.24 & 17.31 & -10.22 & 27.83 \\
\hline $12.474-11.056$ & -4.65 & 333.71 & -0.163 & 47.84 & -16.74 & -0.99 & 20.56 & -11.92 & 34.73 \\
\hline $13.739-12.474$ & -4.84 & 334.43 & -0.176 & 88.75 & -30.12 & -4.19 & 36.30 & -24.07 & 67.43 \\
\hline $14.609-13.739$ & -4.50 & 334.86 & -0.180 & 120.75 & -43.25 & -0.29 & 47.30 & -30.55 & 84.34 \\
\hline $15.974-14.609$ & -3.53 & 334.86 & -0.184 & 147.06 & -51.32 & 2.23 & 57.27 & -36.30 & 95.14 \\
\hline $17.235-15.974$ & 0.56 & 332.87 & -0.185 & 227.24 & -43.81 & -37.00 & 103.89 & -94.14 & 198.55 \\
\hline $18.007-17.235$ & 9.13 & 327.63 & -0.180 & 461.79 & 0.01 & -213.63 & 242.88 & -286.28 & 639.10 \\
\hline $18.636-18.007$ & 27.66 & 313.55 & -0.192 & 1181.27 & 264.92 & -1030.23 & 654.02 & -880.26 & 2389.02 \\
\hline $19.535-18.636$ & 46.09 & 289.93 & -0.234 & 2679.47 & 426.16 & -2070.41 & 1292.93 & -1619.66 & 4513.12 \\
\hline $21.806-19.535$ & 13.32 & 320.66 & -0.138 & 365.98 & -84.31 & -67.85 & 157.87 & -133.36 & 367.67 \\
\hline $23.318-21.806$ & 2.16 & 327.29 & -0.177 & 99.19 & -37.42 & 0.09 & 40.99 & -28.33 & 81.64 \\
\hline $24.459-23.318$ & 1.11 & 327.79 & -0.185 & 86.32 & -42.80 & 20.01 & 36.07 & -22.07 & 44.13 \\
\hline $25.987-24.459$ & 0.83 & 327.86 & -0.195 & 86.85 & -45.94 & 26.35 & 35.76 & -23.36 & 35.47 \\
\hline $27.439-25.987$ & 0.75 & 327.84 & -0.214 & 130.78 & -72.39 & 45.49 & 52.42 & -36.51 & 44.53 \\
\hline $28.278-27.439$ & 0.69 & 327.82 & -0.226 & 204.23 & -116.75 & 76.65 & 80.81 & -57.47 & 61.69 \\
\hline $29.183-28.278$ & 0.70 & 327.83 & -0.234 & 229.19 & -131.30 & 86.30 & 90.44 & -64.85 & 68.43 \\
\hline $30.977-29.183$ & 0.67 & 327.78 & -0.259 & 218.39 & -122.23 & 77.34 & 85.98 & -62.38 & 70.01 \\
\hline $33.726-30.977$ & 0.61 & 327.71 & -0.290 & 271.13 & -150.32 & 91.55 & 105.96 & -77.89 & 89.42 \\
\hline $35.102-33.726$ & 0.48 & 327.55 & -0.254 & 218.58 & -113.82 & 60.43 & 85.10 & -62.42 & 86.33 \\
\hline $35.774-35.102$ & 0.42 & 327.50 & -0.245 & 223.23 & -114.86 & 58.28 & 87.14 & -63.60 & 91.82 \\
\hline $36.573-35.774$ & 0.36 & 327.39 & -0.236 & 194.39 & -95.38 & 42.06 & 75.77 & -54.70 & 89.24 \\
\hline $38.398-36.573$ & 0.25 & 327.32 & -0.222 & 155.02 & -68.23 & 19.76 & 59.55 & -43.40 & 86.02 \\
\hline $40.073-38.398$ & 0.15 & 327.20 & -0.222 & 123.15 & -42.49 & -5.00 & 47.72 & -32.95 & 92.27 \\
\hline $41.105-40.073$ & 0.04 & 327.12 & -0.222 & 152.47 & -54.70 & -2.82 & 60.56 & -38.26 & 113.72 \\
\hline $42.196-41.105$ & -0.11 & 327.02 & -0.217 & 199.61 & -78.63 & 6.06 & 81.86 & -47.30 & 141.50 \\
\hline $43.450-42.196$ & -0.59 & 326.80 & -0.197 & 296.61 & -111.25 & -3.33 & 140.42 & -49.67 & 291.44 \\
\hline $46.235-43.450$ & 50.07 & 276.72 & -0.289 & 499.35 & 86.96 & -514.15 & 179.83 & -190.96 & 993.82 \\
\hline $47.760-46.235$ & 56.99 & 243.21 & -0.622 & 2407.84 & 378.66 & -2731.44 & 427.75 & -502.11 & 3982.85 \\
\hline $48.878-47.760$ & 12.32 & 296.69 & -0.160 & 684.72 & 21.64 & -694.29 & 148.70 & -135.02 & 1155.35 \\
\hline $49.666-48.878$ & 6.62 & 299.97 & -0.162 & 439.44 & -28.29 & -312.63 & 160.75 & -114.34 & 670.48 \\
\hline $50.767-49.666$ & 6.62 & 299.61 & -0.165 & 472.61 & -43.03 & -330.27 & 160.96 & -100.03 & 702.04 \\
\hline $51.724-50.767$ & 6.64 & 298.63 & -0.164 & 499.98 & -25.12 & -411.38 & 158.08 & -47.40 & 748.67 \\
\hline
\end{tabular}

Notes: These angular velocities specify Nubia Plate motion relative to the Antarctic Plate during the time period given in the first column, as determined from the REDBACK noise-reduction software (Iaffaldano et al. 2014). The angular rotation rates $\dot{\omega}$ are positive anticlockwise. The Cartesian angular velocity covariances are calculated in a Nubia-fixed reference frame and have units of $10^{-8}$ radians $^{2} \mathrm{Myr}^{-2}$.

rotations are strongly constrained by the numerous magnetic reversal identifications and nearby fracture zone flow lines. A GPS estimate of the present-day stage velocity at the same location (DeMets et al. 2017) agrees with the velocities that are estimated from our best-fitting and noise-reduced angular velocities to within $\pm 0.5 \mathrm{~mm} \mathrm{yr}^{-1}$ and $2^{\circ}$ (red lines in Figs $6 \mathrm{a}$ and $\mathrm{b}$ ), consistent with evidence from our flow line displacements that NubiaAntarctic opening rates have been steady for the past 5-6 Myr (Fig. 5). This concurs with the conclusions reached by DeMets et al. $(2015,2017)$.

The estimated displacements clearly indicate that the spreading rates have changed multiple times since $52 \mathrm{Ma}$. From 49 to $\approx 45$ $\mathrm{Ma}$, the estimated spreading rates increased by $50-70$ per cent and the plate slip direction rotated clockwise by $15-20^{\circ}$ (Fig. 6). Rates then declined from 45 to $40 \mathrm{Ma}$, but recovered to their previous high by 35-34 Ma. Since 33-32 Ma, spreading rates have decreased by $\approx 50$ per cent (Fig. 6a), although the rates are too noisy to determine whether the slowdown ceased by $\approx 20 \mathrm{Ma}$ or continued until 6-5 Ma.

Our new rotations (and the GPS-derived slip direction) indicate that the plate slip direction has rotated $\approx 10^{\circ}$ anticlockwise during the past $17 \mathrm{Myr}$ (Fig. 6b). A well-defined, sustained slowdown of Nubia-South America seafloor spreading rates since $20 \mathrm{Ma}$ and a requirement of closure around the Nubia-Antarctic-South America Plate circuit also independently predict a $7-10^{\circ}$ anticlockwise rotation of the Nubia-Antarctic slip direction near the Bouvet Triple 
(a)
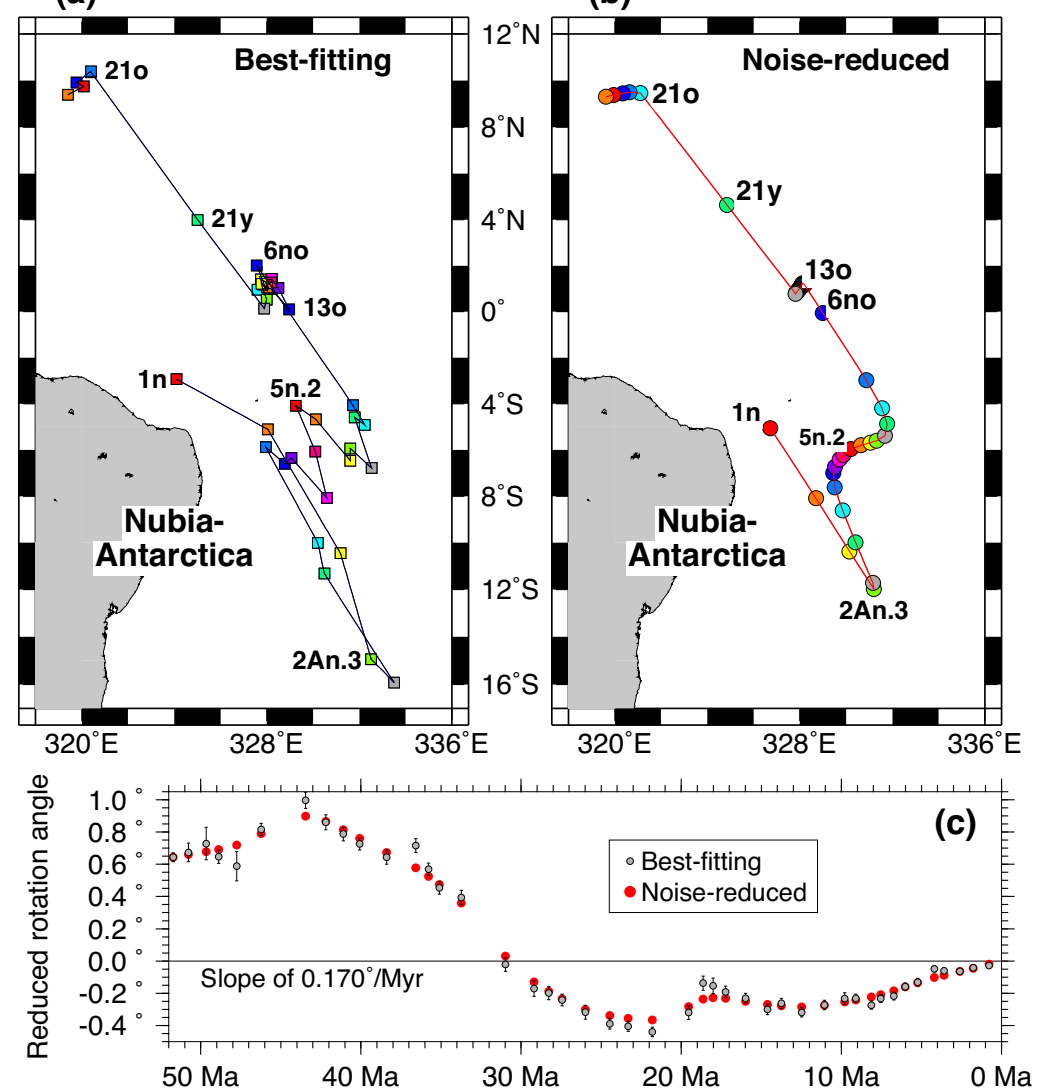

Figure 3. Nubia-Antarctic best-fitting and noise-reduced finite rotation poles (panels a and b, respectively) and reduced opening angles (c), C1n to C23o. Confidence ellipses are omitted for clarity. (a) Best-fitting poles (Table 2). (b) Noise-reduced poles from REDBACK analysis (Table 3). The ages of the labelled poles are as follows (Table 1): C1n, 0.773 Ma; C2An.3, 3.60 Ma; C5n.2, 11.06 Ma; C6no, 19.54 Ma; C13o, 33.73 Ma; C21y, 46.24 Ma and C21o, 47.76 Ma. The opening angles in panel (c) are reduced by a slope of $0.170^{\circ} \mathrm{Myr}^{-1}$ in order to emphasize changes in the angular rates. The opening angle error bars show their 95 per cent uncertainties.

Junction since 14 Ma (see fig. 20 in DeMets \& Merkouriev 2019). The Nubia-Antarctic pole location thus appears to have changed continuously since at least $14 \mathrm{Ma}$.

In our previous analysis of post-20-Ma SWIR plate motions (DeMets et al. 2015), we found that Nubia-Antarctic seafloor spreading rates declined $\sim 50$ per cent between 20 and $15 \mathrm{Ma}$ (magneta line in Fig. 6a), with the caveat that our previous estimates for this period were unreliable due to difficulties identifying C6, C5E and C5D along the western SWIR. Our new bestfitting and noise-reduced rotations for C5D-C6no (Tables 2 and 3 ), which are derived from new identifications of C5D and C5E and revised identifications of C6no and C6ny along the western SWIR, indicate a significantly smaller spreading rate slowdown from 20 to $15 \mathrm{Ma}$ (blue line in Fig. 6a). Despite the more plausible opening rate history that derives from our new C5D-C6 reversal identifications, we remain skeptical of their reliability.

Cande \& Patriat (2015) estimated Africa-Antarctic Plate finite rotations by reconstructing crossings of Chrons 24 to 13 and selected fracture zone crossings everywhere along the SWIR. Stage spreading rates estimated with angular velocities derived from their finite rotations (red circles in Fig. 6) also increase by $\approx 30-40$ per cent from 52 to $33 \mathrm{Ma}$, approximately the same as indicated by our higher resolution spreading rates. From reconstructions of C24 and older reversals, Bernard et al. (2005) and Cande \& Patriat (2015) document a $30-35^{\circ}$ clockwise change of the Nubia-Antarctic slip direction between 59 and $~ 53$ Ma. Our newly determined slip directions instead suggest that the clockwise rotation continued until $\approx 45 \mathrm{Ma}$ (Fig. 6b). Better mapping of the prominent fracture zone bends east of the Andrew Bain fracture zone is needed to discriminate between these possibilities.

\subsection{Lwandle-Antarctic Plate motion}

\subsubsection{Best-fitting and noise-reduced rotations and poles}

Best-fitting Lwandle-Antarctic rotations (Table 5) were determined from an inversion of 2244 magnetic reversal crossings, 2678 crossings of seven fracture zones and 611 crossings of six transform faults, all located between the southern end of the Andrew Bain fracture zone and Gallieni fracture zone (Fig. 2b). The rotations are constrained by as many as 128 reversal crossings $(\mathrm{C} 1 \mathrm{n})$ and as few as $25(\mathrm{C} 5 \mathrm{Cn} .1)$, generally diminishing with seafloor age (Table 1). The degrees of freedom for the individual rotations range from 754 for $\mathrm{C} 1 \mathrm{n}$ to only 23-25 for the sparsely surveyed C22 and C23 (Table 5). Lwandle-Antarctic 


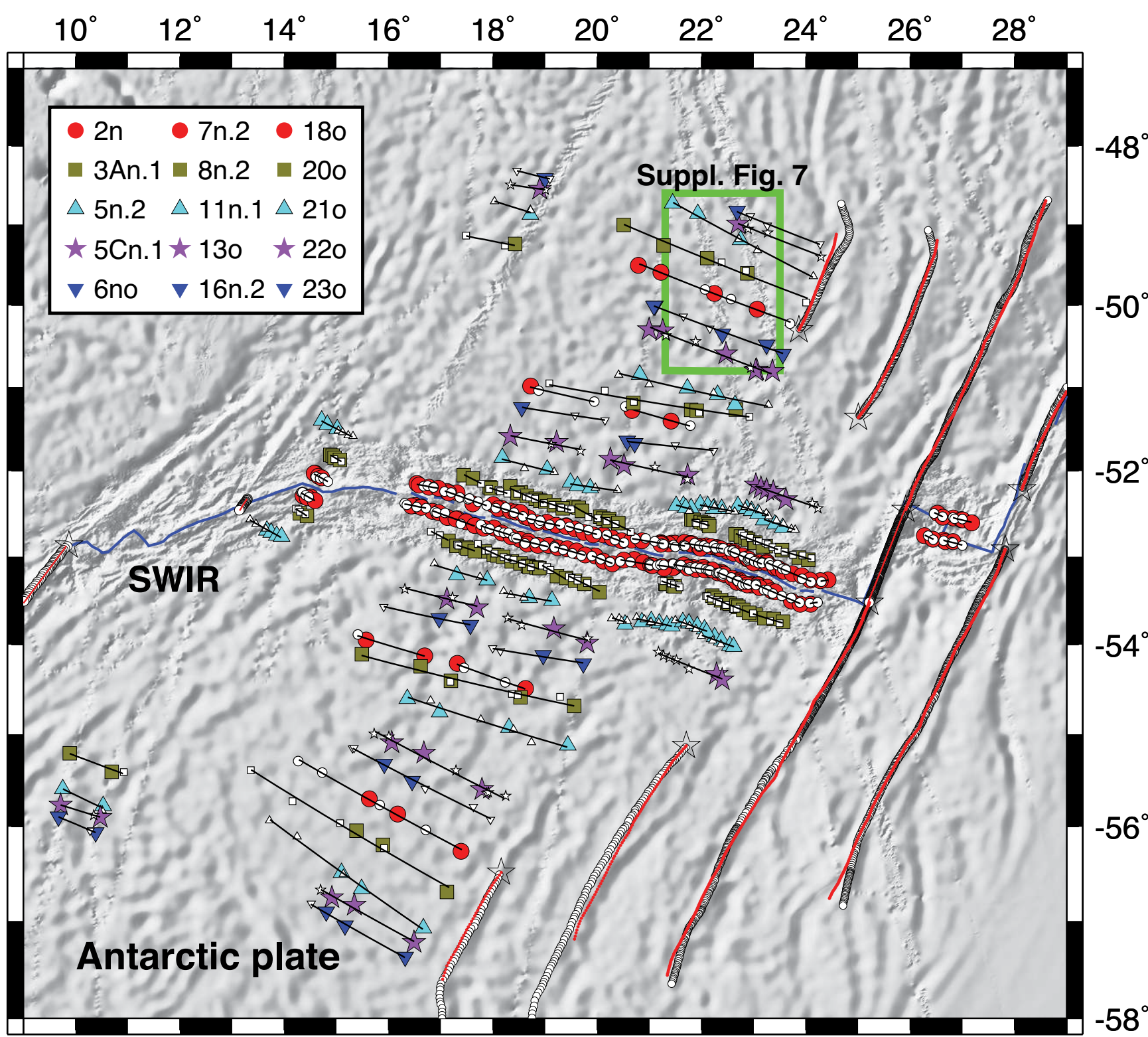

Figure 4. Selected magnetic reversal and fracture zone flow line reconstructions, $9-29^{\circ} \mathrm{E}$, with the best-fitting Nubia-Antarctic rotations in Table 2. The circles with black rims and coloured cores show the in-place reversal identifications. The circles with black rims and white cores show the rotated reversal crossing locations. Black lines show the great circles that best fit the reconstructed reversal crossings for each palaeo-spreading segment. The blue line identifies the present spreading axis. The original and reconstructed fracture zone flow lines are shown by the open black and red filled circles, respectively. The open black stars show the flow line seed points. Reconstructions of all 44 reversals for the entire Nubia-Antarctic segment of the ridge are shown with the along-track magnetic anomalies in Figs S10-S13. SWIR, Southwest Indian Ridge.

noise-reduced rotations and angular velocities from our REDBACK analysis of the best-fitting rotations and covariances are listed in Tables 6 and 7.

The best-fitting poles are clustered tightly within a several angular-degree radius (Fig. 7a) except for the $\mathrm{C} 1 \mathrm{n}$ pole, which has a 2-D 95 per cent confidence ellipse that encompasses the other best-fitting poles. The noise-reduced poles, which are even more tightly clustered (Fig. 7b), are consistent with northward wander of the pole from $\mathrm{C} 23$ to $\mathrm{C} 19 \mathrm{c}$ and slow southward wander of the pole from $\mathrm{C} 18$ until $\mathrm{C} 3$.

Similar to the Nubia-Antarctic rotation angles, the LwandleAntarctic opening angles have multiple inflections that are consistent with multiple spreading rate changes (Fig. 7c), most of which are also apparent in the Lwandle-Antarctic and SomaliaAntarctic flow line displacements. These are described in more detail in Section 4.2.4 and are compared to Nubia-Antarctic and Somalia-Antarctic motion changes in Section 4.5.

\subsubsection{Magnetic reversal reconstructions and misfits}

The reconstructed Lwandle-Antarctic magnetic reversal crossings are well distributed along the plate boundary except for a sparsely surveyed gap from $40^{\circ} \mathrm{E}$ to $45^{\circ} \mathrm{E}$ (Figs 8 and S14-S17). The bestfitting rotation WRMS misfits range from 1.23 to $4.73 \mathrm{~km}$ (Table 1 


\section{Millions of years before present}

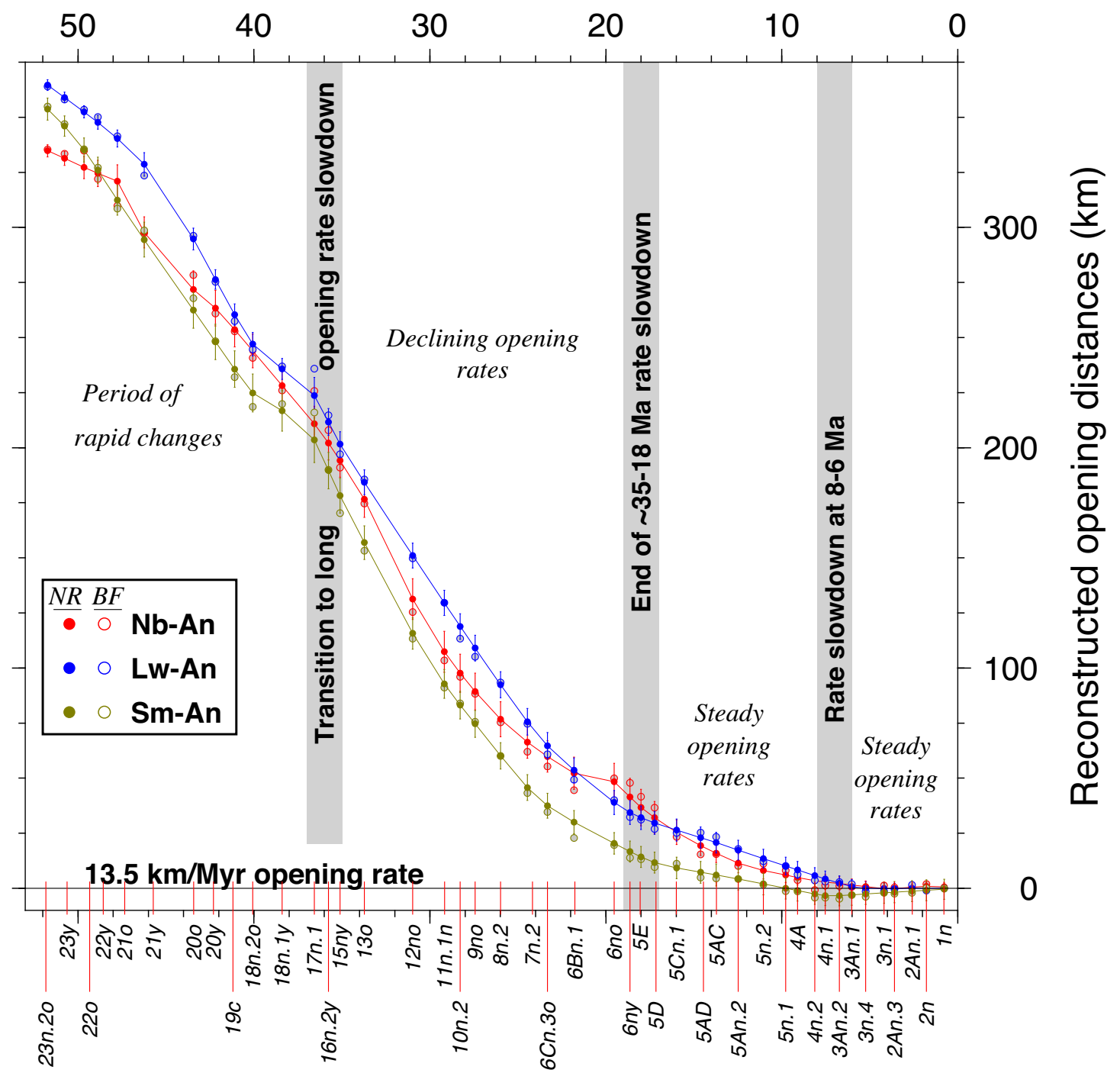

Figure 5. Cumulative flow line displacements, C23 to present, reduced by an assumed $13.5 \mathrm{~km} \mathrm{Myr}^{-1}$ opening rate to better emphasize changes. The NubiaAntarctic (Nb-An), Lwandle-Antarctic (Lw-An) and Somalia-Antarctic (Sm-An) flow lines along which the distances were estimated originate at respective locations of $52.8^{\circ} \mathrm{S}, 20.0^{\circ} \mathrm{E}(\mathrm{Nb}-\mathrm{An}), 45.0^{\circ} \mathrm{S}, 36.0^{\circ} \mathrm{E}(\mathrm{Lw}-\mathrm{An})$ and $31.6^{\circ} \mathrm{S}, 58.0^{\circ} \mathrm{E}(\mathrm{Sm}-\mathrm{An})$, the same as for the stage velocities in Figs 6,13 and 17. Distances were calculated using the best-fitting (BF) and noise-reduced (NR) rotations. Error bars show the $1 \sigma$ displacement uncertainties propagated from the finite rotation covariances. The grey bars indicate major spreading rate transitions that are described in the text.

and Fig. S2), nearly the same as for the Nubia-Antarctic reconstructions (Fig. S2) and for reconstructions of $\mathrm{C} 1 \mathrm{n}$ to $\mathrm{C} 13$ in the southern Atlantic basin (DeMets \& Merkouriev 2019). For 35 of the 44 reconstructions, the differences between the WRMS reversal misfits for the noise-reduced and best-fitting rotations are $1000 \mathrm{~m}$ or less, too small to affect any of our subsequent results or interpretations. Nine noise-reduced rotations, all for magnetic reversals C9 or older, have fitting penalties of $1.0-3.5 \mathrm{~km}$ relative to their corresponding best-fitting rotations. We attribute these larger misfits to the same factors as for the Nubia-Antarctic Plate pair (Section 4.1.2).

\subsubsection{Transform fault and fracture zone flow line fits}

The WRMS misfit of the C1n opening pole to the crossings of the six Lwandle-Antarctic transform faults is $1.0 \mathrm{~km}$, close to the $0.90 \mathrm{~km}$ WRMS misfit for the Nubia-Antarctic transform faults. The C1n noise-reduced pole is located $\approx 7$ angular degrees closer to the other young poles than is the best-fitting pole (Fig. 7), reflecting the REDBACK criteria of minimizing changes in plate motion within the limits of the rotation covariances. The azimuths that are estimated with the C1n best-fitting and noise-reduced poles at the locations of all six Lwandle-Antarctic transform faults differ insignificantly from their measured MORVEL azimuths (DeMets et al. 2010). The noise-reduced and best-fitting $\mathrm{C} 1 \mathrm{n}$ poles thus provide equivalent fits within their uncertainties.

The estimated Lwandle-Antarctic flow line traces are generally located within their bathymetrically defined fracture zone valleys (Fig. 8 plus Fig. S4 and Supplemental Maps 14-17). The WRMS flow line misfits for the best-fitting rotations increase from a few hundred metres for young seafloor ages to $\approx 9 \mathrm{~km}$ at $50 \mathrm{Ma}$ (Table 1 and Fig. S2b), similar to the misfits for reconstructed fracture zones in the southern Atlantic basin (red line and circles in Fig. S2b). 

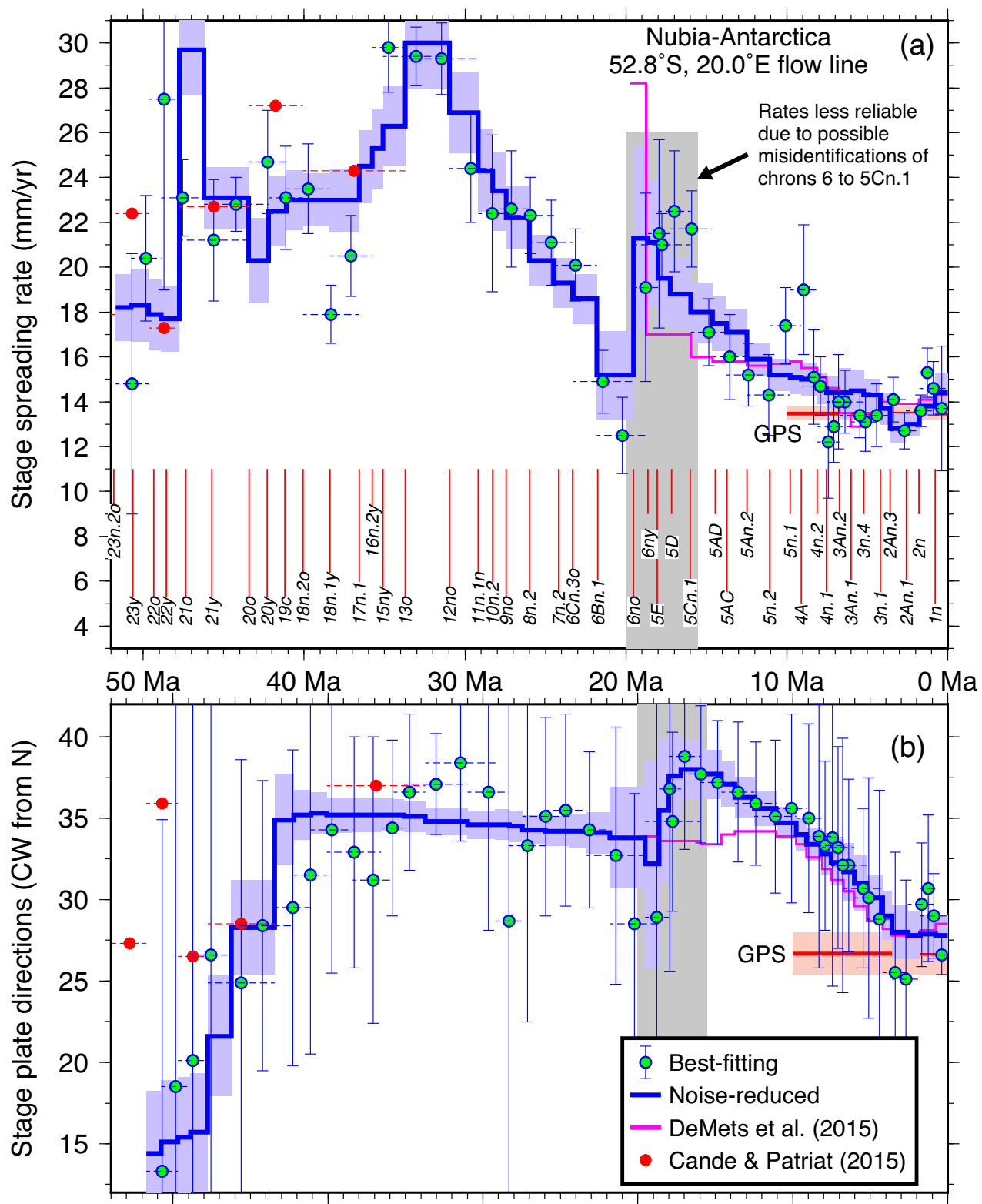

Figure 6. Nubia-Antarctic stage spreading rates (a) and directions (b) along an Antarctic Plate flow line that originates at the ridge at $52.8^{\circ} \mathrm{S}, 20.0^{\circ} \mathrm{E}$. Blue-green circles show velocities and their $1 \sigma$ uncertainties that were determined with stage rotations and covariances that were derived from the best-fitting finite rotations in Table 2. Blue lines and light blue areas show stage velocities and $1 \sigma$ uncertainties estimated with the noise-reduced stage rotations in Table 4. Purple lines show noise-reduced estimates from DeMets et al. (2015). Red circles show stage velocities we determined by combining finite rotations for C13o, C18o, C20o, C21o, C22o and C23o from Cande \& Patriat (2015). Red lines and pink shaded areas show instantaneous velocities and their 95 per cent uncertainties estimated with a GPS Nubia-Antarctic angular velocity from DeMets et al. (2017). Horizontal dashed lines specify the time interval that is spanned by a given stage rotation.

The noise-reduced flow lines fit the fracture zone traces nearly as well, with misfits that are typically just $100-300 \mathrm{~m}$ larger than those for the best-fitting flow lines and never more than $2.8 \mathrm{~km}$ larger.

\subsubsection{Spreading history: displacements, rates and directions}

The time-series of Lwandle-Antarctic opening distances (Fig. 5; also see Fig. 7c) that we reconstructed with the best-fitting and noise-reduced rotations (Tables 5 and 6, respectively) exhibits clear slope breaks at $\approx 45,40,20$ and $7 \mathrm{Ma}$, consistent with plate motion changes at or near those times. These changes are apparent in the reconstructed spreading rate history (Fig. 9a), which exhibits a nearly 50 per cent speedup from 49 to $44 \mathrm{Ma}$, a $\approx 50$ per cent slowdown from 44-43 to $40 \mathrm{Ma}$, and full rate recovery by $37-36$ Ma. After $\approx 30 \mathrm{Ma}$, spreading rates declined gradually by $\approx 60$ per cent until $18-17 \mathrm{Ma}$. The most recent resolvable change was a $\approx 20$ per cent spreading rate slowdown at 7-6 Ma (Fig. 9a and DeMets et al. 2015).

The reconstructed plate slip directions rotated $25-30^{\circ}$ clockwise from 52 to $40 \mathrm{Ma}$ (Fig. 9b), driven primarily by changes 
Table 5. Lwandle-Antarctic best-fitting finite rotations.

\begin{tabular}{|c|c|c|c|c|c|c|c|c|c|c|}
\hline \multirow[t]{2}{*}{ Chron } & \multirow[t]{2}{*}{ DOF } & \multirow{2}{*}{$\begin{array}{l}\text { Lat. } \\
\left({ }^{\circ} \mathrm{N}\right)\end{array}$} & \multirow{2}{*}{$\begin{array}{l}\text { Long. } \\
\left({ }^{\circ} \mathrm{E}\right)\end{array}$} & \multirow{2}{*}{$\begin{array}{l}\Omega \\
\left({ }^{\circ}\right)\end{array}$} & \multicolumn{6}{|c|}{ Rotation covariances* } \\
\hline & & & & & $\mathrm{a}$ & $\mathrm{b}$ & $\mathrm{c}$ & d & $\mathrm{e}$ & $\mathrm{f}$ \\
\hline $1 \mathrm{n} *$ & 754 & 13.91 & 307.25 & -0.096 & 5.1 & 3.9 & -6.2 & 3.3 & -5.0 & 8.0 \\
\hline $2 \mathrm{n} *$ & 121 & 9.58 & 317.02 & -0.206 & 71.8 & 57.0 & -89.0 & 53.1 & -77.4 & 120.8 \\
\hline 2An.1 & 130 & 8.40 & 319.93 & -0.330 & 31.0 & 13.1 & -17.6 & 19.5 & -16.7 & 26.9 \\
\hline 2An. 3 & 106 & 7.93 & 321.03 & -0.435 & 13.2 & 5.7 & -7.9 & 10.2 & -8.9 & 22.1 \\
\hline $3 n .1$ & 68 & 8.92 & 320.98 & -0.499 & 33.4 & 7.8 & -15.5 & 21.6 & -11.0 & 25.5 \\
\hline $3 \mathrm{n} .4$ & 97 & 7.89 & 322.30 & -0.627 & 33.0 & 10.6 & -15.1 & 20.7 & -13.5 & 25.1 \\
\hline 3An.1 & 86 & 7.82 & 322.37 & -0.753 & 36.0 & 16.4 & -21.0 & 25.0 & -22.4 & 38.2 \\
\hline 3An.2 & 64 & 9.33 & 321.16 & -0.844 & 30.2 & 13.3 & -20.3 & 20.1 & -16.0 & 36.4 \\
\hline $4 n .1$ & 60 & 7.62 & 323.48 & -0.950 & 40.1 & 13.9 & -21.5 & 26.2 & -18.0 & 40.7 \\
\hline $4 n .2$ & 47 & 6.82 & 324.79 & -1.030 & 35.3 & 11.7 & -17.1 & 24.3 & -14.1 & 51.1 \\
\hline $4 \mathrm{~A}$ & 112 & 8.79 & 323.28 & -1.168 & 32.0 & 13.3 & -10.2 & 19.0 & -5.2 & 56.5 \\
\hline $5 \mathrm{n} .1$ & 130 & 11.07 & 321.65 & -1.282 & 45.2 & 13.6 & 12.3 & 30.9 & 18.1 & 83.6 \\
\hline $5 \mathrm{n} .2$ & 160 & 11.30 & 320.90 & -1.455 & 62.5 & 13.0 & -42.1 & 24.0 & -17.7 & 160.0 \\
\hline $5 \mathrm{An} .2$ & 161 & 8.23 & 324.79 & -1.690 & 87.0 & 1.0 & 11.8 & 40.9 & -3.5 & 93.0 \\
\hline $5 \mathrm{AC}$ & 130 & 8.94 & 324.44 & -1.892 & 86.5 & 37.8 & 1.0 & 56.3 & 10.3 & 70.4 \\
\hline $5 \mathrm{AD}$ & 79 & 9.57 & 324.38 & -2.013 & 122.6 & 45.9 & 40.9 & 62.1 & 27.9 & 115.9 \\
\hline $5 \mathrm{Cn} .1$ & 83 & 9.42 & 323.91 & -2.178 & 127.8 & -17.5 & 1.4 & 87.8 & 6.4 & 97.7 \\
\hline $5 \mathrm{D}$ & 98 & 9.76 & 323.42 & -2.346 & 59.4 & 23.8 & -17.3 & 51.5 & -2.9 & 80.1 \\
\hline $5 \mathrm{E}$ & 99 & 10.92 & 322.15 & -2.472 & 51.0 & 19.9 & -21.9 & 39.3 & -1.9 & 100.1 \\
\hline 6ny & 75 & 11.35 & 321.81 & -2.558 & 93.7 & 15.7 & -1.4 & 42.9 & 1.6 & 131.4 \\
\hline 6 no & 117 & 10.70 & 322.40 & -2.739 & 111.2 & 41.4 & -31.9 & 65.9 & -30.6 & 185.0 \\
\hline $6 \mathrm{Bn} .1$ & 184 & 10.95 & 322.17 & -3.098 & 208.8 & 96.7 & -15.5 & 131.9 & -0.4 & 125.6 \\
\hline $6 \mathrm{Cn} .3$ & 160 & 10.70 & 322.62 & -3.388 & 198.4 & 87.4 & -10.6 & 149.1 & -10.3 & 134.8 \\
\hline $7 \mathrm{n} .2$ & 122 & 10.35 & 322.97 & -3.655 & 170.3 & 82.3 & -24.8 & 91.3 & -20.5 & 218.0 \\
\hline $8 \mathrm{n} .2$ & 155 & 10.41 & 323.30 & -4.011 & 168.6 & 24.8 & -12.8 & 93.4 & -76.2 & 364.3 \\
\hline 9 no & 120 & 10.94 & 322.89 & -4.290 & 209.5 & 54.7 & -99.9 & 86.7 & -82.0 & 409.2 \\
\hline 10n.2 & 72 & 11.20 & 322.69 & -4.465 & 212.9 & 77.4 & -60.5 & 110.5 & -41.1 & 307.8 \\
\hline $11 \mathrm{n} .1$ & 97 & 11.07 & 323.08 & -4.724 & 277.9 & 147.7 & -21.6 & 148.6 & -22.4 & 282.7 \\
\hline $12 \mathrm{no}$ & 125 & 11.19 & 322.95 & -5.123 & 258.5 & 150.9 & 34.8 & 204.7 & 6.1 & 288.1 \\
\hline 130 & 192 & 11.70 & 322.47 & -5.778 & 489.5 & 198.0 & 9.9 & 326.0 & -10.0 & 366.7 \\
\hline 15 ny & 75 & 12.15 & 321.91 & -6.044 & 296.1 & 184.3 & -49.4 & 164.7 & -62.4 & 434.2 \\
\hline 16n.2 & 72 & 12.79 & 321.08 & -6.283 & 462.9 & 207.2 & -46.0 & 298.9 & -51.9 & 275.7 \\
\hline $17 \mathrm{n} .1$ & 63 & 12.58 & 321.23 & -6.572 & 353.7 & 351.7 & -89.7 & 414.6 & -63.9 & 218.9 \\
\hline $18 \mathrm{y}$ & 77 & 12.67 & 320.71 & -6.802 & 243.6 & 165.8 & -55.6 & 214.1 & -69.1 & 301.1 \\
\hline 180 & 80 & 12.36 & 320.58 & -7.076 & 294.9 & 132.5 & -66.4 & 379.4 & -118.3 & 524.0 \\
\hline $19 \mathrm{c}$ & 70 & 12.11 & 320.58 & -7.317 & 367.5 & 162.6 & -34.8 & 424.7 & -228.3 & 966.0 \\
\hline $20 y$ & 82 & 12.76 & 320.03 & -7.609 & 278.4 & 186.9 & -69.8 & 223.6 & -183.8 & 1191.1 \\
\hline $20 \mathrm{o}$ & 72 & 11.69 & 321.16 & -7.955 & 355.3 & 279.5 & -237.4 & 325.7 & -363.6 & 1443.7 \\
\hline $21 y$ & 52 & 11.58 & 320.21 & -8.539 & 493.3 & 428.9 & -734.1 & 677.5 & -1850.0 & 10839.2 \\
\hline 210 & 34 & 10.70 & 320.01 & -8.889 & 550.3 & 576.7 & -871.8 & 868.1 & -1346.6 & 4617.9 \\
\hline $22 y$ & 23 & 9.04 & 321.44 & -9.124 & 298.1 & 229.0 & 294.3 & 564.5 & -1652.9 & 9960.0 \\
\hline 220 & 23 & 8.38 & 321.15 & -9.254 & 734.7 & 108.6 & 133.5 & 917.2 & -1719.9 & 8000.6 \\
\hline $23 y$ & 25 & 8.02 & 320.99 & -9.432 & 371.4 & 277.9 & 264.6 & 538.2 & -1263.0 & 7024.4 \\
\hline 230 & 25 & 7.55 & 320.71 & -9.605 & 934.0 & 169.9 & 1280.8 & 1423.1 & -4062.6 & 22438.7 \\
\hline
\end{tabular}

Notes: These finite rotations reconstruct movement of the Lwandle Plate relative to the Antarctic Plate and include corrections for $2 \mathrm{~km}$ of outward displacement described in the text. The rotation angles $\Omega$ are positive CCW. Each rotation is the mean of 1000 bootstrap solutions (see text). *The rotations marked with an asterisk have covariances that were determined from the geometric distribution of the observations using the method of Chang [1988]. Other covariances are determined from the bootstrapping procedure described in the text. DOF, the degrees of freedom, equals the total number of anomaly, transform fault, and fracture zone flow-line crossings used to estimate the rotation for a given time reduced by the number of estimated parameters. The weighted RMS misfits for these rotations are given in Table 1 . The Cartesian rotation covariances are calculated in a Lwandle-fixed reference frame and have units of $10^{-9}$ radians ${ }^{2}$. See Table 2 footnotes for further information about the rotation covariances.

in the trends of the Marion and Prince Edwards fracture zones south of the ridge during this time (Fig. S4). After $\approx 40 \mathrm{Ma}$, the plate slip direction remained steady until at least $8 \mathrm{Ma}$ and possibly until 4-3 Ma. A slow anticlockwise rotation of the plate slip direction during the past $\approx 5 \mathrm{Myr}$ (Fig. 6b) agrees with a similar rotation of the Nubia-Antarctic slip direction during this period.

\subsection{Somalia-Antarctic Plate motion}

\subsubsection{Best-fitting and noise-reduced rotations and poles}

The Somalia-Antarctic segment of the SWIR (Figs 2b and 10) is well surveyed east of $54^{\circ} \mathrm{E}$ (Figs S1 and S18-S21), including nearly complete multibeam and magnetic coverage that clearly reveals the 
Table 6. Lwandle-Antarctic noise-reduced finite rotations.

\begin{tabular}{|c|c|c|c|c|c|c|c|c|c|}
\hline \multirow[t]{2}{*}{ Chron } & \multirow{2}{*}{$\begin{array}{l}\text { Lat. } \\
\left({ }^{\circ} \mathrm{N}\right)\end{array}$} & \multirow{2}{*}{$\begin{array}{l}\text { Long. } \\
\left({ }^{\circ} \mathrm{E}\right)\end{array}$} & \multirow{2}{*}{$\begin{array}{l}\Omega \\
\left({ }^{\circ}\right)\end{array}$} & \multicolumn{6}{|c|}{ Covariances* } \\
\hline & & & & $\mathrm{a}$ & $\mathrm{b}$ & $\mathrm{c}$ & $\mathrm{d}$ & $\mathrm{e}$ & $\mathrm{f}$ \\
\hline 1n & 11.79 & 314.10 & -0.094 & 23.8 & -17.4 & 20.1 & 18.0 & -26.1 & 41.5 \\
\hline $2 n$ & 10.74 & 316.83 & -0.216 & 64.4 & -18.9 & -1.3 & 20.4 & -29.5 & 60.9 \\
\hline 2An.1 & 10.01 & 318.79 & -0.315 & 128.2 & -16.6 & -39.3 & 24.1 & -37.4 & 95.8 \\
\hline $2 \mathrm{An} .3$ & 9.38 & 320.65 & -0.437 & 225.0 & -12.2 & -97.0 & 30.5 & -51.0 & 151.0 \\
\hline $3 n .1$ & 9.14 & 321.40 & -0.509 & 288.9 & -10.3 & -134.1 & 34.8 & -60.0 & 187.9 \\
\hline $3 n .4$ & 8.95 & 322.16 & -0.638 & 411.1 & -6.8 & -206.3 & 42.3 & -76.3 & 258.8 \\
\hline $3 \mathrm{An} .1$ & 8.94 & 322.42 & -0.742 & 510.5 & 1.2 & -275.4 & 45.3 & -86.2 & 315.3 \\
\hline $3 \mathrm{An} .2$ & 8.97 & 322.54 & -0.841 & 612.9 & 10.3 & -347.7 & 48.2 & -96.6 & 373.9 \\
\hline $4 n .1$ & 9.03 & 322.60 & -0.958 & 741.1 & 24.7 & -442.4 & 50.8 & -109.0 & 447.3 \\
\hline $4 n .2$ & 9.08 & 322.62 & -1.043 & 837.1 & 37.2 & -516.2 & 52.2 & -117.8 & 502.3 \\
\hline $4 \mathrm{~A}$ & 9.19 & 322.61 & -1.186 & 999.7 & 59.5 & -641.8 & 54.7 & -133.5 & 596.2 \\
\hline $5 n .1$ & 9.26 & 322.60 & -1.285 & 1115.1 & 75.5 & -730.4 & 56.9 & -145.4 & 663.4 \\
\hline $5 n .2$ & 9.39 & 322.57 & -1.470 & 1329.2 & 105.6 & -893.4 & 61.8 & -169.3 & 789.2 \\
\hline $5 \mathrm{An} .2$ & 9.54 & 322.54 & -1.677 & 1562.7 & 138.8 & -1068.3 & 69.0 & -198.8 & 928.8 \\
\hline $5 \mathrm{AC}$ & 9.67 & 322.49 & -1.862 & 1760.1 & 166.5 & -1212.2 & 77.4 & -227.3 & 1049.1 \\
\hline $5 \mathrm{AD}$ & 9.76 & 322.46 & -1.988 & 1883.6 & 185.4 & -1303.4 & 82.6 & -245.7 & 1124.8 \\
\hline $5 \mathrm{Cn} .1$ & 9.90 & 322.40 & -2.185 & 2055.5 & 212.3 & -1428.1 & 91.6 & -274.5 & 1232.3 \\
\hline $5 \mathrm{D}$ & 10.02 & 322.35 & -2.367 & 2195.4 & 231.2 & -1520.7 & 102.7 & -303.1 & 1322.9 \\
\hline $5 \mathrm{E}$ & 10.10 & 322.31 & -2.482 & 2269.5 & 245.8 & -1576.5 & 107.1 & -317.3 & 1370.7 \\
\hline 6ny & 10.16 & 322.28 & -2.580 & 2330.9 & 257.0 & -1620.5 & 111.8 & -330.7 & 1412.1 \\
\hline 6 no & 10.26 & 322.24 & -2.730 & 2426.9 & 273.8 & -1688.2 & 119.5 & -351.5 & 1475.9 \\
\hline $6 \mathrm{Bn} .1$ & 10.48 & 322.13 & -3.138 & 2641.4 & 322.1 & -1852.1 & 134.0 & -397.1 & 1617.2 \\
\hline $6 \mathrm{Cn} .3$ & 10.63 & 322.06 & -3.421 & 2786.3 & 312.2 & -1880.2 & 171.2 & -458.7 & 1729.0 \\
\hline $7 \mathrm{n} .2$ & 10.74 & 322.00 & -3.659 & 2855.7 & 335.7 & -1939.4 & 177.5 & -478.4 & 1780.1 \\
\hline $8 \mathrm{n} .2$ & 10.89 & 321.91 & -3.995 & 2903.8 & 377.1 & -2015.4 & 175.8 & -490.2 & 1818.8 \\
\hline 9 no & 11.03 & 321.83 & -4.322 & 2904.5 & 398.7 & -2033.8 & 178.3 & -501.0 & 1829.9 \\
\hline $10 \mathrm{n} .2$ & 11.11 & 321.77 & -4.512 & 2878.0 & 405.9 & -2023.0 & 178.6 & -502.6 & 1818.7 \\
\hline $11 \mathrm{n} .1$ & 11.20 & 321.72 & -4.719 & 2827.0 & 407.6 & -1991.0 & 178.7 & -501.5 & 1792.8 \\
\hline $12 \mathrm{no}$ & 11.37 & 321.60 & -5.129 & 2663.0 & 381.1 & -1849.0 & 184.5 & -497.3 & 1706.2 \\
\hline 130 & 11.64 & 321.40 & -5.763 & 2251.4 & 267.4 & -1442.7 & 203.0 & -479.1 & 1481.2 \\
\hline 15 ny & 11.78 & 321.28 & -6.085 & 1990.6 & 193.3 & -1191.3 & 208.9 & -457.9 & 1331.3 \\
\hline $16 \mathrm{n} .2$ & 11.85 & 321.23 & -6.258 & 1923.8 & 119.8 & -1027.3 & 244.5 & -491.0 & 1319.8 \\
\hline $17 \mathrm{n} .1$ & 11.92 & 321.16 & -6.463 & 2144.2 & -193.0 & -552.1 & 470.6 & -767.4 & 1617.3 \\
\hline $18 y$ & 12.09 & 321.01 & -6.793 & 1374.6 & 130.7 & -809.4 & 153.5 & -330.2 & 932.7 \\
\hline $18 \mathrm{o}$ & 12.18 & 320.90 & -7.098 & 1310.1 & 44.8 & -627.9 & 196.8 & -372.6 & 933.5 \\
\hline $19 \mathrm{c}$ & 12.13 & 320.84 & -7.345 & 1245.2 & 77.7 & -661.8 & 164.1 & -327.8 & 868.1 \\
\hline $20 y$ & 11.94 & 320.81 & -7.622 & 1194.0 & 114.4 & -708.5 & 131.0 & -283.8 & 809.9 \\
\hline $20 \mathrm{o}$ & 11.51 & 320.81 & -7.942 & 1214.3 & 58.0 & -615.9 & 168.4 & -327.9 & 851.3 \\
\hline $21 \mathrm{y}$ & 10.25 & 320.85 & -8.594 & 1115.1 & -20.9 & -431.8 & 198.7 & -349.6 & 813.2 \\
\hline 210 & 9.49 & 320.89 & -8.891 & 812.6 & 58.0 & -445.7 & 101.7 & -207.3 & 561.0 \\
\hline $22 y$ & 8.93 & 320.91 & -9.098 & 673.4 & 76.9 & -420.9 & 67.0 & -152.4 & 451.1 \\
\hline 220 & 8.54 & 320.92 & -9.241 & 594.2 & 84.4 & -401.4 & 49.1 & -123.3 & 390.5 \\
\hline $23 y$ & 7.99 & 320.93 & -9.440 & 532.7 & 90.5 & -386.7 & 35.3 & -100.8 & 343.6 \\
\hline 230 & 7.51 & 320.94 & -9.613 & 564.9 & 97.1 & -411.8 & 37.0 & -106.3 & 363.7 \\
\hline
\end{tabular}

Notes: These rotations were determined from the best-fitting Lwandle-Antarctica finite rotations and covariances in Table 5 using Bayesian noise reduction as implemented in REDBACK software (Iaffaldano et al. 2014). The finite rotations reconstruct movement of the Lwandle Plate relative to the Antarctic Plate and include corrections for $2 \mathrm{~km}$ of outward displacement described in the text. The rotation angles $\Omega$ are positive anticlockwise. The Cartesian rotation covariances are calculated in a Lwandle-fixed reference frame and have units of $10^{-9}$ radians $^{2}$.

palaeoridge geometry and several fracture zone flow lines. The superior data coverage relative to other parts of the SWIR contributes to smaller WRMS misfits for this plate pair than elsewhere along the ridge (Fig. S2).

The best-fitting Somalia-Antarctic rotations (Table 8) were determined from 2863 magnetic reversal crossings, 397 crossings of six transform faults and 5219 crossings of seven fracture zones that originate at the present ridge axis and 14 other fracture zone segments that originate in older seafloor (Fig. 10 and S1). The rotations are constrained by as many as 236 reversal crossings (C1n) or as few as $6(\mathrm{C} 23 \mathrm{y})$, diminishing with seafloor age (Table 1). The degrees of freedom for the individual rotations range from 629 for $\mathrm{C} 1 \mathrm{n}$ to only 24 for $\mathrm{C} 23$ (Table 8 ). The noise-reduced rotations and angular velocities from our REDBACK analysis of the best-fitting rotations and covariances are given in Tables 9 and 10 .

Somalia-Antarctic best-fitting poles migrated slowly northward between $\mathrm{C} 23$ and $\mathrm{C} 18$, since which they have migrated slowly to the south (Fig. 11a). The noise-reduced poles display a similar path, but with less scatter (Fig. 11b). The well-constrained rotation angles exhibit at least five changes in slope, the most prominent at $\approx 20 \mathrm{Ma}$ 
Table 7. Lwandle-Antarctic stage angular velocities from REDBACK.

\begin{tabular}{|c|c|c|c|c|c|c|c|c|c|}
\hline \multirow{2}{*}{$\begin{array}{l}\text { Interval } \\
\text { (Ma) }\end{array}$} & \multirow{2}{*}{$\begin{array}{l}\text { Lat. } \\
\left({ }^{\circ} \mathrm{N}\right)\end{array}$} & \multirow{2}{*}{$\begin{array}{l}\text { Long. } \\
\left({ }^{\circ} \mathrm{E}\right)\end{array}$} & \multirow{2}{*}{$\begin{array}{c}\dot{\omega} \\
\left({ }^{\circ} \mathrm{Myr}^{-1}\right)\end{array}$} & \multicolumn{6}{|c|}{ Covariances } \\
\hline & & & & $\mathrm{a}$ & $\mathrm{b}$ & $\mathrm{c}$ & d & $\mathrm{e}$ & $\mathrm{f}$ \\
\hline $0.000-0.773$ & 11.78 & 314.12 & -0.122 & 2.00 & -0.92 & 0.36 & 2.17 & -0.52 & 0.27 \\
\hline $0.773-1.775$ & 9.91 & 318.91 & -0.122 & 1.86 & 0.45 & -0.28 & 1.77 & -0.59 & 0.44 \\
\hline $1.775-2.595$ & 8.40 & 322.99 & -0.122 & 2.42 & 1.24 & -0.67 & 2.34 & -0.90 & 0.66 \\
\hline $2.595-3.596$ & 7.66 & 325.41 & -0.122 & 2.60 & 1.45 & -0.75 & 2.54 & -0.98 & 0.71 \\
\hline $3.596-4.187$ & 7.69 & 325.88 & -0.122 & 3.04 & 1.59 & -0.82 & 3.07 & -1.15 & 0.82 \\
\hline $4.187-5.235$ & 8.17 & 325.18 & -0.123 & 2.93 & 0.84 & -0.59 & 2.74 & -1.04 & 0.71 \\
\hline $5.235-6.023$ & 8.82 & 324.01 & -0.132 & 4.50 & -0.79 & -0.10 & 3.51 & -1.17 & 0.69 \\
\hline $6.023-6.727$ & 9.19 & 323.41 & -0.140 & 3.50 & -0.40 & -0.14 & 2.77 & -0.91 & 0.58 \\
\hline $6.727-7.537$ & 9.47 & 323.06 & -0.144 & 2.09 & 0.12 & -0.22 & 1.78 & -0.61 & 0.46 \\
\hline $7.537-8.125$ & 9.70 & 322.80 & -0.145 & 1.50 & 0.22 & -0.19 & 1.32 & -0.43 & 0.39 \\
\hline $8.125-9.105$ & 9.94 & 322.59 & -0.145 & 1.11 & 0.21 & -0.17 & 0.99 & -0.32 & 0.35 \\
\hline $9.105-9.786$ & 10.14 & 322.47 & -0.146 & 1.06 & 0.21 & -0.19 & 0.92 & -0.32 & 0.40 \\
\hline $9.786-11.056$ & 10.31 & 322.39 & -0.146 & 0.88 & 0.14 & -0.12 & 0.77 & -0.24 & 0.31 \\
\hline $11.056-12.474$ & 10.58 & 322.28 & -0.146 & 1.01 & -0.03 & -0.07 & 0.85 & -0.25 & 0.34 \\
\hline $12.474-13.739$ & 10.86 & 322.11 & -0.146 & 0.82 & -0.12 & -0.01 & 0.67 & -0.17 & 0.32 \\
\hline $13.739-14.609$ & 11.08 & 321.99 & -0.145 & 0.84 & -0.21 & 0.02 & 0.66 & -0.16 & 0.34 \\
\hline $14.609-15.974$ & 11.31 & 321.86 & -0.144 & 1.26 & -0.60 & 0.14 & 0.89 & -0.21 & 0.37 \\
\hline $15.974-17.235$ & 11.57 & 321.72 & -0.145 & 1.70 & -0.98 & 0.25 & 1.14 & -0.28 & 0.44 \\
\hline $17.235-18.007$ & 11.72 & 321.63 & -0.149 & 2.34 & -1.48 & 0.39 & 1.55 & -0.38 & 0.53 \\
\hline $18.007-18.636$ & 11.78 & 321.59 & -0.155 & 4.22 & -2.93 & 0.81 & 2.69 & -0.71 & 0.66 \\
\hline $18.636-19.535$ & 11.80 & 321.56 & -0.167 & 4.53 & -3.13 & 0.87 & 2.88 & -0.77 & 0.74 \\
\hline $19.535-21.806$ & 12.00 & 321.44 & -0.180 & 2.55 & -1.60 & 0.41 & 1.70 & -0.42 & 0.74 \\
\hline $21.806-23.318$ & 12.29 & 321.25 & -0.187 & 3.46 & -2.25 & 0.60 & 2.28 & -0.59 & 0.97 \\
\hline $23.318-24.459$ & 12.36 & 321.18 & -0.208 & 5.57 & -3.86 & 1.05 & 3.62 & -0.98 & 1.29 \\
\hline $24.459-25.987$ & 12.52 & 321.05 & -0.220 & 3.08 & -1.90 & 0.43 & 2.09 & -0.50 & 1.32 \\
\hline $25.987-27.439$ & 12.80 & 320.84 & -0.225 & 2.10 & -1.06 & 0.14 & 1.51 & -0.31 & 1.49 \\
\hline $27.439-28.278$ & 13.00 & 320.68 & -0.227 & 1.96 & -0.85 & 0.04 & 1.47 & -0.28 & 1.70 \\
\hline $28.278-29.183$ & 13.16 & 320.55 & -0.228 & 1.99 & -0.79 & -0.01 & 1.52 & -0.28 & 1.85 \\
\hline $29.183-30.977$ & 13.42 & 320.31 & -0.229 & 1.84 & -0.54 & -0.17 & 1.43 & -0.29 & 2.06 \\
\hline $30.977-33.726$ & 13.90 & 319.85 & -0.231 & 2.28 & -0.48 & -0.36 & 1.79 & -0.47 & 2.64 \\
\hline $33.726-35.102$ & 14.32 & 319.42 & -0.235 & 6.69 & -2.69 & 0.05 & 5.00 & -1.64 & 4.01 \\
\hline $35.102-35.774$ & 14.30 & 319.38 & -0.257 & 53.40 & -39.03 & 11.84 & 35.04 & -11.68 & 8.34 \\
\hline $35.774-36.573$ & 14.42 & 319.25 & -0.257 & 72.89 & -53.97 & 16.99 & 48.00 & -15.99 & 10.15 \\
\hline $36.573-38.398$ & 15.54 & 318.29 & -0.181 & 32.01 & -21.82 & 6.59 & 22.09 & -6.97 & 6.67 \\
\hline $38.398-40.073$ & 14.23 & 318.38 & -0.182 & 16.56 & -9.02 & 1.38 & 12.15 & -2.91 & 10.80 \\
\hline $40.073-41.105$ & 10.93 & 319.25 & -0.239 & 13.72 & -5.66 & -3.07 & 10.18 & -0.83 & 26.56 \\
\hline $41.105-42.196$ & 7.02 & 319.68 & -0.255 & 12.64 & -4.48 & -5.31 & 9.41 & 0.67 & 35.56 \\
\hline $42.196-43.450$ & 1.31 & 320.14 & -0.260 & 12.75 & -5.32 & -3.72 & 9.66 & 0.27 & 29.81 \\
\hline $43.450-46.235$ & -4.69 & 320.20 & -0.243 & 5.17 & -1.53 & -2.29 & 4.14 & 0.54 & 15.39 \\
\hline $46.235-47.760$ & -11.32 & 320.10 & -0.209 & 9.04 & -3.30 & -3.63 & 6.59 & -0.07 & 23.61 \\
\hline $47.760-48.878$ & -13.82 & 319.96 & -0.201 & 6.47 & 0.04 & -6.23 & 5.05 & 0.06 & 31.99 \\
\hline $48.878-49.666$ & -14.95 & 319.67 & -0.198 & 4.21 & 0.77 & -3.89 & 4.15 & 1.59 & 27.54 \\
\hline $49.666-50.767$ & -15.91 & 319.53 & -0.198 & 5.01 & 1.73 & -4.03 & 5.36 & 1.77 & 31.15 \\
\hline $50.767-51.724$ & -16.95 & 319.44 & -0.199 & 9.12 & 5.41 & -5.27 & 11.01 & 2.77 & 44.73 \\
\hline
\end{tabular}

Notes: These angular velocities specify Lwandle Plate motion relative to the Antarctic Plate during the period given in the first column, as determined from the REDBACK noise-reduction software (Iaffaldano et al. 2014). The angular rotation rates $\dot{\omega}$ are positive anticlockwise. The Cartesian angular velocity covariances are calculated in a Lwandle-fixed reference frame and have units of $10^{-8}$ radians ${ }^{2}$ $\mathrm{Myr}^{-2}$.

(Fig. 11c). The changes, which resemble those for the independently derived Lwandle-Antarctic and Nubia-Antarctic rotation angles (Figs 3c and 7c), are discussed further in Sections 4.3.4 and 4.5.

\subsubsection{Magnetic reversal reconstructions and misfits}

Our best-fitting Somalia-Antarctic reconstructions (Figs 10 and Figs S18-S21) indicate that the ridge geometry changed at the time of $\mathrm{C} 18$, including a rapid clockwise rotation in slip directions and likely abandonment of some of the fracture zones that were active before $\mathrm{C} 18$. The WRMS misfits to the reversal crossing range from 1.1 to $3.6 \mathrm{~km}$ (Table 1 and Fig. S2a), smaller than for the rest of the SWIR. The WRMS misfits for 38 of the 44 noise-reduced rotations are only $0-1000 \mathrm{~m}$ larger than for their corresponding best-fitting rotations, too small to affect our results. None of the noise-reduced rotations differ from their best-fitting counterparts enough to significantly alter our results or interpretations.

\subsubsection{Transform fault and fracture zone flow line fits}

The traces of all six Somalia-Antarctic transform faults are well fit by small circles around the best-fitting $\mathrm{C} 1 \mathrm{n}$ pole, with a WRMS misfit of $1.04 \mathrm{~km}$ to the 397 transform fault crossings, nearly the same as for the Nubia-Antarctic $(0.90 \mathrm{~km})$ and Lwandle-Antarctic 
(a)

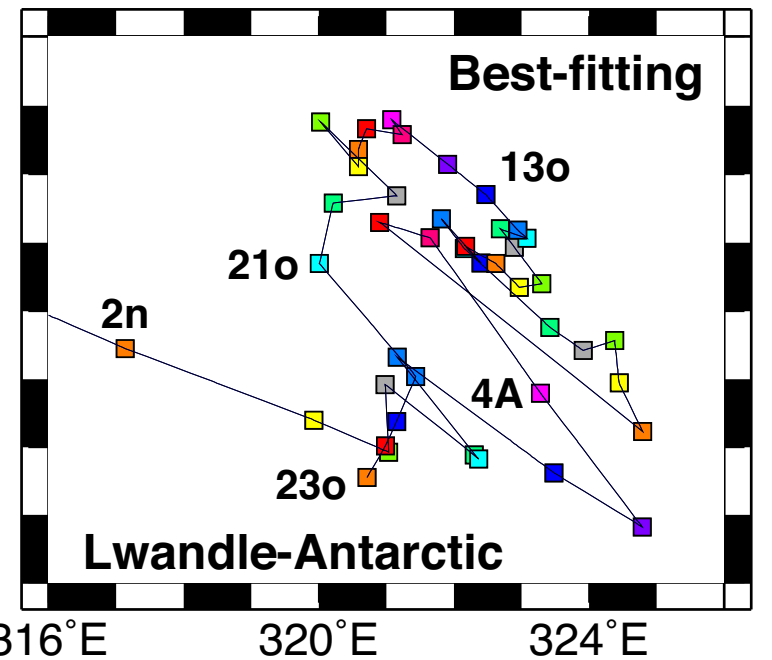

(b)

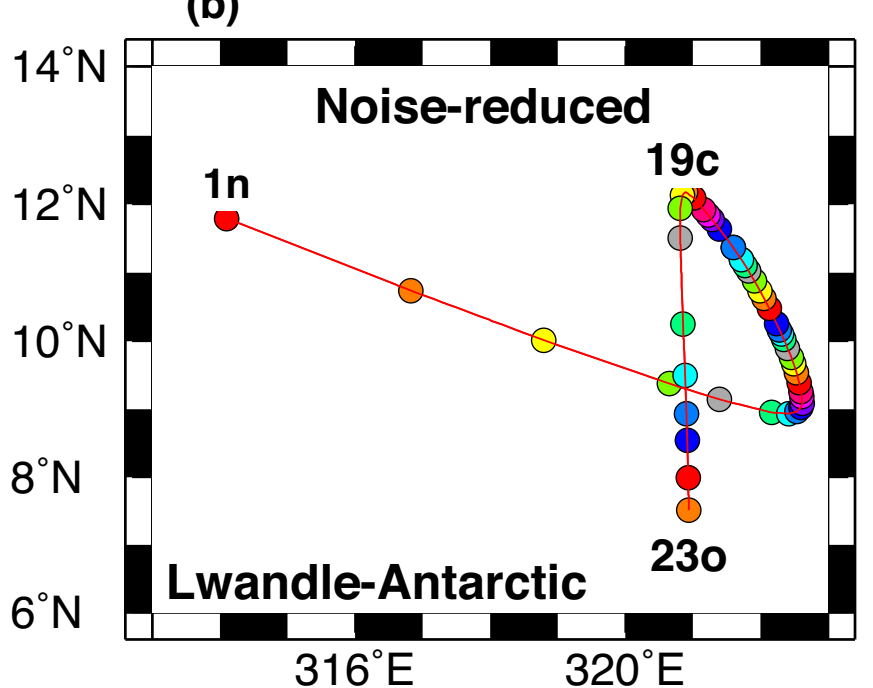

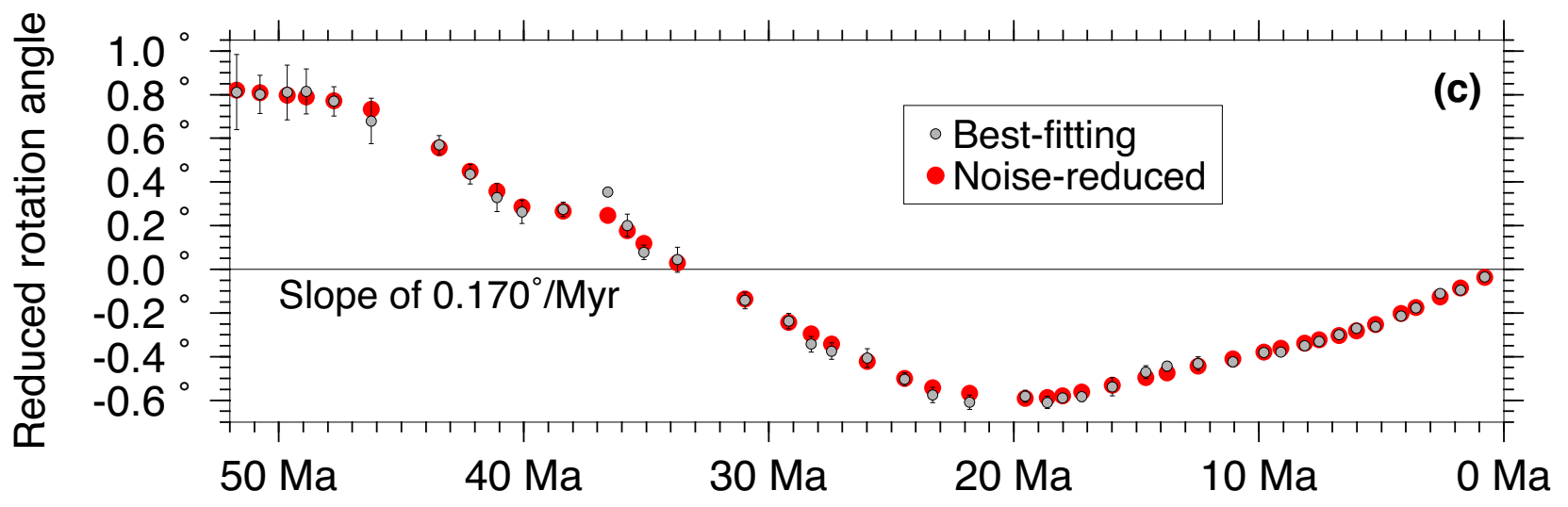

Figure 7. Lwandle-Antarctic best-fitting and noise-reduced finite rotation poles (panels a and b, respectively) and reduced opening angles (C), C1n to C23o. Confidence ellipses are omitted for clarity. (a) Best-fitting poles (Table 5). (b) Noise-reduced poles from REDBACK analysis (Table 6). See Fig. 8 in the supplementary document for the location of the C1n pole and comparative locations to the Nubia-Antarctic and Somalia-Antarctic poles. The labelled poles, which indicate the general direction of the pole path, have ages as follows (Table 1): C1n, 0.773 Ma; C2n, 1.775 Ma; C4A, 9.10 Ma; C13o, 33.73 Ma; C19c, $41.10 \mathrm{Ma}$; C21o, 47.76 Ma and C23o, 51.72 Ma. The opening angles in panel (c) are reduced by a slope of $0.170^{\circ} \mathrm{Myr}^{-1}$ in to emphasize changes in the angular rates. The opening angle error bars show their 95 per cent uncertainties.

$(1.03 \mathrm{~km})$ Plate pairs. The noise-reduced $\mathrm{C} 1 \mathrm{n}$ rotation, which is located 4.5 angular degrees east of the best-fitting C1n pole (Fig. 11), has a modestly larger WRMS misfit of $1.7 \mathrm{~km}$. Despite its poorer fit, two lines of evidence suggest that the noise-reduced pole may give the present slip direction more accurately than the best-fitting pole. First, at the location of the Atlantis II transform fault, where DeMets et al. (2010) estimate a fault azimuth of $\mathrm{N} 00.5^{\circ} \mathrm{E} \pm 0.4^{\circ}$ from a high-quality multibeam survey of this well-defined transform fault (Dick et al. 1991), the noise-reduced and best-fitting C1n poles give respective slip directions of $\mathrm{N} 00.1^{\circ} \mathrm{E}$ and $\mathrm{N} 01.6^{\circ} \mathrm{W}$. The $\mathrm{N} 00.1^{\circ} \mathrm{E}$ noise-reduced azimuth agrees with the $\mathrm{N} 00.5^{\circ} \mathrm{E} \pm 0.4^{\circ}$ observed azimuth within its $1 \sigma$ uncertainty. In contrast, the $\mathrm{N} 01.6^{\circ} \mathrm{W}$ bestfitting azimuth is $2.1^{\circ}$ anticlockwise from the observed azimuth, more than five times larger than its estimated uncertainty. Second, the noise-reduced $\mathrm{C} 1 \mathrm{n}$ pole gives slip directions along the whole Somalia-Antarctic Plate boundary that are $\approx 1.5^{\circ}$ closer to the instantaneous directions estimated with a GPS angular velocity than are the best-fitting directions.

The WRMS flow line misfits to the Somalia-Antarctic fracture zone crossings increase gradually from $0.1 \mathrm{~km}$ for $\mathrm{C} 1 \mathrm{n}$ to nearly $8 \mathrm{~km}$ for $\mathrm{C} 23$ (Fig. S2b), the same on average as for the remainder of the SWIR and better fit than the southern Atlantic basin fracture zones (red lines in Fig. S2b). The WRMS misfits for the noise-reduced rotations are only $0-1.5 \mathrm{~km}$ larger than for the best-fitting rotations between the present and $\mathrm{C} 21(\mathrm{o})$. The fitting penalty associated with the noise-reduced Somalia-Antarctic rotations is thus small for most of the time spanned by our study. For reversals older than $\mathrm{C} 21$, the noise-reduced misfits increase gradually to $\approx 9 \mathrm{~km}$ by $\mathrm{C} 23(\mathrm{o})$, comparable to elsewhere along the SWIR.

Unlike the Nubia-Antarctic and Lwandle-Antarctic segments of the SWIR, several Somalia-Antarctic fracture zones have been surveyed extensively by multibeam systems north of the ridge, including the Novara fracture zone at $58^{\circ} \mathrm{E}$, an unnamed off-ridge fracture zone at $59.5^{\circ} \mathrm{E}$, and the Melville fracture zone at $61^{\circ} \mathrm{E}$ (Fig. S9). The locus of palaeoslip within these three fracture zone valleys is better determined than is the case for most other fracture zones, thereby allowing us to assign correspondingly smaller uncertainties to this subset of the data. The close correspondences between the observed and estimated traces of these three fracture zones north of the ridge (Figs 10, S5, S18 and S19) reflect their heavier weighting in our inversions. 


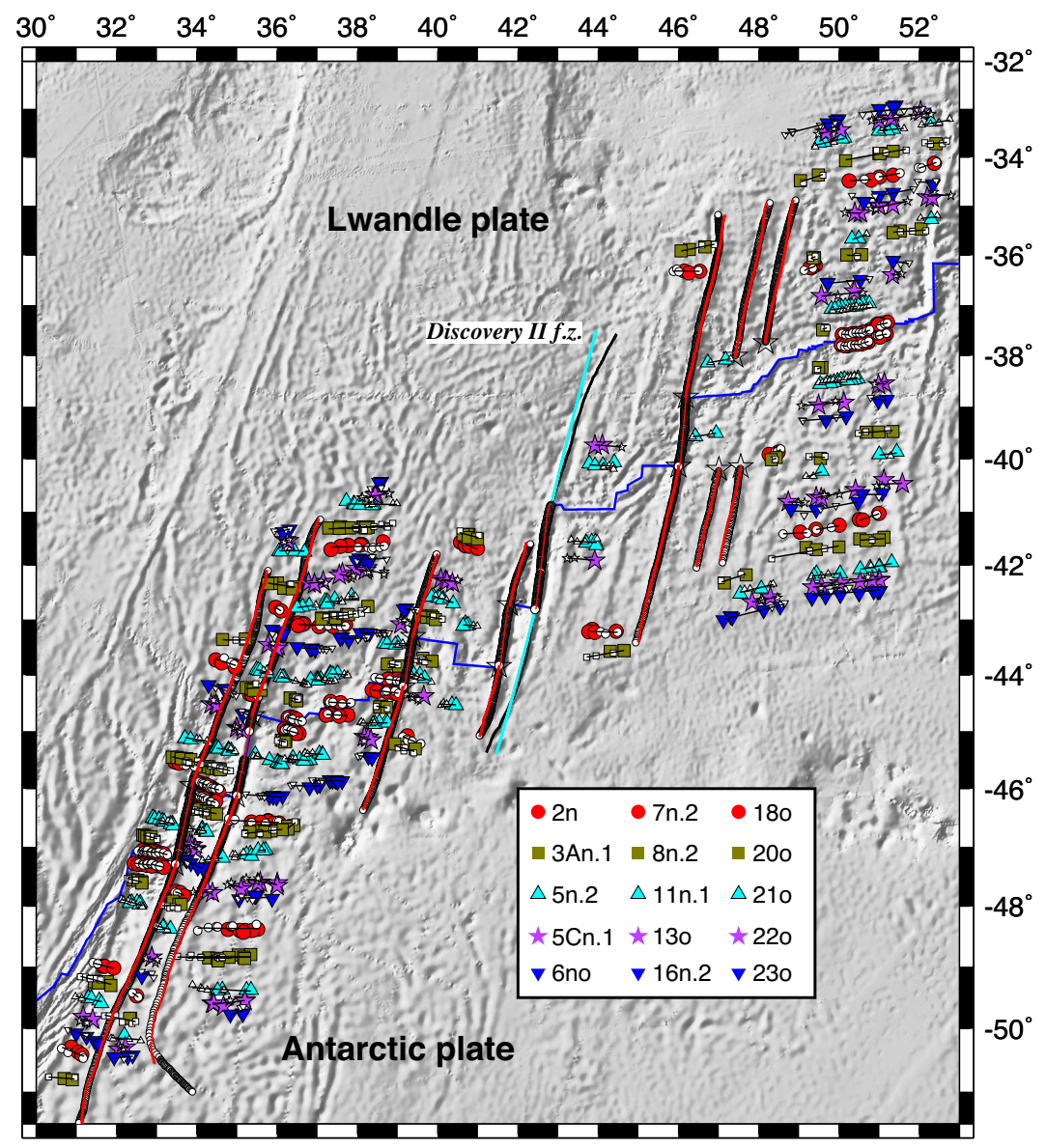

Figure 8. Selected magnetic reversal and fracture zone flow line reconstructions for with the best-fitting Lwandle-Antarctic rotations in Table 5. The circles with black rims and coloured cores show the in-place reversal identifications. The circles with black rims and white cores show the rotated reversal crossing locations. Black lines show the great circles that best fit the reconstructed reversal crossings for each palaeo-spreading segment. The original and reconstructed fracture zone flow lines are shown by the open black and red filled circles, respectively. The open black stars show the flow line seed points. Reconstructions of all 44 reversals for the Lwandle-Antarctic segment of the ridge are shown with the along-track magnetic anomalies in Figs S14-S17. The Discovery II fracture zone (black line) was omitted from the inversion due to the inconsistency of its trace with its estimated flow line (cyan line).

\subsubsection{Spreading history: displacements, rates, directions and GPS}

Somalia-Antarctic opening distances that we reconstructed along a flow line that originates at $58^{\circ} \mathrm{E}$, where numerous well-constrained reversal crossings constrain the rotation sequence, define a smoothly varying opening history with multiple spreading rate changes (Fig. 5) that include the 8-6 Ma slowdown described by DeMets et al. (2015) and other changes observed for the Nubia-Antarctic and Lwandle-Antarctic Plate pairs (Figs 3c and 7c). Not surprisingly, Somalia-Antarctic seafloor spreading rates since $52 \mathrm{Ma}$ have evolved in a manner that is broadly similar to the remainder of the SWIR (Fig. 12). Spreading rates increased from 49 to $43-42 \mathrm{Ma}$, mirroring increases elsewhere along the SWIR during this period. The plate slip direction rotated rapidly anticlockwise from 49 to $43-$ $42 \mathrm{Ma}$, a pattern not observed elsewhere along the SWIR possibly due to the lack of good multibeam survey coverage of older seafloor along the Lwandle-Antarctic and Nubia-Antarctic segments. A 50 per cent spreading rate slowdown that began after $35 \mathrm{Ma}$ and no later than 31 Ma concluded by $18 \pm 1 \mathrm{Ma}$, similar to the timing and magnitude of slowdowns elsewhere along the ridge (Figs 6 and 9).

The newly estimated rates agree well with stage rates we estimated from finite rotations compiled from Cannat et al. (2006), Patriat et al. (2008) and Cande \& Patriat (2015) (red and purple circles in Fig. 12a). By implication, our Somalia-Antarctic magnetic reversal correlations are consistent with those of previous authors.

At a central location along the plate boundary (Fig. 12), the opening rates and directions that are estimated with the SomaliaAntarctic angular velocities for the past $\approx 5 \mathrm{Myr}$ are $2 \pm 0.5 \mathrm{~mm} \mathrm{yr}^{-1}$ faster than and $2-3^{\circ}\left( \pm 3^{\circ}\right)$ anticlockwise from the instantaneous rate and direction that are estimated with an angular velocity that best fits the velocities of GPS sites on the Somalia and Antarctic plates (DeMets et al. 2017). Based on a similar mismatch between their geodetic and long-term plate kinematic estimate of SomaliaAntarctic Plate motion, DeMets et al. (2017) conclude that random or systematic biases in the geodetic estimate are the most likely cause of the difference, possibly including internal deformation of the Antarctic Plate.

\subsection{Consistency of new kinematic estimates and abyssal hill orientations}

Abyssal hills form in response to near-ridge extensional stresses that may be modulated by other factors that include seafloor spreading rate, fracture zone proximity, ridge segmentation and variations in the lithosphere's thermal structure (Cormier \& Sloan 2018). In 


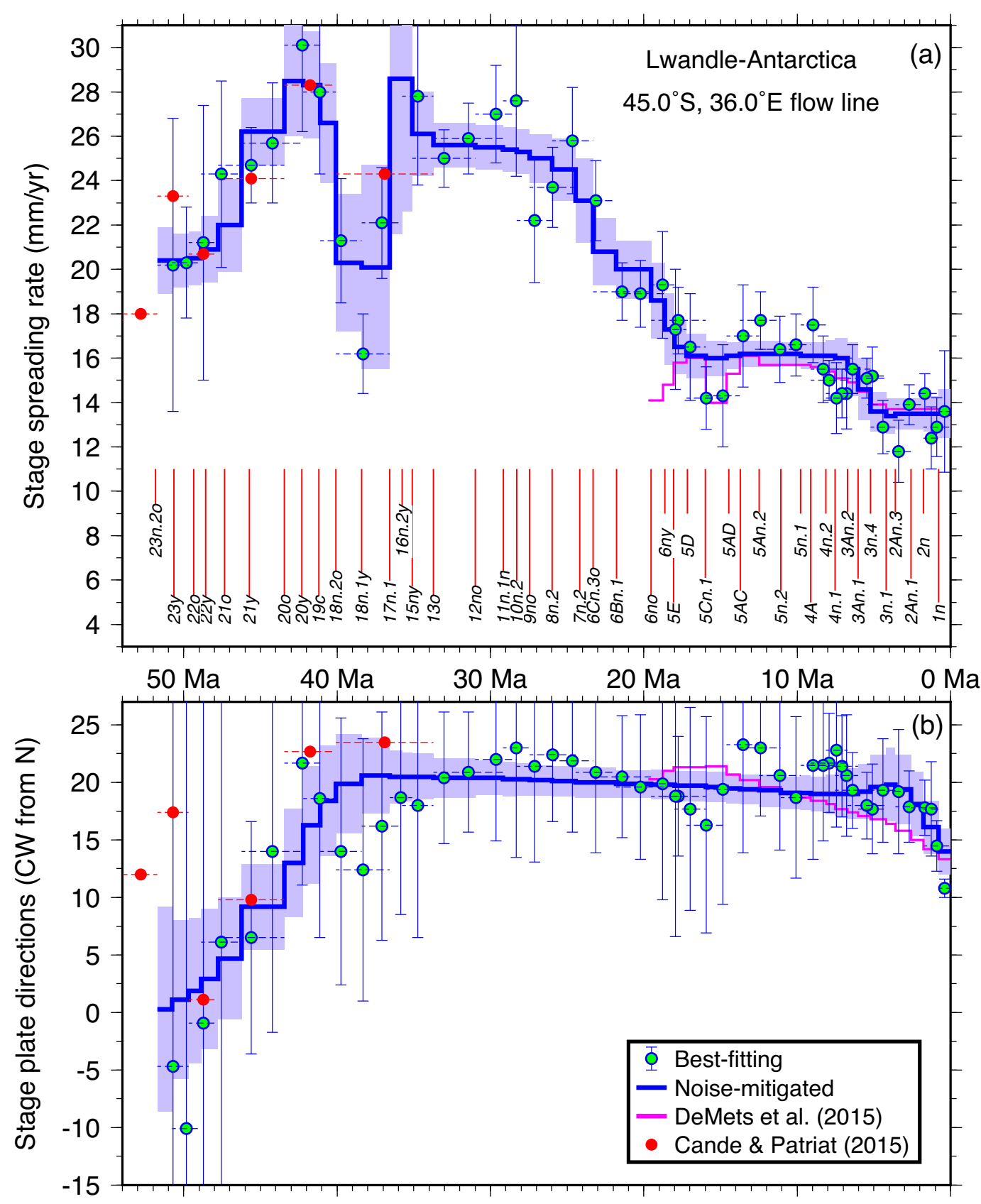

Figure 9. Lwandle-Antarctic stage spreading rates (a) and directions (b) along an Antarctic Plate flow line that originates at the ridge at $45.8^{\circ} \mathrm{S}, 36.0^{\circ} \mathrm{E}$. Blue-green circles show velocities and their $1 \sigma$ uncertainties that were determined with stage rotations and covariances that were derived from the best-fitting finite rotations in Table 5. Blue lines and light blue areas show stage velocities and $1 \sigma$ uncertainties estimated with the noise-reduced stage angular velocities in Table 7. Purple lines show noise-reduced estimates from DeMets et al. (2015). Red circles show stage velocities we determined by combining finite rotations for C13o, C18o, C20o, C21o, C22o and C23o from Cande \& Patriat (2015). Horizontal dashed lines specify the time interval spanned by a given stage rotation.

areas where the stresses that give rise to abyssal hills are determined primarily by the direction of seafloor spreading, abyssal hill orientations may be a useful independent proxy for changes in plate slip directions if the spreading obliquity is small or the obliquity changes more slowly than the plate slip direction. We examine the consistency of SWIR abyssal hill azimuths with the post-52-Ma evolution of SWIR slip directions estimated with our stage angular velocities, with emphasis on the following questions: (1) did the Somalia-Antarctic Plate slip direction rotate clockwise by $\approx 10^{\circ}$ at $20 \mathrm{Ma}$, as postulated by Dick et al. (1991) and Hosford et al.
(2003) from their analyses of seafloor morphology near the Atlantis II fracture zone? (2) Are abyssal hill azimuths consistent with a $\approx 20^{\circ}$ anticlockwise rotation of Somalia-Antarctic slip directions between $38 \mathrm{Ma}$ and the present? (3) Are abyssal hill azimuths consistent with a rapid anticlockwise rotation of slip directions along some or all of the SWIR from 45 to $\approx 40 \mathrm{Ma}$ ?

We determined the azimuths of $\approx 900$ abyssal hills that are imaged by multibeam surveys or transit tracks along eight SomaliaAntarctic spreading segments from $54^{\circ} \mathrm{E}$ to $61^{\circ} \mathrm{E}$ (Figs 13 and Fig. S9), and another $\approx 450$ abyssal hills that are variously imaged by 


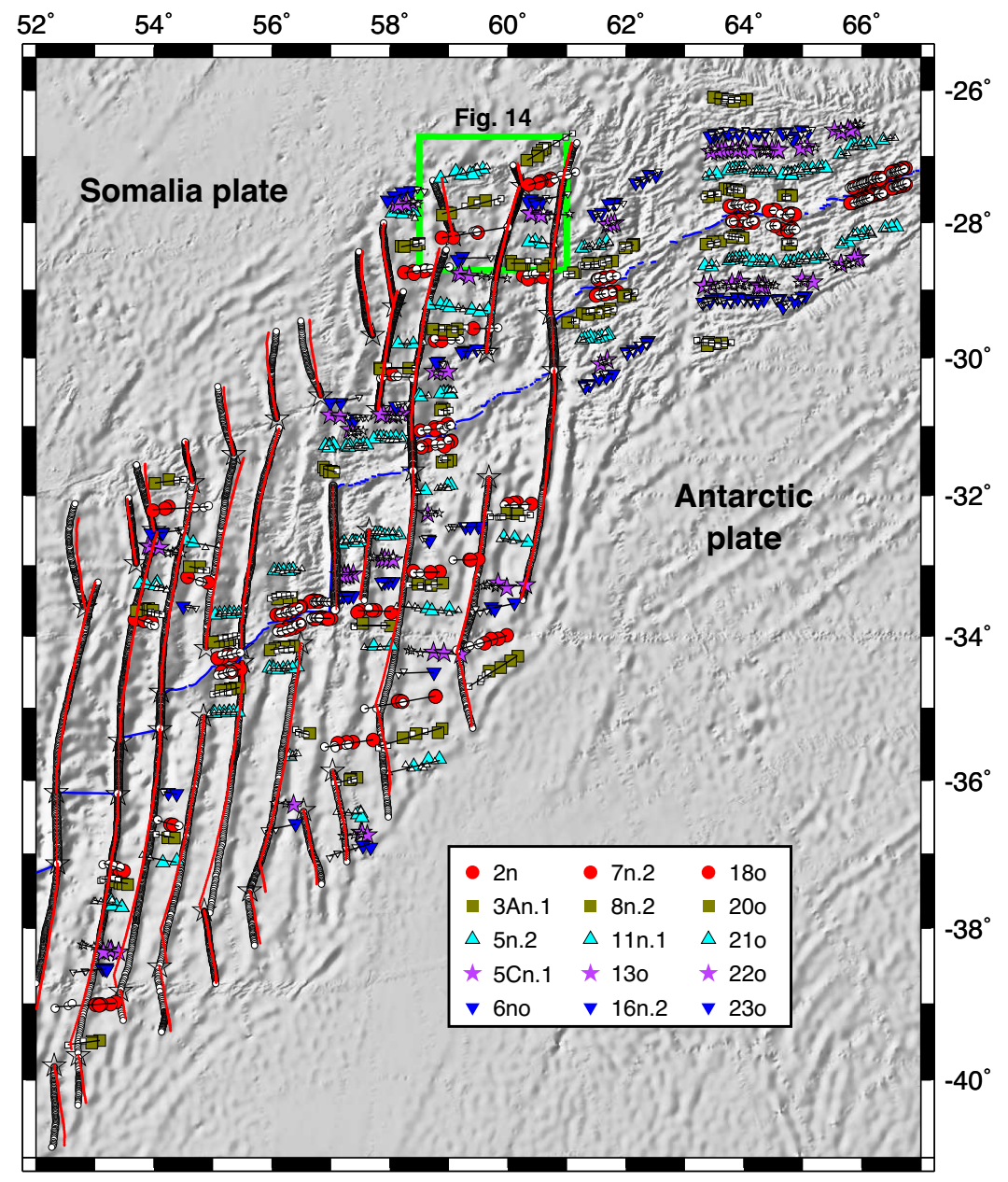

Figure 10. Selected magnetic reversal and fracture zone flow line reconstructions for with the best-fitting Somalia-Antarctic rotations in Table 8. The circles with black rims and coloured cores show the in-place reversal identifications. The circles with black rims and white cores show the rotated reversal crossing locations. Black lines show the great circles that best fit the reconstructed reversal crossings for each palaeo-spreading segment. The original and reconstructed fracture zone flow lines are shown by the open black and red filled circles, respectively. The open black stars show the flow line seed points. Reconstructions of all 44 reversals for the Somalia-Antarctic segment of the ridge are shown with the along-track magnetic anomalies in Figs S18-S21.

multibeam transects north of the ridge at $51^{\circ} \mathrm{E}$ along the LwandleAntarctic segment and at $22-23^{\circ} \mathrm{E}$ along the Nubia-Antarctic segment (Figs S6 and S7). Most of the multibeam data are displayed in Fig. S9; the remainder variously consist of transit tracks from the R/V Gallieni and others that are available through GeoMapApp (Carbotte et al. 2004 and www.marine-geo.org).

We estimated the age of each seafloor lineation by comparing its distance to the present ridge axis to distances estimated with our new rotations and corrected for asymmetric seafloor spreading. We estimated the spreading rate asymmetry along the eastern SWIR by comparing the distances between the ridge axis and C6 (20 Ma) and $\mathrm{C} 18$ (40 Ma) on both sides of the ridge for three well-mapped spreading segments between $57^{\circ} \mathrm{E}$ and $59^{\circ} \mathrm{E}$. For both reversals and all three spreading corridors, 43-45 per cent of the seafloor consistently accreted north of the ridge and the remaining 55-57 per cent south of the ridge. An Africa-versus-Antarctic Plate spreading asymmetry in the ratio of 44-to-56 per cent has thus persisted in this area since at least $40 \mathrm{Ma}$. This robust result agrees well with a 40/60 spreading rate asymmetry that was estimated by Hosford et al. (2003) for the seafloor adjacent to the Atlantis II fracture zone at $58^{\circ} \mathrm{E}$. Using similar methods, we find the same $44 / 56$ spreading asymmetry at $20-23^{\circ} \mathrm{E}$ along the Nubia-Antarctic segment. Given the similarity of the asymmetry on the eastern and western ends of the ridge, we apply the same asymmetry to estimate seafloor ages everywhere along the ridge.

Fig. 13 compares all $\sim 900$ Somalia-Antarctic abyssal hill azimuths to directions that we estimated with the Somalia-Antarctic stage angular velocities (Table 10). During the past $37 \mathrm{Myr}$, abyssal hill orientations have rotated gradually anticlockwise by $\approx 20^{\circ}$ (Fig. 13), close to the $13^{\circ} \pm 3^{\circ}$ anticlockwise change in the plate slip direction estimated with our noise-reduced angular velocities. The sustained anticlockwise changes in the plate slip direction and seafloor fabric are consistent with the estimated $\approx 14^{\circ}$ of southward latitudinal drift of the Somalia-Antarctic stage pole since 37 Ma (Table 10). The abyssal hill azimuths exhibit no evidence for a sudden clockwise rotation at $\sim 20 \mathrm{Ma}$. The $10^{\circ}$ clockwise change in the plate slip direction at 20 Ma postulated by Dick et al. (1991) and Hosford et al. (2003) is thus not supported by our analysis.

The abssyal hill lineations on seafloor older than 38 Ma clearly rotated $25-30^{\circ}$ clockwise between 45 and $38 \mathrm{Ma}$, consistent with the rapid clockwise change estimated with our angular velocities for this period (Fig. 13). A transit multibeam track north of the ridge (Fig. 14) clearly illustrates this clockwise change and suggests that it mostly occurred between C19c (41.2 Ma) and C18y (38.6 Ma). 
Table 8. Somalia-Antarctic best-fitting finite rotations.

\begin{tabular}{|c|c|c|c|c|c|c|c|c|c|c|}
\hline \multirow[t]{2}{*}{ Chron } & \multirow[t]{2}{*}{ DOF } & \multirow{2}{*}{$\begin{array}{l}\text { Lat. } \\
\left({ }^{\circ} \mathrm{N}\right)\end{array}$} & \multirow{2}{*}{$\begin{array}{l}\text { Long. } \\
\left({ }^{\circ} \mathrm{E}\right)\end{array}$} & \multirow{2}{*}{$\begin{array}{l}\Omega \\
\left.{ }^{\circ}\right)\end{array}$} & \multicolumn{6}{|c|}{ Rotation covariances $*$} \\
\hline & & & & & a & $\mathrm{b}$ & $\mathrm{c}$ & d & $\mathrm{e}$ & $\mathrm{f}$ \\
\hline $1 \mathrm{n} *$ & 629 & 5.37 & 315.77 & -0.097 & 8.1 & 14.1 & -10.2 & 26.1 & -18.6 & 13.5 \\
\hline $2 \mathrm{n} *$ & 179 & 2.83 & 320.76 & -0.219 & 16.5 & 30.3 & -20.9 & 58.7 & -40.5 & 29.7 \\
\hline 2An.1 & 202 & 6.46 & 316.16 & -0.305 & 7.8 & -1.0 & -0.4 & 7.2 & 0.4 & 7.3 \\
\hline 2An.3 & 166 & 5.67 & 316.84 & -0.425 & 8.9 & -1.8 & 2.6 & 10.7 & -1.7 & 41.3 \\
\hline $3 n .1$ & 114 & 3.79 & 320.11 & -0.496 & 17.5 & -2.8 & 0.4 & 18.1 & 3.5 & 17.6 \\
\hline $3 \mathrm{n} .4$ & 108 & 2.84 & 320.20 & -0.607 & 29.9 & 3.2 & 9.0 & 22.0 & 5.7 & 69.2 \\
\hline 3An.1 & 104 & 4.14 & 320.62 & -0.711 & 19.4 & -1.2 & 1.2 & 14.9 & 4.1 & 16.6 \\
\hline $3 \mathrm{An} .2$ & 70 & 3.84 & 322.32 & -0.780 & 20.0 & 3.5 & 2.5 & 14.6 & 1.2 & 28.2 \\
\hline $4 n .1$ & 83 & 5.73 & 321.19 & -0.889 & 15.6 & 3.6 & 1.0 & 35.1 & 12.4 & 18.0 \\
\hline $4 \mathrm{n} .2$ & 77 & 5.32 & 321.92 & -0.958 & 19.9 & 3.0 & 1.9 & 17.1 & 1.2 & 15.3 \\
\hline $4 \mathrm{~A}$ & 162 & 6.18 & 320.78 & -1.108 & 10.4 & 1.6 & -2.4 & 13.1 & -4.2 & 10.6 \\
\hline $5 \mathrm{n} .1$ & 157 & 6.38 & 321.00 & -1.193 & 8.2 & 3.2 & 1.0 & 11.4 & -3.5 & 32.3 \\
\hline $5 n .2$ & 231 & 7.59 & 319.94 & -1.382 & 9.2 & 5.7 & -2.0 & 15.4 & -4.5 & 11.8 \\
\hline $5 \mathrm{An} .2$ & 164 & 6.17 & 323.20 & -1.566 & 24.3 & 3.5 & -3.6 & 21.9 & -7.0 & 15.4 \\
\hline $5 \mathrm{AC}$ & 146 & 7.43 & 322.56 & -1.729 & 19.6 & 2.1 & -6.7 & 34.5 & 1.3 & 20.2 \\
\hline $5 \mathrm{AD}$ & 113 & 7.64 & 322.41 & -1.840 & 18.1 & 10.4 & -4.2 & 26.4 & -8.4 & 16.4 \\
\hline $5 \mathrm{Cn} .1$ & 178 & 7.50 & 323.08 & -2.062 & 36.1 & 5.5 & -6.8 & 36.1 & -11.2 & 18.7 \\
\hline $5 \mathrm{D}$ & 118 & 8.57 & 321.76 & -2.212 & 32.0 & 9.6 & -5.4 & 32.5 & -12.3 & 18.5 \\
\hline $5 \mathrm{E}$ & 124 & 9.01 & 321.43 & -2.344 & 26.5 & 7.1 & -7.8 & 32.6 & -13.5 & 18.2 \\
\hline 6ny & 110 & 9.27 & 321.32 & -2.429 & 41.3 & 8.6 & -8.2 & 35.4 & -17.5 & 20.4 \\
\hline 6 no & 171 & 10.19 & 320.39 & -2.605 & 36.6 & 13.9 & -5.8 & 42.3 & -19.2 & 23.7 \\
\hline $6 \mathrm{Bn} .1$ & 233 & 10.31 & 320.90 & -2.912 & 235.1 & -28.5 & -10.0 & 69.4 & -17.8 & 36.1 \\
\hline $6 \mathrm{Cn} .3$ & 239 & 10.29 & 321.39 & -3.203 & 120.8 & 8.6 & -14.0 & 82.3 & -19.1 & 43.0 \\
\hline $7 \mathrm{n} .2$ & 150 & 10.05 & 322.09 & -3.415 & 120.2 & 23.3 & -22.6 & 89.3 & -25.4 & 50.8 \\
\hline $8 n .2$ & 246 & 10.34 & 321.92 & -3.761 & 81.4 & 31.6 & -14.4 & 94.3 & -21.2 & 57.7 \\
\hline 9no & 195 & 10.08 & 322.87 & -4.071 & 79.7 & 47.5 & -27.1 & 115.1 & -30.5 & 63.3 \\
\hline $10 \mathrm{n} .2$ & 112 & 10.40 & 322.79 & -4.254 & 101.0 & 50.1 & -15.1 & 100.4 & -28.1 & 68.0 \\
\hline $11 \mathrm{n} .1$ & 130 & 10.76 & 322.64 & -4.435 & 85.0 & 56.4 & -23.9 & 120.7 & -26.1 & 82.0 \\
\hline 12 no & 263 & 12.66 & 320.55 & -4.907 & 161.5 & 60.8 & -7.3 & 171.1 & -9.7 & 132.6 \\
\hline 130 & 397 & 13.91 & 319.89 & -5.647 & 106.2 & 108.2 & -8.2 & 217.2 & 15.1 & 191.4 \\
\hline 15 ny & 151 & 13.98 & 320.46 & -5.967 & 164.2 & 124.8 & -13.4 & 217.4 & -18.8 & 154.9 \\
\hline $16 n .2$ & 112 & 14.22 & 320.73 & -6.230 & 176.0 & 116.2 & -21.8 & 204.2 & -65.3 & 128.3 \\
\hline $17 \mathrm{n} .1$ & 116 & 14.42 & 321.47 & -6.557 & 249.7 & 94.8 & -40.6 & 223.0 & -81.0 & 120.2 \\
\hline $18 \mathrm{y}$ & 73 & 15.04 & 321.48 & -6.829 & 359.3 & 156.0 & -25.6 & 289.3 & -80.4 & 179.8 \\
\hline 180 & 117 & 14.85 & 320.58 & -7.046 & 137.6 & 166.1 & -25.6 & 260.3 & -86.3 & 190.0 \\
\hline $19 \mathrm{c}$ & 251 & 13.84 & 320.74 & -7.281 & 175.4 & 207.9 & -51.8 & 328.1 & -85.8 & 249.7 \\
\hline $20 y$ & 283 & 12.90 & 320.99 & -7.548 & 188.3 & 213.9 & 5.0 & 328.5 & -77.4 & 250.3 \\
\hline $20 \mathrm{o}$ & 324 & 11.78 & 321.36 & -7.859 & 167.7 & 217.4 & -24.9 & 361.7 & -134.8 & 259.1 \\
\hline $21 y$ & 452 & 10.57 & 320.74 & -8.486 & 193.7 & 255.4 & 33.8 & 411.9 & -98.9 & 442.5 \\
\hline 210 & 166 & 10.43 & 320.72 & -8.765 & 204.3 & 281.7 & -46.3 & 501.5 & -102.8 & 398.6 \\
\hline $22 y$ & 112 & 10.02 & 320.73 & -9.069 & 308.7 & 373.9 & -51.0 & 673.7 & -56.7 & 779.5 \\
\hline 220 & 51 & 10.15 & 320.76 & -9.245 & 696.3 & 640.1 & 280.8 & 1118.9 & -75.1 & 1226.6 \\
\hline $23 y$ & 48 & 10.02 & 321.03 & -9.477 & 929.6 & 641.8 & 370.0 & 1237.9 & 66.5 & 1862.0 \\
\hline 230 & 24 & 10.04 & 321.62 & -9.653 & 2021.3 & 841.9 & 1624.4 & 1122.9 & -235.6 & 3754.2 \\
\hline
\end{tabular}

Notes: These finite rotations reconstruct movement of the Somalia Plate relative to the Antarctic Plate and include corrections for $2 \mathrm{~km}$ of outward displacement described in the text. The rotation angles $\Omega$ are positive CCW. Each rotation is the mean of 1000 bootstrap solutions (see text). $*$ Rotations that are marked with an asterisk have covariances that were determined from the geometric distribution of the observations using the method of Chang [1988]. All other covariances are determined from the bootstrapping procedure described in the text. DOF, the degrees of freedom, equals the total number of anomaly, transform fault, and fracture zone flow-line crossings used to estimate the rotation for a given time reduced by the number of estimated parameters. The weighted RMS misfits for these rotations are given in Table 1. The Cartesian rotation covariances are calculated in a Somalia-fixed reference frame and have units of $10^{-9}$ radians $^{2}$. See Table 2 footnotes for further information about the rotation covariances.

During the same period, Somalia-Antarctic spreading rates slowed by $\approx 50$ per cent and then recovered (Fig. 12a). The evidence for a significant change in Somalia-Antarctic Plate motion at $\approx 40 \mathrm{Ma}$ is thus compelling.

Only one multibeam transect of seafloor created along the Lwandle-Antarctic Plate boundary is available, a transect that samples seafloor of ages 10-52 Ma north of the ridge. The azimuths of $\approx 90$ lineations along this transect rotate clockwise by $10-15^{\circ}$ between 40 and $38 \mathrm{Ma}$ (Fig. S6), similar to the pattern for the abyssal hills farther east. During the same period, $\mathrm{a} \approx 10^{\circ}$ clockwise change in the relative slip direction is indicated by our LwandleAntarctic angular velocities (red line in Fig. S6). Our newly determined Lwandle-Antarctic rotations and the seafloor fabric lineations thus independently signal a significant change in LwandleAntarctic Plate motion at 40-38 Ma, when Somalia-Antarctic Plate motion also changed (Fig. 13).

Abyssal hills we identified along two transit multibeam tracks of the Nubia-Antarctic segment of the SWIR at $22-23^{\circ} \mathrm{E}$ do not show 
Table 9. Somalia-Antarctic noise-reduced finite rotations.

\begin{tabular}{|c|c|c|c|c|c|c|c|c|c|}
\hline \multirow[t]{2}{*}{ Chron } & \multirow{2}{*}{$\begin{array}{l}\text { Lat. } \\
\left({ }^{\circ} \mathrm{N}\right)\end{array}$} & \multirow{2}{*}{$\begin{array}{l}\text { Long. } \\
\left({ }^{\circ} \mathrm{E}\right)\end{array}$} & \multirow{2}{*}{$\begin{array}{l}\Omega \\
\left({ }^{\circ}\right)\end{array}$} & \multicolumn{6}{|c|}{ Covariances* } \\
\hline & & & & $\mathrm{a}$ & $\mathrm{b}$ & $\mathrm{c}$ & d & $\mathrm{e}$ & $\mathrm{f}$ \\
\hline 1n & 4.52 & 320.26 & -0.091 & 307.5 & -252.7 & 327.5 & 210.4 & -274.3 & 358.5 \\
\hline $2 n$ & 4.65 & 320.43 & -0.210 & 334.0 & -266.6 & 341.1 & 221.9 & -289.1 & 379.6 \\
\hline $2 \mathrm{An} .1$ & 4.79 & 320.55 & -0.307 & 349.5 & -271.3 & 342.9 & 226.1 & -294.8 & 389.1 \\
\hline $2 \mathrm{An} .3$ & 4.97 & 320.70 & -0.426 & 360.0 & -270.0 & 335.9 & 225.6 & -294.3 & 391.2 \\
\hline $3 n .1$ & 5.09 & 320.80 & -0.496 & 361.6 & -266.1 & 328.3 & 222.7 & -290.7 & 387.7 \\
\hline $3 n .4$ & 5.31 & 320.94 & -0.620 & 357.7 & -254.9 & 309.7 & 214.1 & -279.7 & 375.5 \\
\hline $3 A n .1$ & 5.49 & 321.04 & -0.714 & 349.6 & -243.4 & 292.4 & 205.1 & -268.2 & 361.8 \\
\hline 3 An. 2 & 5.65 & 321.11 & -0.797 & 340.7 & -232.0 & 275.6 & 196.1 & -256.8 & 348.2 \\
\hline $4 n .1$ & 5.85 & 321.17 & -0.897 & 338.7 & -225.2 & 264.4 & 191.0 & -250.4 & 341.3 \\
\hline $4 n .2$ & 6.00 & 321.22 & -0.975 & 351.1 & -231.0 & 269.6 & 196.0 & -257.0 & 350.9 \\
\hline $4 \mathrm{~A}$ & 6.25 & 321.28 & -1.110 & 373.7 & -242.2 & 280.4 & 206.0 & -270.3 & 370.3 \\
\hline $5 n .1$ & 6.43 & 321.31 & -1.204 & 386.8 & -247.2 & 284.1 & 210.9 & -277.0 & 380.8 \\
\hline $5 n .2$ & 6.76 & 321.38 & -1.379 & 405.4 & -249.8 & 281.1 & 215.1 & -283.4 & 393.6 \\
\hline $5 \mathrm{An} .2$ & 7.12 & 321.45 & -1.574 & 418.0 & -244.9 & 267.5 & 214.0 & -283.4 & 398.9 \\
\hline $5 \mathrm{AC}$ & 7.46 & 321.48 & -1.747 & 425.5 & -234.6 & 246.1 & 209.1 & -278.8 & 399.3 \\
\hline $5 \mathrm{AD}$ & 7.69 & 321.50 & -1.866 & 426.8 & -224.9 & 228.4 & 203.7 & -273.0 & 396.0 \\
\hline $5 \mathrm{Cn} .1$ & 8.05 & 321.51 & -2.053 & 422.7 & -206.5 & 197.3 & 192.4 & -260.2 & 385.5 \\
\hline $5 \mathrm{D}$ & 8.40 & 321.51 & -2.232 & 415.7 & -189.9 & 170.3 & 181.8 & -248.0 & 374.7 \\
\hline $5 \mathrm{E}$ & 8.61 & 321.51 & -2.352 & 421.8 & -184.5 & 158.3 & 179.9 & -246.8 & 377.4 \\
\hline 6 ny & 8.78 & 321.50 & -2.452 & 435.8 & -182.7 & 149.4 & 181.3 & -250.0 & 386.7 \\
\hline 6 no & 9.02 & 321.49 & -2.599 & 466.1 & -180.9 & 133.9 & 185.6 & -258.4 & 408.0 \\
\hline $6 \mathrm{Bn} .1$ & 9.60 & 321.51 & -2.969 & 571.9 & -199.7 & 125.3 & 215.8 & -304.6 & 493.6 \\
\hline $6 \mathrm{Cn} .3$ & 9.97 & 321.53 & -3.226 & 646.1 & -218.5 & 130.2 & 240.1 & -340.2 & 554.2 \\
\hline $7 \mathrm{n} .2$ & 10.24 & 321.54 & -3.444 & 716.7 & -224.2 & 113.0 & 255.9 & -365.8 & 605.9 \\
\hline $8 \mathrm{n} .2$ & 10.60 & 321.55 & -3.768 & 802.9 & -188.5 & 16.6 & 252.2 & -373.1 & 656.2 \\
\hline 9 no & 10.96 & 321.55 & -4.083 & 916.0 & -156.1 & -84.6 & 254.6 & -389.8 & 725.0 \\
\hline $10 \mathrm{n} .2$ & 11.19 & 321.53 & -4.268 & 990.4 & -158.7 & -109.4 & 270.0 & -416.1 & 781.5 \\
\hline $11 \mathrm{n} .1$ & 11.44 & 321.48 & -4.470 & 1048.2 & -185.8 & -85.7 & 296.5 & -452.8 & 838.3 \\
\hline $12 \mathrm{no}$ & 12.04 & 321.29 & -4.912 & 1219.1 & -224.7 & -97.5 & 340.6 & -518.1 & 969.2 \\
\hline 130 & 12.89 & 321.09 & -5.646 & 1549.9 & -174.8 & -333.2 & 362.1 & -579.4 & 1184.2 \\
\hline 15 ny & 13.26 & 321.03 & -6.019 & 1694.3 & -174.0 & -392.4 & 388.5 & -627.0 & 1292.9 \\
\hline $16 \mathrm{n} .2$ & 13.43 & 321.01 & -6.211 & 1836.2 & -191.4 & -420.4 & 422.5 & -681.0 & 1401.9 \\
\hline $17 n .1$ & 13.61 & 320.99 & -6.441 & 2414.9 & -503.1 & -100.9 & 701.9 & -1054.7 & 1942.9 \\
\hline $18 \mathrm{y}$ & 13.85 & 320.97 & -6.796 & 2365.0 & -224.4 & -582.2 & 530.1 & -861.2 & 1794.8 \\
\hline 180 & 13.60 & 320.92 & -7.077 & 2106.8 & -142.9 & -622.5 & 446.2 & -744.2 & 1601.6 \\
\hline $19 \mathrm{c}$ & 13.15 & 320.85 & -7.302 & 1876.3 & -167.0 & -487.1 & 418.6 & -685.5 & 1442.6 \\
\hline $20 y$ & 12.61 & 320.75 & -7.547 & 1789.9 & -152.3 & -483.3 & 389.6 & -640.4 & 1364.2 \\
\hline 200 & 11.99 & 320.65 & -7.829 & 2024.9 & -80.7 & -723.7 & 373.5 & -643.7 & 1480.8 \\
\hline $21 y$ & 10.90 & 320.60 & -8.457 & 2044.8 & 15.4 & -910.1 & 317.2 & -583.4 & 1453.9 \\
\hline 210 & 10.51 & 320.73 & -8.802 & 1401.2 & -43.5 & -514.5 & 261.2 & -454.2 & 1039.6 \\
\hline $22 y$ & 10.29 & 320.87 & -9.058 & 983.3 & -94.7 & -239.6 & 225.3 & -366.4 & 760.1 \\
\hline 220 & 10.15 & 321.01 & -9.236 & 721.5 & -129.9 & -64.0 & 202.6 & -310.1 & 583.2 \\
\hline $23 y$ & 9.99 & 321.22 & -9.463 & 494.4 & -110.5 & -2.7 & 150.9 & -224.9 & 402.9 \\
\hline 230 & 9.86 & 321.42 & -9.645 & 680.5 & -70.7 & -144.8 & 162.7 & -261.0 & 521.5 \\
\hline
\end{tabular}

Notes: These rotations were determined from the best-fitting Somalia-Antarctica finite rotations and covariances in Table 8 using Bayesian noise reduction as implemented in REDBACK software (Iaffaldano et al. 2014). The finite rotations reconstruct the movement of the Somalia Plate onto the Antarctic Plate and include corrections for $2 \mathrm{~km}$ of outward displacement described in the text. The rotation angles $\Omega$ are positive anticlockwise. The Cartesian rotation covariances are calculated in a Somalia-fixed reference frame and have units of $10^{-9}$ radians $^{2}$.

any evidence for an obvious clockwise change at the time of $\mathrm{C} 18$ (Fig. S7). In contrast, our Nubia-Antarctic noise-reduced and bestfitting stage angular velocities indicate that the plate slip direction changed clockwise before $\approx 35 \mathrm{Ma}$ (Fig. 6b). The evidence for a significant change in Nubia-Antarctic motion at the time of Chron 18 is thus equivocal.

\subsection{Timing of motion changes from Bayesian and plate kinematic results: significance and artefacts}

The new best-fitting and noise-reduced rotations for the NubiaAntarctic, Lwandle-Antarctic and Somalia-Antarctic Plate pairs clearly show that relative plate motions across the SWIR have 
Table 10. Somalia-Antarctic stage angular velocities from REDBACK.

\begin{tabular}{|c|c|c|c|c|c|c|c|c|c|}
\hline \multirow{2}{*}{$\begin{array}{l}\text { Interval } \\
\text { (Ma) }\end{array}$} & \multirow{2}{*}{$\begin{array}{l}\text { Lat. } \\
\left({ }^{\circ} \mathrm{N}\right)\end{array}$} & \multirow{2}{*}{$\begin{array}{l}\text { Long. } \\
\left({ }^{\circ} \mathrm{E}\right)\end{array}$} & \multirow{2}{*}{$\begin{array}{c}\dot{\omega} \\
\left({ }^{\circ} \mathrm{Myr}^{-1}\right)\end{array}$} & \multicolumn{6}{|c|}{ Covariances } \\
\hline & & & & $\mathrm{a}$ & $\mathrm{b}$ & $\mathrm{c}$ & $\mathrm{d}$ & e & $\mathrm{f}$ \\
\hline $0.000-0.773$ & 4.52 & 320.26 & -0.119 & 20.77 & -16.97 & 2.04 & 14.53 & -1.80 & 0.39 \\
\hline $0.773-1.775$ & 4.75 & 320.56 & -0.119 & 7.03 & -5.59 & 0.68 & 4.90 & -0.63 & 0.20 \\
\hline $1.775-2.595$ & 5.08 & 320.81 & -0.119 & 4.83 & -3.79 & 0.48 & 3.35 & -0.44 & 0.18 \\
\hline $2.595-3.596$ & 5.46 & 321.11 & -0.119 & 4.00 & -3.10 & 0.40 & 2.75 & -0.37 & 0.18 \\
\hline $3.596-4.187$ & 5.79 & 321.38 & -0.118 & 4.32 & -3.23 & 0.39 & 2.99 & -0.44 & 0.27 \\
\hline $4.187-5.235$ & 6.19 & 321.53 & -0.118 & 4.44 & -3.42 & 0.45 & 3.01 & -0.45 & 0.22 \\
\hline $5.235-6.023$ & 6.66 & 321.66 & -0.118 & 6.15 & -4.75 & 0.65 & 4.12 & -0.64 & 0.28 \\
\hline $6.023-6.727$ & 7.08 & 321.71 & -0.119 & 9.97 & -7.87 & 1.18 & 6.57 & -1.02 & 0.28 \\
\hline $6.727-7.537$ & 7.44 & 321.72 & -0.123 & 16.63 & -13.25 & 2.10 & 10.86 & -1.73 & 0.39 \\
\hline $7.537-8.125$ & 7.67 & 321.71 & -0.133 & 18.15 & -14.45 & 2.38 & 11.82 & -1.95 & 0.46 \\
\hline $8.125-9.105$ & 8.06 & 321.74 & -0.138 & 7.09 & -5.52 & 0.93 & 4.63 & -0.79 & 0.30 \\
\hline $9.105-9.786$ & 8.53 & 321.77 & -0.138 & 4.44 & -3.28 & 0.51 & 2.94 & -0.55 & 0.42 \\
\hline $9.786-11.056$ & 9.04 & 321.84 & -0.138 & 2.92 & -2.04 & 0.30 & 1.96 & -0.39 & 0.41 \\
\hline $11.056-12.474$ & 9.68 & 321.98 & -0.137 & 2.52 & -1.58 & 0.20 & 1.75 & -0.40 & 0.42 \\
\hline $12.474-13.739$ & 10.48 & 321.87 & -0.137 & 2.61 & -1.87 & 0.37 & 1.75 & -0.32 & 0.26 \\
\hline $13.739-14.609$ & 11.06 & 321.80 & -0.137 & 3.37 & -2.49 & 0.51 & 2.23 & -0.43 & 0.31 \\
\hline $14.609-15.974$ & 11.68 & 321.72 & -0.137 & 4.22 & -3.16 & 0.67 & 2.75 & -0.57 & 0.40 \\
\hline $15.974-17.235$ & 12.34 & 321.57 & -0.142 & 8.15 & -6.16 & 1.34 & 5.28 & -1.23 & 0.70 \\
\hline $17.235-18.007$ & 12.57 & 321.49 & -0.155 & 13.33 & -10.06 & 2.24 & 8.60 & -2.12 & 1.12 \\
\hline $18.007-18.636$ & 12.79 & 321.46 & -0.161 & 10.69 & -7.76 & 1.64 & 6.97 & -1.81 & 1.22 \\
\hline $18.636-19.535$ & 13.07 & 321.48 & -0.163 & 7.78 & -5.40 & 1.14 & 5.18 & -1.35 & 1.10 \\
\hline $19.535-21.806$ & 13.65 & 321.70 & -0.164 & 4.88 & -3.48 & 0.85 & 3.24 & -0.78 & 0.82 \\
\hline $21.806-23.318$ & 14.19 & 321.89 & -0.170 & 9.08 & -6.45 & 1.53 & 5.93 & -1.68 & 1.54 \\
\hline $23.318-24.459$ & 14.20 & 321.90 & -0.192 & 16.38 & -11.88 & 2.94 & 10.62 & -3.16 & 2.62 \\
\hline $24.459-25.987$ & 14.46 & 321.81 & -0.212 & 9.38 & -6.37 & 1.39 & 6.24 & -1.83 & 2.50 \\
\hline $25.987-27.439$ & 15.27 & 321.62 & -0.218 & 8.19 & -5.32 & 1.10 & 5.51 & -1.63 & 2.77 \\
\hline $27.439-28.278$ & 16.11 & 321.27 & -0.220 & 10.79 & -6.98 & 1.52 & 7.31 & -2.32 & 3.55 \\
\hline $28.278-29.183$ & 16.91 & 320.74 & -0.225 & 14.28 & -8.25 & 1.37 & 9.75 & -3.50 & 5.33 \\
\hline $29.183-30.977$ & 18.14 & 319.59 & -0.248 & 18.81 & -3.16 & -4.11 & 13.34 & -7.05 & 12.98 \\
\hline $30.977-33.726$ & 18.58 & 319.98 & -0.269 & 10.60 & -3.24 & -1.34 & 7.44 & -3.08 & 8.26 \\
\hline $33.726-35.102$ & 18.88 & 320.48 & -0.273 & 16.92 & -7.96 & 1.15 & 12.18 & -3.56 & 9.39 \\
\hline $35.102-35.774$ & 18.66 & 320.64 & -0.287 & 54.49 & -38.02 & 12.27 & 36.99 & -12.40 & 15.11 \\
\hline $35.774-36.573$ & 18.48 & 320.73 & -0.290 & 95.78 & -71.08 & 25.45 & 63.95 & -22.38 & 22.15 \\
\hline $36.573-38.398$ & 18.37 & 320.83 & -0.195 & 45.88 & -33.01 & 9.86 & 32.34 & -8.26 & 21.38 \\
\hline $38.398-40.073$ & 7.42 & 319.43 & -0.169 & 48.07 & -34.17 & 10.11 & 35.31 & -4.35 & 31.51 \\
\hline $40.073-41.105$ & -0.26 & 317.81 & -0.224 & 19.35 & -5.03 & 5.02 & 22.66 & 9.21 & 32.18 \\
\hline $41.105-42.196$ & -3.02 & 317.07 & -0.234 & 13.80 & 3.50 & 5.74 & 24.08 & 19.24 & 45.53 \\
\hline $42.196-43.450$ & -3.96 & 316.91 & -0.235 & 11.29 & 5.27 & 6.16 & 21.52 & 19.66 & 45.10 \\
\hline $43.450-46.235$ & -2.27 & 319.03 & -0.232 & 6.19 & 1.86 & 2.44 & 9.81 & 7.18 & 18.67 \\
\hline $46.235-47.760$ & 0.88 & 323.05 & -0.230 & 10.26 & 1.45 & 4.11 & 13.81 & 7.17 & 17.43 \\
\hline $47.760-48.878$ & 2.19 & 325.20 & -0.233 & 16.94 & -3.59 & 5.62 & 18.45 & 5.64 & 16.82 \\
\hline $48.878-49.666$ & 2.90 & 327.03 & -0.228 & 16.20 & -1.14 & 5.56 & 18.64 & 6.65 & 18.02 \\
\hline $49.666-50.767$ & 2.70 & 328.99 & -0.210 & 27.23 & -7.50 & 8.22 & 27.85 & 6.28 & 21.16 \\
\hline $50.767-51.724$ & 2.46 & 331.01 & -0.194 & 62.78 & -25.50 & 18.04 & 57.03 & 6.72 & 31.88 \\
\hline
\end{tabular}

Notes: These angular velocities specify Somalia Plate motion relative to the Antarctic Plate during the time period given in the first column, as determined from the REDBACK noise-reduction software (Iaffaldano et al. 2014). The angular rotation rates $\dot{\omega}$ are positive anticlockwise. The Cartesian angular velocity covariances are calculated in a Somalia-fixed reference frame and have units of $10^{-8}$ radians ${ }^{2} \mathrm{Myr}^{-2}$.

changed multiple times since $52 \mathrm{Ma}$. Figs 15 (a) and 16(a) summarize the ages of the likeliest changes in the motions of all three plate pairs, whereby the likelihood of change determined by REDBACK is based on the frequency with which a particular change model satisfies the REDBACK acceptance criteria during the exploration of numerous (millions) of candidate models. The most frequently accepted change-model is normalized to a likelihood of 1.0 (Iaffaldano et al. 2014).

The ages of the likeliest changes in the Lwandle-Antarctic and Somalia-Antarctic angular rates are nearly the same (green and blue curves in Fig. 15a), with possible changes at 49, 41, 37, 24, 19-18 and 8-6 Ma. The similarity of these two independent estimates not only suggests that our Lwandle-Antarctic and Somalia-Antarctic rotation sequences are robust, but also implies that the Lwandle and Somalia Plate motions are strongly coupled. In addition to the numerous simultaneous changes in the angular rates, the stage poles for both plate pairs changed at $42-40 \mathrm{Ma}$ (Fig. 16a), when the slow northward drifts of the poles for both plate pairs reversed direction (Figs $7 \mathrm{~b}$ and $11 \mathrm{~b}$ ).

The changes in Somalia-Antarctic and Lwandle-Antarctic angular rates at 49 and 38-37 Ma both coincide with spreading rate accelerations (Fig. 15b). The changes at 41, 24 and 8-6 Ma mark spreading rate slowdowns. The high-probability change at 19-18 Ma marks the transition from the preceding period of gradually 

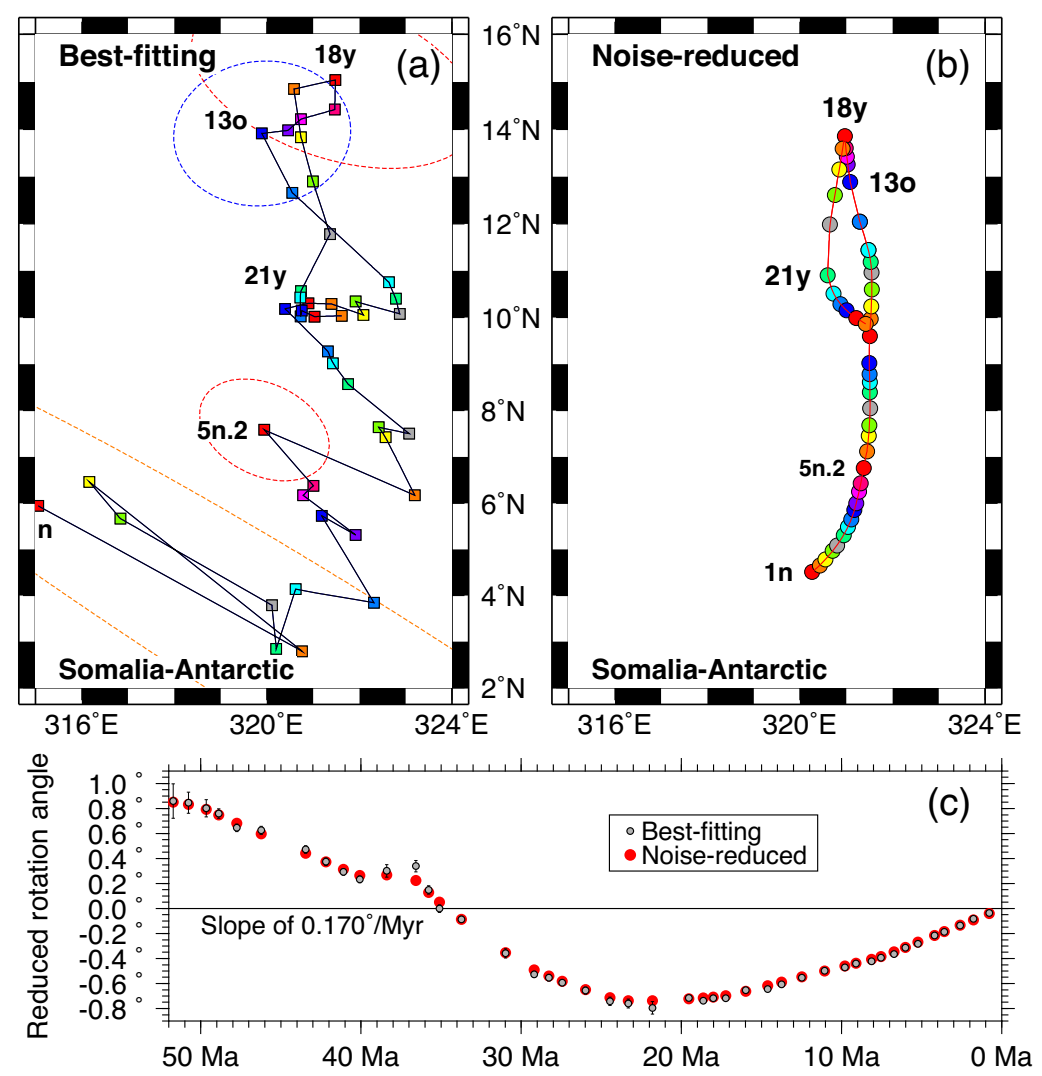

Figure 11. Somalia-Antarctic best-fitting and noise-reduced finite rotation poles (panels a and b, respectively) and reduced opening angles (C), C1n to C23o. (a) Best-fitting poles (Table 8). For clarity, only selected confidence ellipses are shown (i.e. C2n, C5n.2, C13o, C18y). (b) Noise-reduced poles from REDBACK analysis (Table 9). The labelled poles, which indicate the general direction of the pole path, have ages as follows (Table 1): C1n, $0.78 \mathrm{Ma}$; C2n, 1.78 Ma; C4A, 9.10 Ma; C13o, 33.70 Ma; C19c, $41.27 \mathrm{Ma}$; C21o, $47.35 \mathrm{Ma}$ and C23o, $51.83 \mathrm{Ma}$. The opening angles in panel (c) are reduced by a slope of $0.170^{\circ} \mathrm{Myr}^{-1}$ in order to emphasize changes in the angular rates. The opening angle error bars show their 95 per cent uncertainties.

declining spreading rates to steady opening rates from 18 to $8-6$ Ma (Fig. 15b).

The identically timed change events at 40.5 and 37.5 Ma for the Lwandle-Antarctic and Somalia-Antarctic rotation sequences mark the 42-40 Ma spreading rate slowdowns for both plate pairs and their subsequent rapid recoveries (Fig. 15b). To our knowledge, this 6-Myr-long spreading rate decline and recovery was previously unknown. Stage spreading rates we estimated from Cande \& $\mathrm{Pa}-$ triat's (2015) finite rotations hint at its existence (red circles in Figs $9 \mathrm{a}$ and $12 \mathrm{a}$ ), but their temporal resolution is too coarse to define the event.

Our REDBACK analysis of the Nubia-Antarctic rotation sequence identifies a high probability change in the angular rotation rate at $44 \mathrm{Ma}$ (red lines in Fig. 15a), $\approx 2$ Myr earlier than the 42-40 Ma spreading rate speed-ups for the other two plate pairs (Fig. 15b). Several lower likelihood discrete changes that are indicated between 35 and 20 Ma collectively approximate the continuous slowdown in Nubia-Antarctic spreading rates that began after $31 \mathrm{Ma}$. An apparent change in the Nubia-Antarctic pole location at 19 Ma (Fig. 16 A) is associated with an erratic, small change in the plate slip direction (Fig. 16b). We interpret this apparent change as an artefact of problems with our identifications of C5D, C5E and C6 along some or all of the Nubia-Antarctic Plate boundary.

REDBACK's identification of two or more change events between 33 and $18 \mathrm{Ma}$ for all three plate pairs (Fig. 15a) illustrates a limitation of the REDBACK software, namely its approximation of all plate motion changes as discrete. Although the 31-18 Ma spreading rate decline everywhere along the SWIR may have consisted of several discrete (short-duration) slowdowns, the principle of parsimony instead suggests it was continuous, similar to the continuous decline of Nubia-South America spreading rates in the southern Atlantic basin since $22 \mathrm{Ma}$ (see fig. 13 in DeMets \& Merkouriev 2019).

The best-fitting spreading rate histories for all three plate pairs (Figs 6, 9 and 12) feature implausibly fast stage rates for the 1.47Myr-long interval between C15y and C17n.1 (typically 37-45 mm $\mathrm{yr}^{-1}$ ), but implausibly slow rates for the 3.50-Myr-long interval between $\mathrm{C} 17 \mathrm{n} .1$ and $\mathrm{C} 18 \mathrm{n} .2\left(14-18 \mathrm{~mm} \mathrm{yr}^{-1}\right)$. We interpret this as a likely artefact of an apparent error in the GTS20 age for the young edge of C17n.1 (36.57 Ma). An increase of $200000 \mathrm{yr}$ or more in the GTS20 C17n.1 age estimate would be needed to rectify these anomalous interval rates with the stage rates for other nearby times.

Although other features of the three stage spreading histories are likely to be artefacts of errors in the GTS20 reversal timescale, we found that alternative spreading rate histories that we estimated with the GTS12 timescale (Ogg 2012) or more recent MQSD20 timescale (Malinverno et al. 2020) were not sufficiently different to alter any of our interpretations. The primary features in the stage spreading histories, including the rapid rate slowdown and recovery from 42-37 Ma (Fig. 15b), thus appear to be robust with respect to the timescales we investigated. 

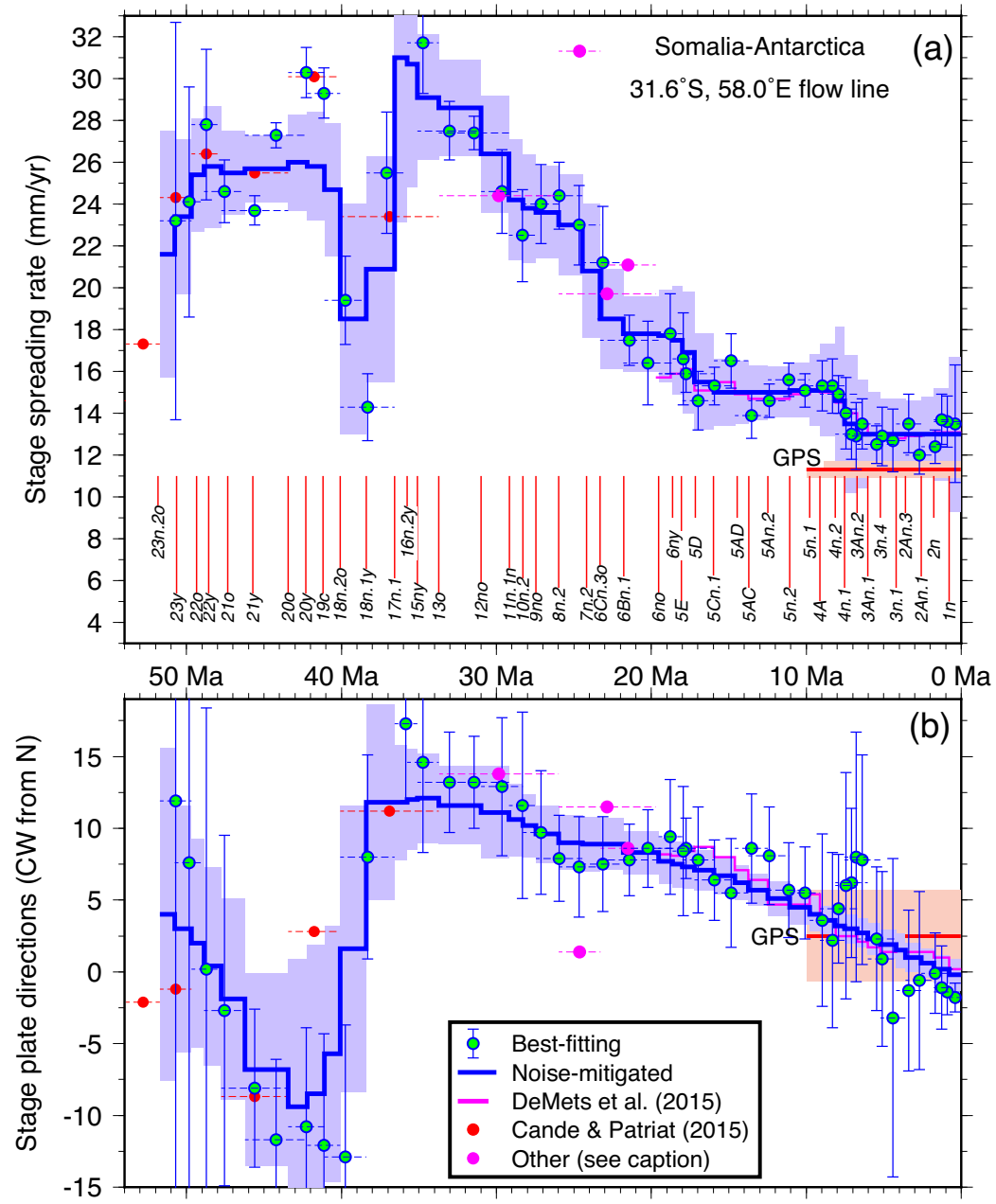

Figure 12. Somalia-Antarctic stage spreading rates (a) and directions (b) along an Antarctic Plate flow line that originates at the ridge at $31.6^{\circ} \mathrm{S}, 58.0^{\circ} \mathrm{E}$. Blue-green circles show velocities and their $1 \sigma$ uncertainties that were estimated with stage rotations and covariances that were derived from the best-fitting finite rotations in Table 8. Blue lines and light blue areas show stage velocities and $1 \sigma$ uncertainties estimated with noise-reduced stage angular velocities in Table 10. Purple lines show noise-reduced estimates from DeMets et al. (2015). Red circles show stage velocities derived from Cande \& Patriat (2015) $\mathrm{C} 13 \mathrm{o}, \mathrm{C} 18 \mathrm{o}, \mathrm{C} 20 \mathrm{o}, \mathrm{C} 21 \mathrm{o}, \mathrm{C} 22 \mathrm{o}$ and C23o finite rotations. Velocities shown by purple circles are derived from Cannat et al. (2006) and Patriat et al. (2008) C6o, C6Cn.3, C8n.2 and C13 rotations. Red lines and pink shaded areas show instantaneous velocities and 95 per cent uncertainties that are estimated with a Somalia-Antarctic GPS angular velocity from DeMets et al. (2017). Horizontal dashed lines specify the time interval that is spanned by a given stage rotation.

\section{DISCUSSION}

\subsection{Factor-of-two slowdown in Southwest Indian Ridge spreading rates at $\approx 24 \mathrm{Ma}$}

From their modelling of several long SWIR magnetic profiles and reconstructions of magnetic anomalies $\mathrm{C} 6, \mathrm{C} 8$ and $\mathrm{C} 13$, Patriat et al. (2008) identified an apparent factor-of-two SWIR spreading rate slowdown (grey line in Fig. 15b), which they propose occurred at $\approx 24 \mathrm{Ma}$ from their matching of observed and synthetic magnetic profiles. Our Nubia-Antarctic, Lwandle-Antarctic and SomaliaAntarctic angular velocities confirm the factor-of-two slowdown (Fig. 15b), but show that the spreading rates declined gradually between 31 and $18 \pm 1 \mathrm{Ma}$, less abrupt than suggested by Patriat et al. (2008).

\subsection{Comparison to previous work}

Our new SWIR plate reconstructions confirm important aspects of previous reconstructions for the period from 52 to $40 \mathrm{Ma}$
(C23-C18, Fig. 17). Our C23 poles for all three plate pairs are located within 2.5 arc-degrees of the Bernard et al. (2005) and Cande \& Patriat (2015) Africa-Antarctic poles even though both previous studies treated the lithosphere north of the ridge as a single Africa Plate. The Africa-Antarctic poles that were estimated in both previous studies migrate 5-7 arc-degrees to the NNW between chron 23 and C18 (Fig. 17), similar to the 4-5 arc-degree northward migrations of our $\mathrm{C} 23-\mathrm{C} 180$ poles for the Lwandle-Antarctic and Somalia-Antarctic Plate pairs (Fig. 17).

Spreading rates that are estimated with our new angular velocities and with stage rotations we derived from $\mathrm{C} 23 \mathrm{o}$ to $\mathrm{C} 13$ rotations estimated by Cande \& Patriat (2015) and Cande et al. (2010) generally agree well (often to within $1-2 \mathrm{~mm} \mathrm{yr}^{-1}$ ) everywhere along the ridge (Figs 6, 9 and 12). The good agreement between our new and previous estimates confirms that SWIR plate motions fluctuated rapidly from 49 to $40 \mathrm{Ma}$, consisting of a rapid acceleration of seafloor spreading rates and clockwise rotation of the slip direction from 49 to 45 Ma followed by a rapid spreading rate slowdown from $\approx 45$ to $40 \mathrm{Ma}$. 


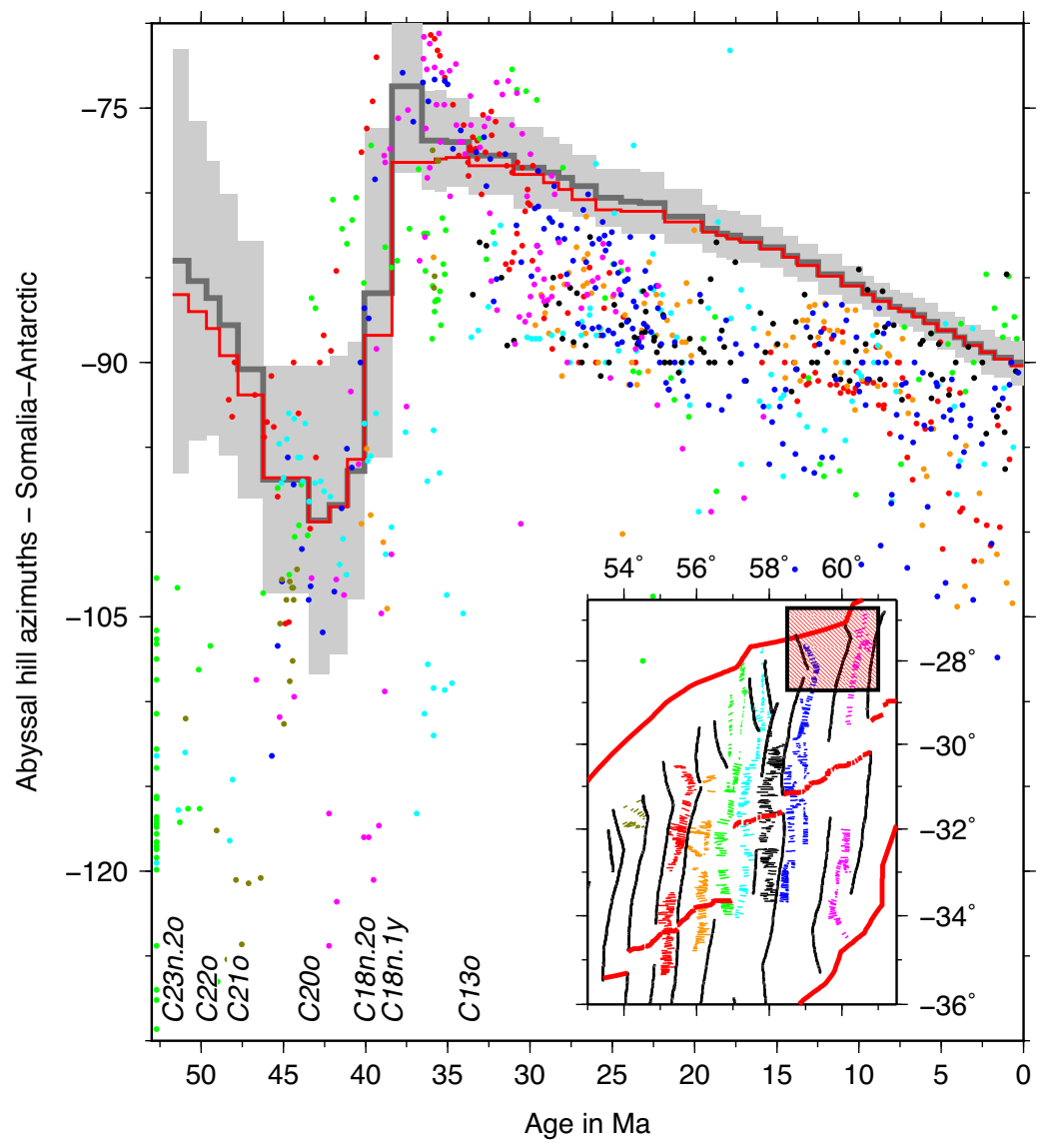

Figure 13. Abyssal hill azimuths (coloured circles) versus seafloor age for the Somalia-Antarctic portion of the Southwest Indian Ridge. The circle colours identify each abyssal hill's associated multibeam transect in the inset map. The inset map shows the abyssal hill lineations that were digitized from multibeam data that sample the seafloor from eight distinct seafloor spreading segments. The grey and red lines show directions that are orthogonal to plate slip directions that are estimated with Somalia-Antarctic noise-reduced angular velocities in Somalia Plate (grey) and Antarctic Plate (red) frames of reference. The red-shaded box within the inset map locates the map in Fig. 14.

Bernard et al. (2005) and Baines et al. (2007) describe evidence based on seafloor morphology that a major change in the SWIR geometry occurred at the time of $\mathrm{C} 18(40 \mathrm{Ma})$. Our rotations and abyssal hill lineation analysis independently confirm that this plate boundary reconfiguration coincided with a major change in plate motion at 41-38 Ma, consisting of a 30-70 per cent increase in spreading rates everywhere along the SWIR (Fig. 15b) and rapid clockwise rotation of the plate slip direction (Figs 13, 14 and 16b).

Between 35 and $20 \mathrm{Ma}$, three out of four stage spreading rates that we determined from $\mathrm{C} 13$ to $\mathrm{C} 6$ rotations from Cannat et al. (2006) and Patriat et al. (2008) agree with our new spreading rate estimates to within $\pm 2 \mathrm{~mm} \mathrm{yr}^{-1}$ (Fig. 12). The rotations estimated in these two previous studies are thus consistent with a sustained slowdown in seafloor spreading rates from $31 \mathrm{Ma}$ to 19-18 Ma.

\subsection{Slow relative motion between the Lwandle and Somalia plates}

Although previous authors have documented the existence of a distinct Lwandle Plate since at least $\approx 3 \mathrm{Ma}$ (Horner-Johnson et al. 2007; DeMets et al. 2015), nothing is known about its motion or existence before $3 \mathrm{Ma}$. With our new rotations, we reconstructed the trajectories of the Antarctica Plate relative to the Lwandle, Nubia and Somalia plates along common flow lines that originate within the Lwandle Plate's western and eastern diffuse boundaries near the SWIR (Fig. 18). Within the western diffuse boundary, the reconstructed Antarctic Plate trajectories relative to the Lwandle and Somalia plates are nearly identical (red and blue lines in Fig. 18a), reaching a maximum difference of $28 \pm 20 \mathrm{~km}$ (95 per cent uncertainty) at $\mathrm{C} 11 \mathrm{n} .1$ (29.2 Ma) and diminishing to $17 \pm 12 \mathrm{~km}$ by $\mathrm{C} 18$ (40 Ma). Within the diffuse eastern boundary near the Andrew Bain transform fault (Fig. 18b), where numerous nearby data strongly constrain the Lwandle-Antarctic and Somalia-Antarctic flow lines (Figs 8 and 10), the maximum distance between same-age points along their respective flow lines is $27 \pm 17 \mathrm{~km}$ (95 per cent) at C10n.2, diminishing to $14 \pm 6 \mathrm{~km}$ by $\mathrm{C} 18$.

The nearly identical pole locations, angular opening histories and flow line trajectories for the Lwandle-Antarctic and SomaliaAntarctic Plate pairs (Figs 7, 11, 18 and Fig. S8) indicate that relative motion between the Lwandle and Somalia plates has been slow or zero for much of the past $50 \mathrm{Myr}$. Seafloor spreading rates that are estimated with the Lwandle-Antarctic and Somalia-Antarctic angular velocities in Tables 7 and 10 differ by only $1 \pm 0.5 \mathrm{~mm} \mathrm{yr}^{-1}$ or less at most times since $\approx 30 \mathrm{Ma}$ (Fig. 15b). Differences this small, which are close to the resolution threshold for our reconstructions, may indicate that the Lwandle subplate moved with the Somalia Plate until the past few Myr.

Our reconstructions of Antarctic Plate trajectories relative to fixed Nubia and Somalia plates (the red and black flow lines in Fig. 18) show that the trajectories in a Nubia-fixed frame of reference are 
$59^{\circ}$

$60^{\circ}$

$61^{\circ}$

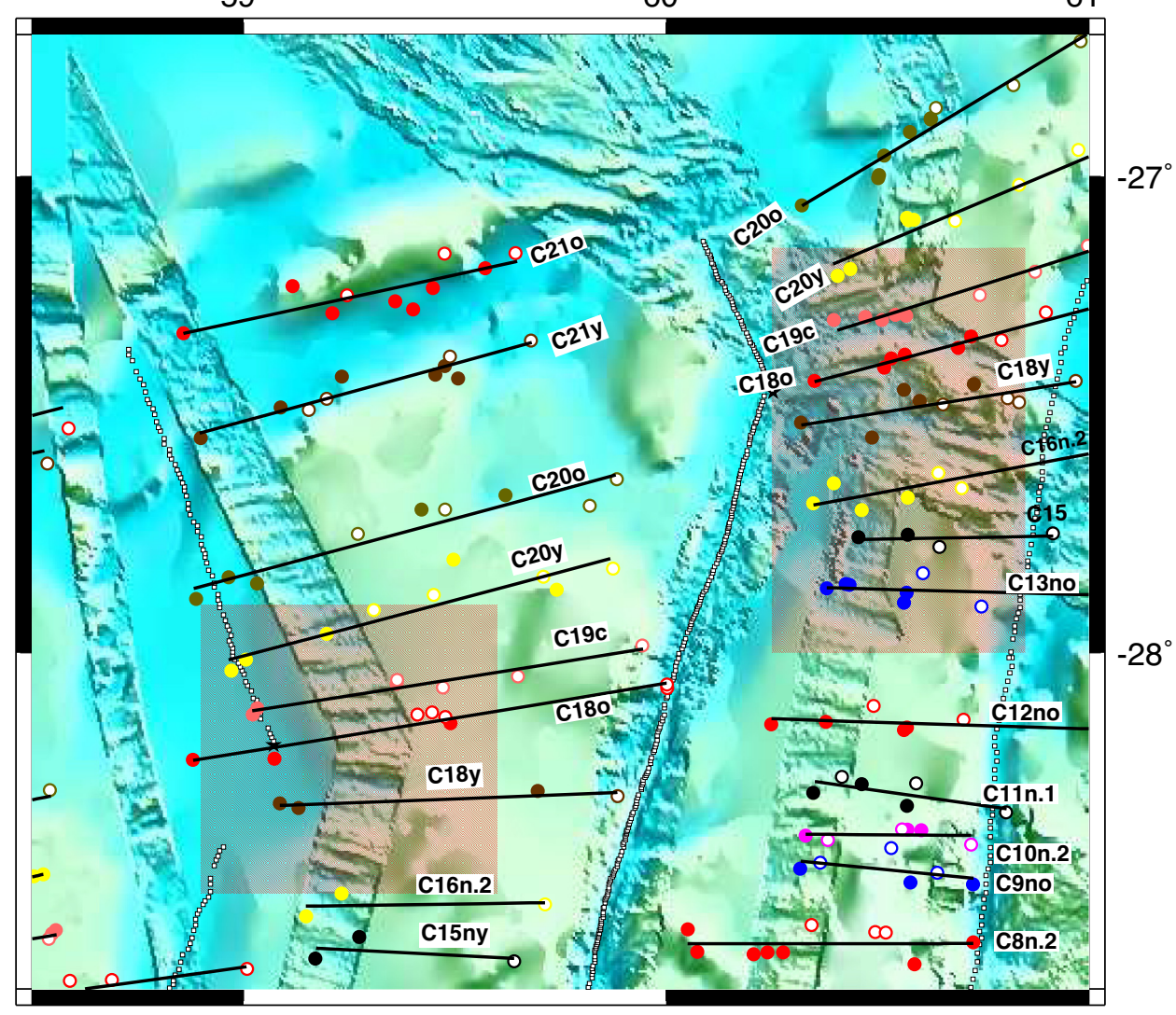

Figure 14. Somalia Plate seafloor bathymetry and reconstructed magnetic lineations for the region identified in the inset maps in Figs 10 and 13 . The shaded rectangles identify the regions where the abyssal hills rotate $30^{\circ}$ or more between $\mathrm{C} 19 \mathrm{c}(41.1 \mathrm{Ma})$ and C18y $(38.4 \mathrm{Ma})$. The circles show our magnetic reversal identifications in place (filled) or rotated from the Antarctic Plate (open). Black lines are the magnetic reversal great circles that best fit each ensemble of stationary and rotated reversal crossings.

systematically west of the trajectories in a Somalia-fixed reference frame for all times back to $\mathrm{C} 18$. Within the diffuse plate boundary near the Andrew Bain transform fault, the maximum distance between same-age points along the two trajectories is a highly significant $58 \pm 7 \mathrm{~km}$ (95 per cent uncertainty) at $\mathrm{C} 18$ (40 Ma). Within the eastern diffuse boundary, the reconstructed Nubia and Somalia Plate flow lines are located even farther apart (Fig. 18b), reaching a maximum distance of $115 \pm 20 \mathrm{~km}$ at the time of $\mathrm{C} 18$.

The reconstructed flow lines are thus consistent with significant movement between Nubia and Somalia as early as Chron 18 or $40 \mathrm{Ma}$. Although some of the apparent Nubia-Somalia movement might instead be an artefact of possible deformation within the seafloor south of the SWIR (i.e. within the Antarctic Plate), the available evidence suggests that any such deformation occurred earlier than $26 \mathrm{Ma}$ and only affected areas of Antarctica south of the Pacific-Antarctic Rise rather than adjacent to the Southwest Indian Ridge (Granot \& Dyment 2018).

\subsection{Timing and magnitude of Nubia-Somalia Plate motion in eastern Africa}

Relatively little is known about when the Africa Plate first fragmented into separate Nubia and Somalia plates and how much if any motion occurred between Nubia and Somalia before $\approx 15 \mathrm{Ma}$. The earliest reported ages for rift basin opening and volcanism in eastern Africa range from 45 to $40 \mathrm{Ma}$ in the Lokichar Basin of Kenya (Boone et al. 2019a) to $\approx 20 \mathrm{Ma}$ at many other locations (e.g. Corti 2009; Balestrieri et al. 2016; Boone et al. 2019b). Such ages may not accurately approximate the onset of movement between Nubia and Somalia because pre-existing weaknesses in the crust, variations in crustal thickness, and heterogeneities in the thermal and mechanical properties of the crust (e.g. Boone et al. 2019a) may all affect when rifting began at a given location.

Table S1 lists Nubia-Somalia finite rotations between C20 (43 Ma) and the present derived from the noise-reduced NubiaAntarctic and Somalia-Antarctic rotations in Tables 3 and 6. Using the new rotations, we reconstructed the path of the Somalia Plate relative to Nubia for a point that originates on the eastern shoulder of the $\approx 100$-km-wide Main Ethiopian Rift (Fig. 19), which separates the two plates near the northern limit of their present plate boundary. The reconstructed point locations for C18o, C19, C20y and $\mathrm{C} 20 \mathrm{o}$ are all close to each other, consistent with no movement between the two plates before C18. After C18o, all of the reconstructed flow line points until C6Bn.1 are located progressively farther to the east, consistent with WNW-ESE divergence between the two plates beginning at $40 \mathrm{Ma}$. From the time of C8n.2 (26 Ma) until C5D or C5Cn.1 (17-16 Ma), the reconstructed point locations differ insignificantly, suggesting little or no movement between Nubia and Somalia during this period. After 17-16 Ma, the flow line points reconstruct to locations that are progressively farther to the east, consistent with WNW-ESE divergence during this period.

If all of the reconstructions are reliable, they imply the following: (1) an earliest age of $40 \mathrm{Ma}$ for the onset of movement between 

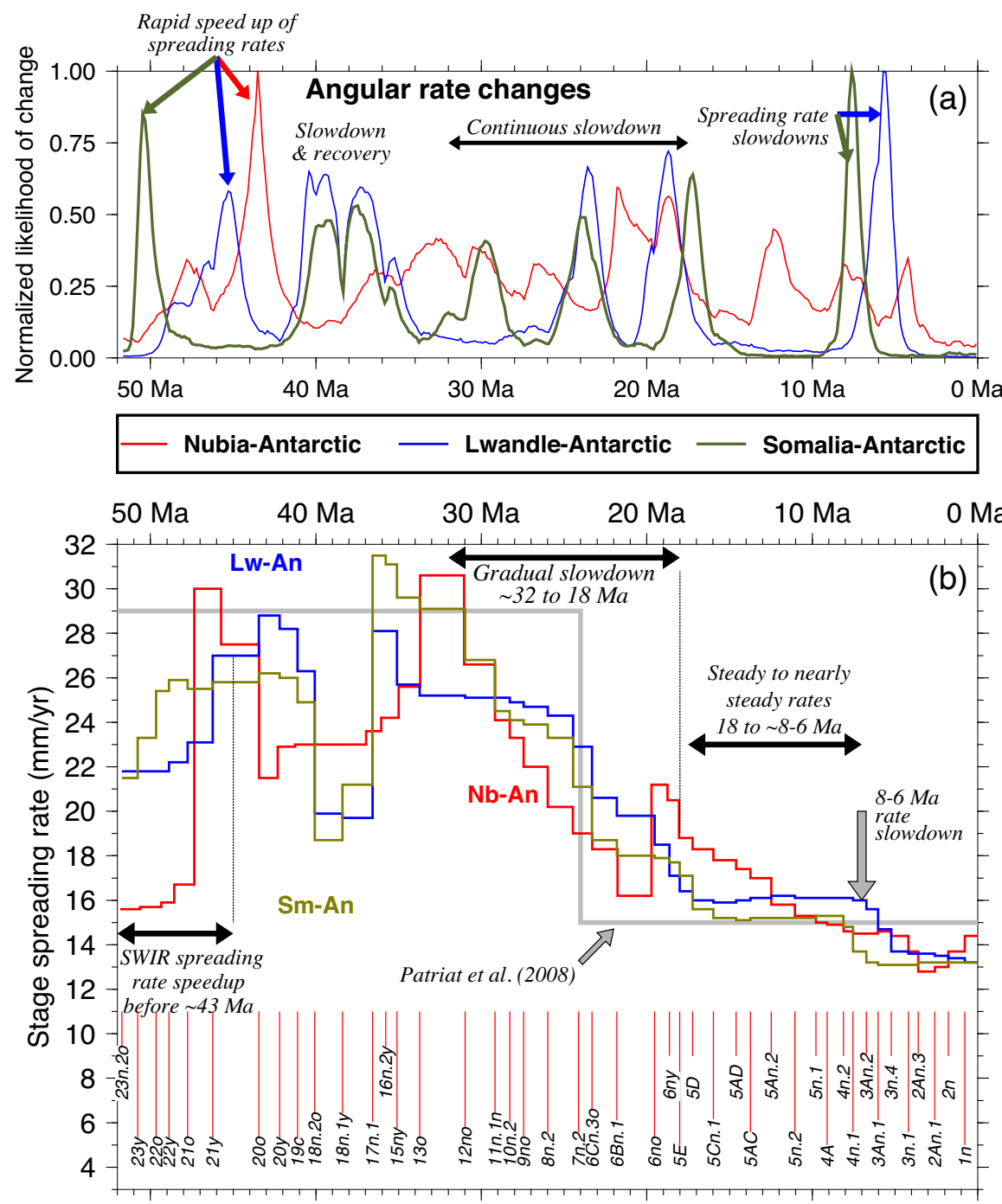

Figure 15. (a) Likelihoods of changes in post-52 Ma Southwest Indian Ridge angular opening rates from REDBACK analyses of the best-fitting NubiaAntarctic (red), Lwandle-Antarctic (blue) and Somalia-Antarctic (green) rotation sequences. The most likely motion changes are marked by narrow, high amplitude peaks. The likelihood of change within the millions of models that were sampled via the REDBACK Bayesian analysis of each rotation sequence is normalized to 1.0. (b) Southwest Indian Ridge (SWIR) noise-reduced spreading rates since 52 Ma. The Nubia-Antarctic (Nb-An) rates are from Fig. 6. The Lwandle-Antarctic (Lw-An) and Somalia-Antarctic (Sm-An) rates are along a common Antarctic Plate flow line that originates at the Gallieni transform fault $\left(37^{\circ} \mathrm{S}, 52.3^{\circ} \mathrm{E}\right)$. The grey line shows Patriat et al.'s (2008) interpretation of the spreading rate history from matching of synthetic magnetic profiles against three observed profiles. The rate uncertainties are omitted for clarity.

Nubia and Somalia in the Afar region of eastern Africa (Fig. 19). (2) An earlier 40-26 Ma period during which $109 \pm 38 \mathrm{~km}(95$ per cent) of WNW-ESE divergence occurred across the northern end of the Main Ethiopian rift. (3) A more recent divergent phase that began at 17-16 Ma (C5D or C5Cn.1), consisting of an additional $79 \pm 12 \mathrm{~km}(\mathrm{C} 5 \mathrm{D})$ or $72 \pm 10 \mathrm{~km}(\mathrm{C} 5 \mathrm{Cn} .1)$ of WNW-ESE divergence. (4) Slow or no movement from 26 to $17 \mathrm{Ma}$. The total estimated divergence since $40 \mathrm{Ma}, 189 \pm 34 \mathrm{~km}$ directed toward $\mathrm{N} 75^{\circ} \mathrm{W}-\mathrm{S} 75^{\circ} \mathrm{E}\left( \pm 6^{\circ}\right)$, is $4-5$ times more than a $40-50 \mathrm{~km}$ estimate for the cumulative stretching across the Main Ethiopian Rift at the location of our flow line (DeMets \& Merkouriev 2016). This either implies that structures outside the present rift valley at the location of our transect accommodated significant amounts of plate motion or that our reconstructions are significantly in error.

The Nubia-Somalia rotations from $\mathrm{C} 1 \mathrm{n}$ back to $\mathrm{C} 5 \mathrm{Cn} .1$ are constrained by numerous magnetic reversal and fracture zone crossings that are well distributed along the Nubia-Antarctic and SomaliaAntarctic Plate boundaries. The reconstructions for these times should thus be reliable. Our Nubia-Antarctic rotations for C5D, C5E and C6 are less reliable due to difficulties in identifying those reversals along much of the westernmost SWIR (Section 4.1). For times before C6, our Nubia-Antarctic rotations are estimated from only 6-10 reversal crossings from one or two spreading segments and five fracture zone flow lines (e.g. Fig. 4, Table 1, and Supplemental Figs 10 and 11). The Nubia-Somalia rotations for times before $\mathrm{C} 6$ are thus less robust with respect to errors due to misidentified magnetic reversals, mismatched palaeoridge segments, and/or mislocated fracture zone flow lines, particularly between the Nubia and Antarctic plates.

As a test of whether errors in our Somalia-Antarctic rotations might be responsible for some or all of the apparent divergence between Nubia and Somalia before 17-16 Ma, we used the noisereduced Lwandle-Antarctic rotations in Table 9 as proxies for the 

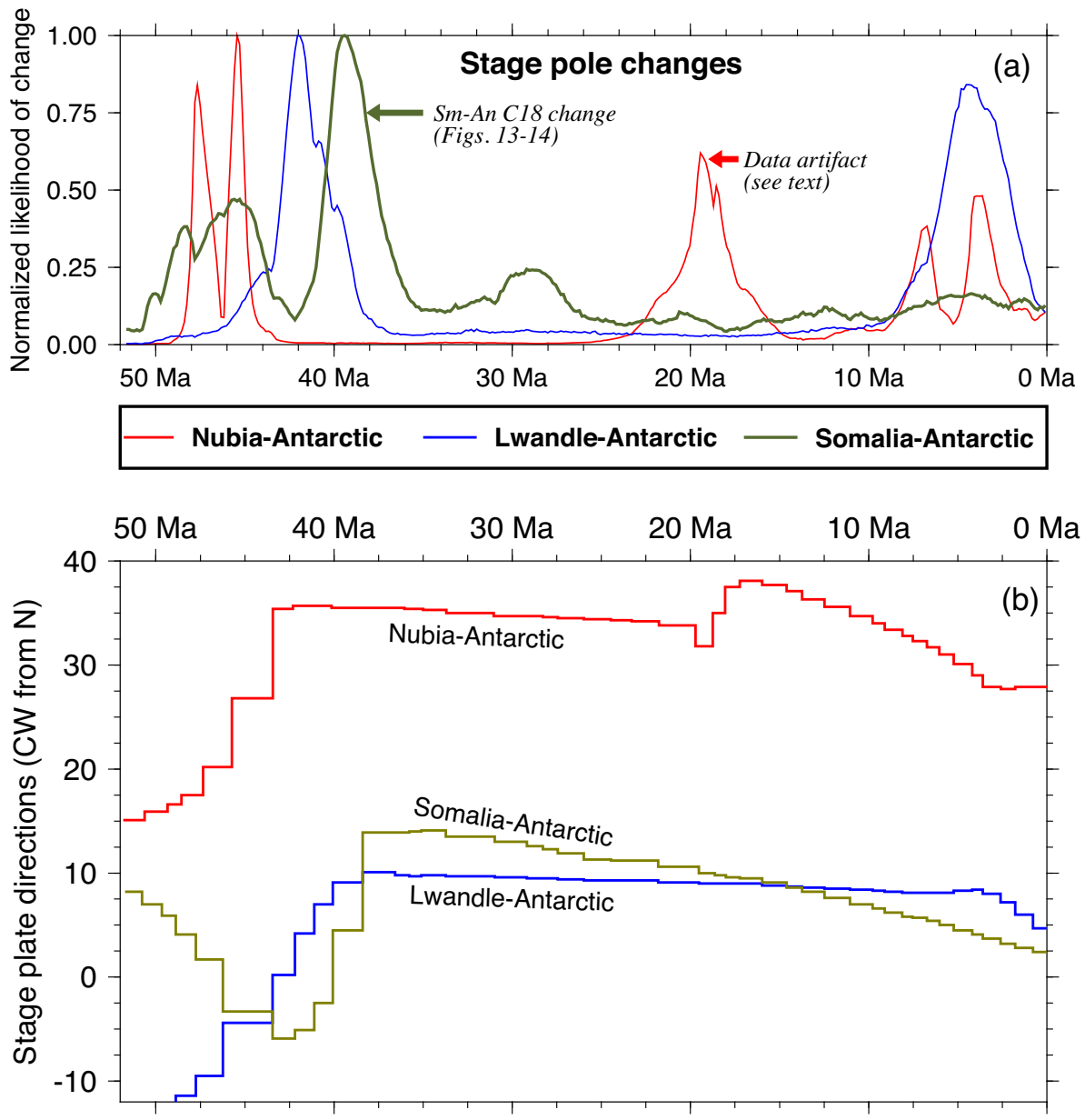

Figure 16. (a) Likelihoods of changes in post-52 Ma Southwest Indian Ridge stage pole locations from REDBACK analyses of the best-fitting Nubia-Antarctic (red), Lwandle-Antarctic (blue) and Somalia-Antarctic (green) rotation sequences. See the previous figure caption for more information. (b) Southwest Indian Ridge noise-reduced plate directions along the flow lines detailed in the previous figure caption. All directional uncertainties are omitted for clarity.

Somalia-Antarctic rotations and re-estimated Somalia relative to Nubia rotations. This approach is warranted given the evidence described in Section 5.3 for possibly insignificant motion between the Lwandle and Somalia plates before $\approx 3 \mathrm{Ma}$. The C5Cn.1 and C18o Lwandle-Nubia rotations indicate WNW-ESE divergences of $76 \pm 21$ and $166 \pm 35 \mathrm{~km}$, respectively, along the flow line shown in Fig. 19, nearly the same as for the Nubia-Somalia rotations. The alternative rotations also indicate that no significant movement occurred between Nubia and Somalia from 26 to $17 \mathrm{Ma}$. We conclude that larger-than-expected errors or systematic biases in our Somalia-Antarctic rotations are unlikely to be responsible for our unexpectedly large estimates of Nubia-Somalia divergence and early date for the initiation of movement between the two plates.

\subsection{What caused the 31-18 Ma Southwest Indian Ridge spreading rate slowdown?}

The factor-of-two SWIR spreading rate slowdown from 31 to 19-18 Ma (Fig. 20a) resulted from an unknown combination of changes in the Somalia and Antarctic plates' absolute motions. We evaluated whether the observed spreading rate slowdown can be explained by a change in the absolute motion of just one of the two plates using two recent estimates of Africa Plate absolute motion that were derived from hotspot tracks beneath the Africa Plate. From the tracks of the Reunion and Tristan hotspots beneath the Africa
Plate, Doubrovine et al. (2012) estimate Africa Plate finite and 10Myr-average stage rotations relative to a moving hot spot reference frame. Maher et al. (2015) estimate Africa Plate absolute rotations from seamount ages and the tracks of three Atlantic Basin hot spot trails beneath the Nubia Plate and the Reunion hot spot trail beneath the Somalia Plate.

We compared Somalia-Antarctic seafloor spreading rates to the Somalia Plate absolute velocities at a common, central location along the Somalia-Antarctic Plate boundary (dark green and cyan lines in Fig. 20a). The absolute plate velocities are projected onto the stage opening directions that are estimated with our noise-reduced Somalia-Antarctic angular velocities so that changes in the absolute velocities can be compared to the spreading rates without any directional ambiguity. Both of the absolute motion estimates indicate that the spreading-parallel component of the Somalia Plate's motion decreased by roughly 50 per cent since $30 \mathrm{Ma}$. For the Doubrovine et al. estimates, the average rate of motion declines from $30.5 \mathrm{~mm}$ $\mathrm{yr}^{-1}$ at $40-30 \mathrm{Ma}$ to only $18.5 \mathrm{~mm} \mathrm{yr}^{-1}$ at $20-10 \mathrm{Ma}$, a net decrease of $12 \mathrm{~mm} \mathrm{yr}^{-1}$. For the Maher et al. estimates, the average rate of motion declines from $26 \mathrm{~mm} \mathrm{yr}^{-1}$ at $40.1-33.7$ Ma to only $15 \mathrm{~mm}$ $\mathrm{yr}^{-1}$ at $19.5-16.0 \mathrm{Ma}$, a net decrease of $11.5 \mathrm{~mm} \mathrm{yr}^{-1}$.

During the same period, the Somalia-Antarctic noise-reduced spreading rates declined from $29 \pm 1 \mathrm{~mm} \mathrm{yr}^{-1}$ at 33.7-31.0 Ma to $15.5 \pm 1 \mathrm{~mm} \mathrm{yr}^{-1}$ since $17.2 \mathrm{Ma}$, a net decrease of $13.5 \mathrm{~mm}$ $\mathrm{yr}^{-1}$ (blue line in Fig. 20 A). The 31-18 Ma slowdown estimated 


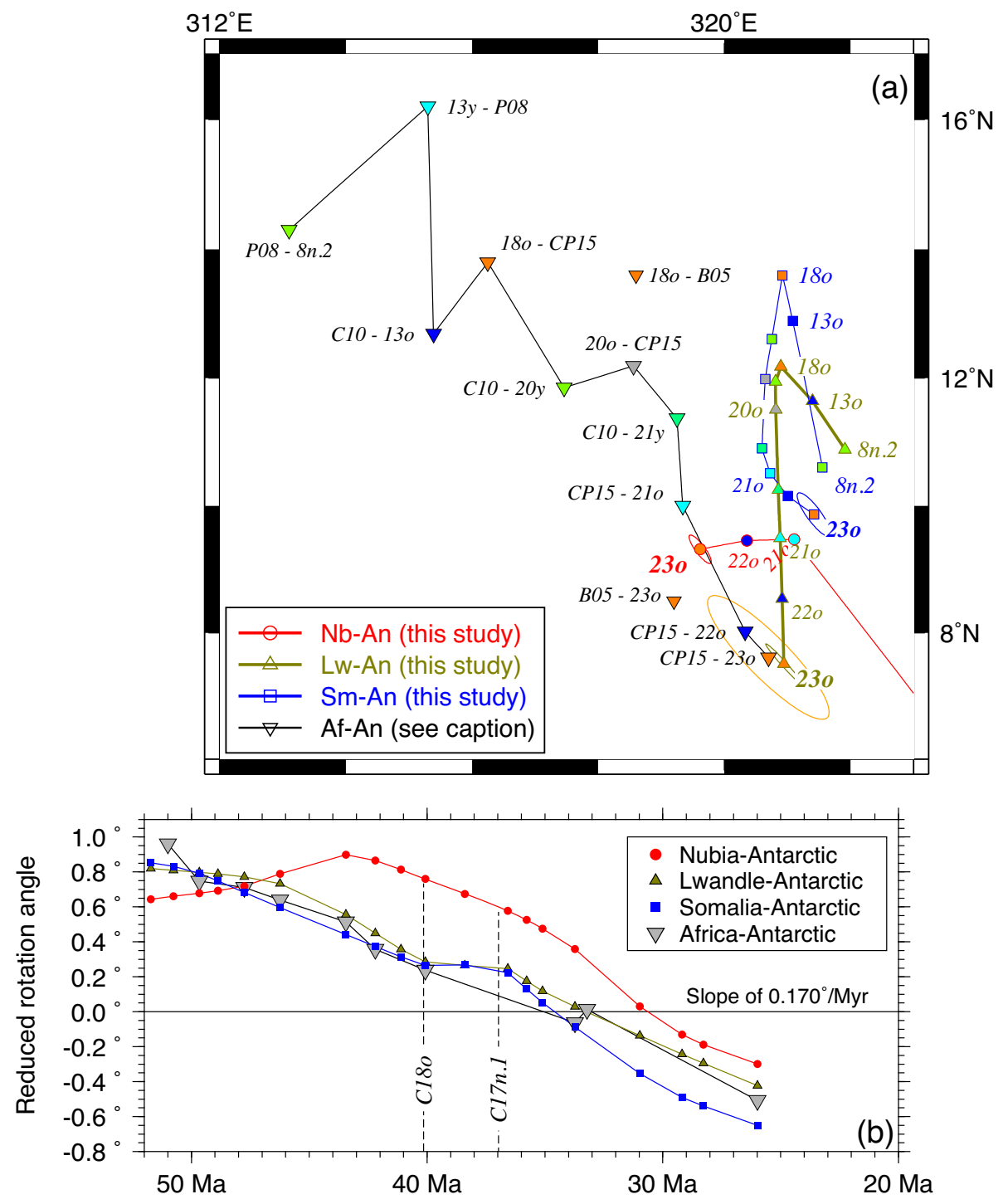

Figure 17. Comparisons of C8n. 2 to $\mathrm{C} 23$ Nubia-Antarctic (Nb-An), Lwandle-Antarctic (Lw-An) and Somalia-Antarctic (Sm-An) noise-reduced finite rotation poles (panel a) and opening angles (panel b) to Africa-Antarctic (Af-An) reconstruction poles and angles (inverted triangles) from Bernard et al. (2005) (C18o and 23o), Patriat et al. (2008) (C8n.2 and 13y), Cande et al. (2010) (C13o, 20y and 21y) and Cande \& Patriat (2015) (C18o, 20o, 21o, 22o and 23o). The 2-D 95 per cent confidence ellipses for C23 are as follows: Sm-An—blue; Nb-An—red; Lw-An—olive; Cande \& Patriat (2015)—orange. Other confidence ellipses are omitted for clarity. All of the opening angles that are shown in (b) are reduced by a slope of $0.170^{\circ} \mathrm{Myr}^{-1}$ in order to facilitate a comparison of the opening angle histories. B05, Bernard et al. (2005); C10, Cande et al. (2010); CP15, Cande \& Patriat (2015); P08, Patriat et al. (2008).

from our magnetic reversal reconstructions, $13.5 \mathrm{~mm} \mathrm{yr}^{-1}$, is thus nearly the same as the slowdowns estimated with Somalia Plate absolute angular velocities (12 and $11.5 \mathrm{~mm} \mathrm{yr}^{-1}$ ). The spreading rate slowdown along the eastern SWIR thus appears to have been caused mostly or entirely by a change in the torques that were acting on the Somalia Plate.

Fig. 20(a) summarizes the major events that may have contributed to the Somalia Plate slowdown. These include the detachment of the northeastward subducting Arabia Plate from the rest of Africa via the openings of the Gulf of Aden and Red Sea. Onland and marine stratigraphic data indicate that continental extension bordering the Gulf of Aden began after 33.9 Ma and no later than 28.4 Ma (Fig. 20 and Bosworth et al. 2005). Along the Red Sea margins, widespread volcanic diking, rift-normal faulting and marine sedimentation initiated at $\approx 24$ Ma and were followed at $\approx 20$ Ma by rapid subsidence and rift-shoulder uplift (Bosworth et al. 2005). The transition to full seafloor spreading within the Gulf of Aden by C6 (19.5 Ma) in the easternmost Gulf (Fournier et al. 2010) and C5D (17.2 Ma) in the central Gulf (d'Acremont et al. 2006) presumably completed the detachment of the Arabia peninsula from the Nubia/Somalia plates. These dates closely match the Somalia-Antarctic spreading rate slowdown, which began at $31 \pm 1 \mathrm{Ma}$ and ceased at 18 $\pm 1 \mathrm{Ma}$ (Fig. 20a). The collision of continental Arabia and Eurasia, which may have occurred at $\approx 28-27 \mathrm{Ma}$ (McQuarrie \& van Hinsbergen 2013), may also have contributed to the Somalia Plate slowdown.

The arrival at $\approx 45$ Ma of the Afar mantle plume beneath eastern Africa (George et al. 1998) and Africa's slow northeastward migration over the plume (Hassan et al. 2020) may also have played an important role in the Somalia Plate's northward slowdown. Enhanced shear at the base of the Africa Plate due to plume-enhanced asthenospheric flow (e.g. Iaffaldano et al. 2018) may have increased 

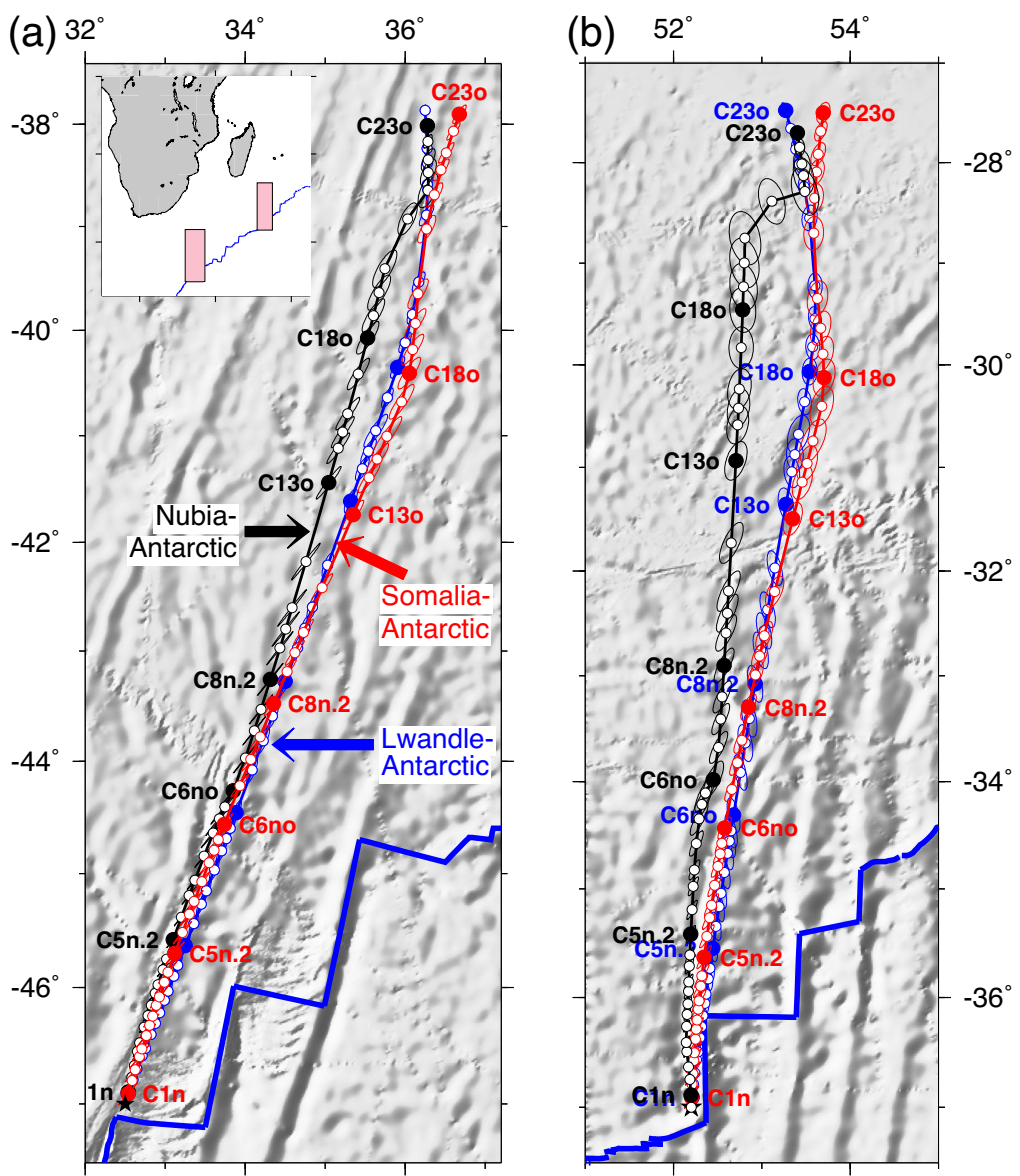

Figure 18. Antarctic Plate flow lines relative to the Nubia (black), Lwandle (blue) and Somalia (red) plates reconstructed with noise-reduced rotations in Tables 3, 6 and 9. (a) Flow lines for all three plate pairs near the north end of the Prince Edward transform fault. (b) Flow lines at the Gallieni fracture zone. Dashed ellipses are the 2-D 95 per cent confidence limits propagated from the rotation covariances. Selected chrons are labeled. The regions shown in (a) and (b) are located by the shaded rectangles in the inset map. The black stars show the flow line origin points.

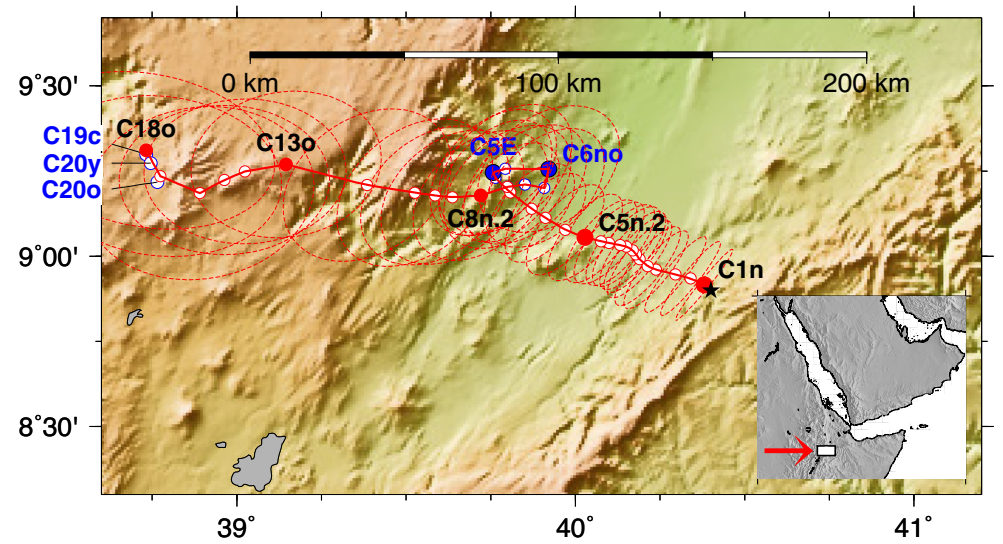

Figure 19. Reconstructed trajectory for the Somalia Plate relative to Nubia since C20o (43.4 Ma) for a flow line that originates at the eastern edge of the Main Ethiopian Rift (at the black star). The path is reconstructed with Nubia-Somalia rotations (Table S1) that we derived from noise-reduced Nubia-Antarctic and Somalia-Antarctic rotations (see text). The open and filled red circles designate periods during which the reconstructed locations are consistent with slow ESE-WNW divergence between the two plates. The open and filled blue circles designate periods of apparent slow or no motion. Dashed ellipses indicate the 2-D 95 per cent confidence limits propagated from the rotation covariances. Selected chrons are labelled. The main map is located within the inset map in the lower left-hand corner.

the southward-directed component of the force-per-unit-length that was acting on the Somalia Plate. Plume-related topographic doming and isostatic uplift in eastern Africa due to increases in lithospheric thickness via volcanic underplating and eruptions such as the
30-29-Ma-old, 2000-m-thick Ethiopian flood basalts (Hofmann et al. 1997) may also have increased the southward-directed push on the Somalia Plate. Modelling is clearly required to determine how these factors may have altered Somalia Plate motion. 


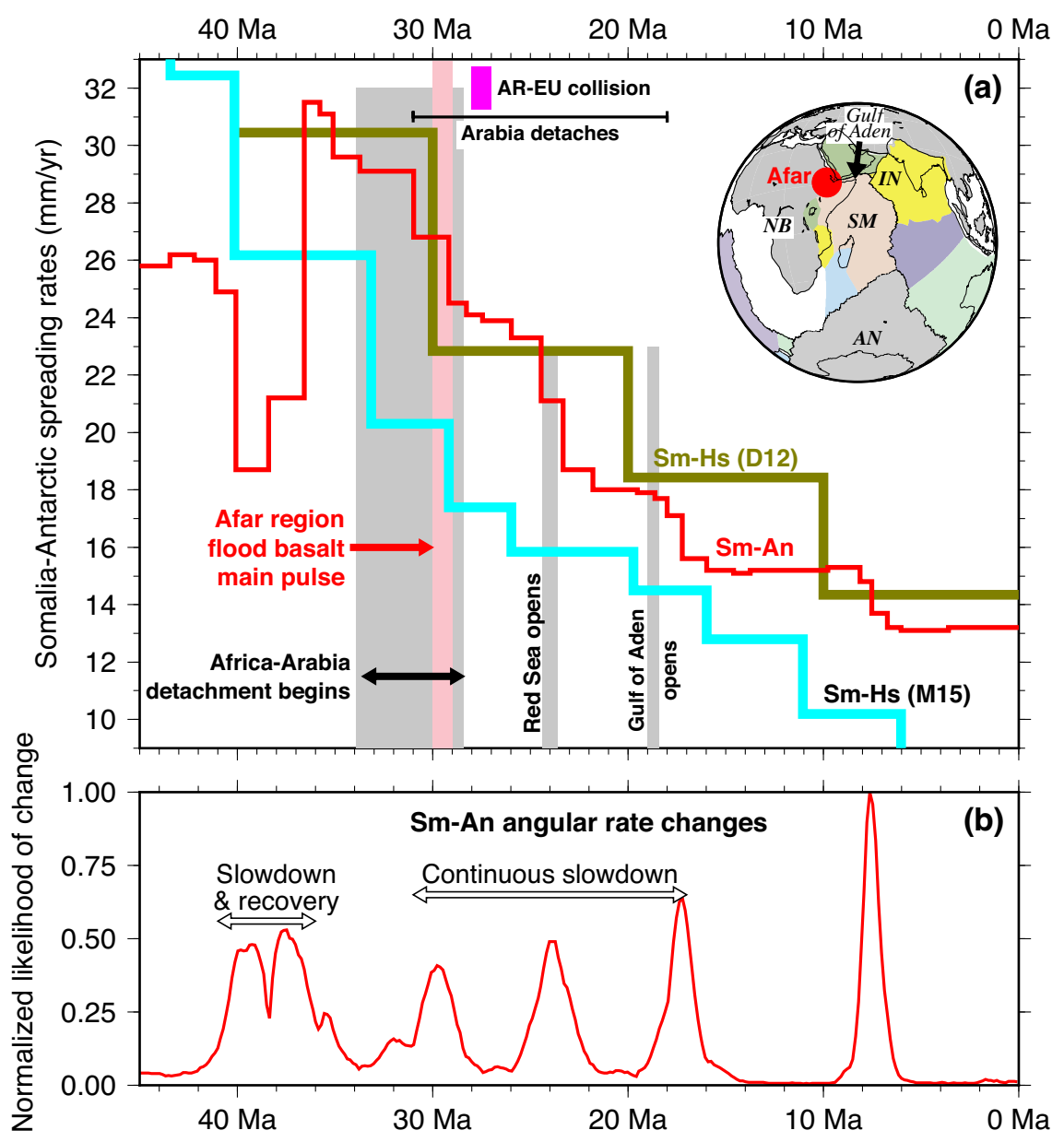

Figure 20. (A) Post-45 Ma Somalia-Antarctic (Sm-An) and Somalia-hotspot (Sm-Hs) rates and tectonic event timeline at the Somalia Plate's northern boundary. See Section 5.5 for discussion. The major events that affected the Somalia Plate's northern boundary between 35 and 18-17 Ma included (1) Early rifting in the Gulf of Aden at 33.6-28.7 Ma (Bosworth et al. 2005), marking the initiation of Arabia's detachment from Africa. (2) The collision of continental Arabia and Eurasia at 35-27 Ma (McQuarrie \& van Hinsbergen 2013). (3) The 30-29 Ma eruption of voluminous flood basalts in the Afar region (Hofmann et al. 1997). (4) The onset of Red Sea extension at $\approx 24-20 \mathrm{Ma}$ (Bosworth et al. 2005). (5) The initiation of seafloor spreading in the Gulf of Aden at 20-18 $\mathrm{Ma}$, which completed the detachment of Arabia from the former Africa Plate. The Somalia-Antarctic noise-reduced rates (red line) are from Fig. 12(a). The dark green and cyan lines show Somalia-relative-to-hotspot rates estimated along the eastern Southwest Indian Ridge and projected onto Somalia-Antarctic stage opening directions. The Sm-Hs rates were approximated with Africa Plate angular velocities from Doubrovine et al. (2012, abbreviated D12) and Maher et al. (2015, abbreviated M15), respectively. (B) Ages associated with the highest probability change points in Somalia-Antarctic angular rates as identified by our REDBACK analysis of the Somalia-Antarctic best-fitting rotations (see text and Fig. 15a).

\subsection{Limitations and next steps}

The most likely artefact in our results is the apparent change in Nubia-Antarctica motion from $\approx 21$ to 16 Ma (Fig. 6), which may be a consequence of possible misidentifications of C5D, C5E and C6 along western third of SWIR. No such variations in LwandleAntarctic or Somalia-Antarctic Plate motions are observed during this period (Fig. 15b), where our identifications of C5D through C6 are more reliable. Improved magnetic survey coverage of seafloor older than $10 \mathrm{Ma}$ on both sides of the $15^{\circ} \mathrm{E}-25^{\circ} \mathrm{E}$ spreading segment and seafloor along the westernmost end of the ridge is clearly needed.

The extreme values for spreading rates that are estimated from stage angular velocities that depend on the $\mathrm{C} 17 \mathrm{n}$. 1 rotations for all three plate pairs are also another likely artefact (Section 4.5), which we attribute to a likely error in the GTS20 reversal age estimate for $\mathrm{C} 17 \mathrm{n}$. Alternative spreading rates that we derived using reversal ages from GTS12 (Ogg 2012) and MQSD20 (Malinverno et al. 2020 ) exhibited $\approx 50$ per cent less variation for stages whose young or old limits included C17n.1, thereby supporting our contention. Notably, the GTS20 ages for C15 through C19 are all from Westerhold et al.'s (2014) astronomically tuned age sequence. For this reason, we suspect that the likely GTS20 mistiming of $\mathrm{C} 17$ also affects the GTS20 age estimates for other proximal reversals.

Another limitation of our work, which is common to all studies that use fracture zones to constrain plate rotations, is the uncertainty associated with fracture zone 'age'. Our flow-line fitting methodology implicitly assigns a starting age for each flow line that equals the age of the youngest seafloor that is offset by the fracture zone. For example, fracture zones that originate at ridge-transform fault intersections are assigned starting ages of $0 \mathrm{Myr}$ independent of the fracture zone age offset at that location. In contrast, the assigned starting age could be as old as the oldest seafloor that abuts the fracture zone at its starting point. Given this ambiguity, well-expressed fracture zones with relatively small age offsets (1 Myr or less) provide better constrained information about the ages of changes 
in relative slip directions than do longer age-offset fracture zones. Unfortunately most SWIR fracture zones are in the latter category.

More multibeam transects of older SWIR seafloor, particularly along the sparsely surveyed eastern and central sections of the ridge, could be used to estimate abyssal hill azimuths for stronger tests of the accuracies of the slip directions that are estimated with our new rotations and the ages they imply for significant slip direction changes (e.g. Fig. 14 and Figs S6 and S7). The consistency between the ages of plate slip direction changes that are indicated by our angular velocities and the ages that are indicated by our abyssal hill analysis (Fig. 14) suggests that abyssal hill azimuths are useful proxies for plate motion changes.

New multibeam and magnetic surveys of 40-20-Myr-old seafloor west of the Andrew Bain transform fault complex at $30^{\circ} \mathrm{E}$ are needed to test the accuracy of Nubia-Somalia rotations for times before $\mathrm{C} 5 \mathrm{Cn} .1$ (16 Ma). The well-expressed but irregularly surveyed anomaly sequence that flanks the $15^{\circ} \mathrm{E}-25^{\circ} \mathrm{E}$ spreading segment is the only area along the western third of the SWIR where anomalies older than $\mathrm{C} 5 \mathrm{C}$ are clearly interpretable. High-quality determinations of the palaeoridge segmentation and reversal locations from this area are critical and may be uniquely suited for determining whether significant movement occurred between Nubia and Somalia before $26 \mathrm{Ma}$ and whether a 5-10-Myr-long hiatus in NubiaSomalia Plate motion occurred between $\approx 26$ and $16 \mathrm{Ma}$ (C8n.2 and $\mathrm{C} 5 \mathrm{Cn} .1$ ). The same surveys could provide much improved flow line information for seafloor older than $20 \mathrm{Ma}$, another essential element for improving estimates of the magnitude and timing of Nubia-Somalia Plate motion.

Finally, modern multibeam and magnetic surveys of 50-35-Myrold seafloor are needed to better model the kinematics and duration of the major plate boundary reconfiguration at $\approx 40 \mathrm{Ma}$ (e.g. Fig. 14) and the processes by which the plate motion shifted from the previously active NNW-trending fracture zones to the presently active NNE-trending fracture zones. Documenting the details of this important but still obscure kinematic transition will also likely deepen our understanding of the regional kinematic changes that accompanied India's Cenozoic continental collision with Eurasia.

\section{CONCLUSIONS}

From inversions of $\approx 20000$ kinematic data that sample Southwest Indian Ridge Plate motions at 44 distinct times between $52 \mathrm{Ma}$ and the present, we estimate Nubia-Antarctic, Lwandle-Antarctic and Somalia-Antarctic rotations and stage angular velocities, comprising the first high resolution plate motion estimates for these plate pairs that span this entire period. From the noise-reduced and bestfitting rotations that best fit our numerous plate kinematic data and a variety of independent sources, we conclude the following:

(1)Seafloor spreading rates everywhere along the ridge increased 50 per cent or more between 49 and $\approx 45 \mathrm{Ma}$, but then declined rapidly from 42 to $40 \mathrm{Ma}$, coinciding with a reconfiguration of the SWIR geometry. From 40 to $37 \mathrm{Ma}$, seafloor spreading rates increased by $30-70$ per cent and the plate slip directions and seafloor fabric rotated $30-40^{\circ}$ clockwise as the ridge established a geometry similar to that of the present day. The cause(s) of the previously unknown spreading rate slowdown and recovery from 42 to $37 \mathrm{Ma}$ are unexplained as yet.

(2)Beginning at $31 \pm 1 \mathrm{Ma}$, seafloor spreading rates declined gradually by 50 per cent. The slowdown concluded at $18 \pm 1 \mathrm{Ma}$ along the well-mapped Lwandle-Antarctic and Somalia-Antarctic segments of the ridge. Along the Nubia-Antarctic segment, where magnetic reversals with ages of 21-16 Ma are harder to identify, the slowdown ended as early as $20 \mathrm{Ma}$ or continued until as recently as 6-5 Ma. Our new results confirm the occurrence of a 50 per cent spreading rate slowdown identified by Patriat et al. (2008), but show that the slowdown was gradual rather than abrupt. Our new results and a parallel analysis of abyssal hill orientations reveal no evidence for a $10^{\circ}$ clockwise rotation of the plate slip direction at 20 Ma postulated by Dick et al. (1991) and Hosford et al. (2003).

(3)Seafloor spreading rates along the eastern two-thirds of the ridge were steady from $18 \pm 1 \mathrm{Ma}$ until 8-6 Ma, when they declined a further 20 per cent to their present-day rates. A sustained anticlockwise rotation of the SWIR opening direction since at least $20 \mathrm{Ma}$ that is estimated with the new rotations is corroborated by an analysis of the orientations of $\approx 900$ well-mapped abyssal hills across the Somalia-Antarctic segment of the ridge and GPS-derived estimates of instantaneous Nubia-Antarctic and Somalia-Antarctic slip directions.

(4)A $\approx 13 \mathrm{~mm} \mathrm{yr}^{-1}$ net spreading rate slowdown from 31 to $18 \mathrm{Ma}$ coincided with $\mathrm{a} \approx 12 \mathrm{~mm} \mathrm{yr}^{-1}$ slowdown in the Somalia Plate's spreading-parallel component of its absolute motion during this period. Likely causes of the Somalia Plate's slowdown include the detachment of the Arabia Plate from the remainder of Africa via the openings of the Gulf of Aden and Red Sea, the arrival of the Afar plume beneath eastern Africa, or possibly the collision between continental Arabia and Eurasia at or before 28-27 Ma.

(5)Flow lines that reconstruct the trajectories of the Antarctic Plate relative to Nubia, Lwandle and Somalia plates suggest little-to-no movement between the Lwandle and Somalia plates for the past 50 Myr. The Lwandle Plate may thus have detached from Somalia within the past few Myr. The trajectories relative to the Nubia and Somalia plates however differ significantly back to $40 \mathrm{Ma}$, consistent with significant motion between the two plates.

(6)A reconstruction of the movement of the Somalia Plate relative to Nubia along the northern end of the East Africa Rift shows no evidence for significant movement before $40 \mathrm{Ma}$ (Chron 18), but evidence for $109 \pm 38 \mathrm{~km}$ of WNW-ESE divergence between the two plates from 40 to $26 \mathrm{Ma}$, little or no motion from $26 \mathrm{Ma}$ until 17-16 $\mathrm{Ma}$ and $70-80 \mathrm{~km}$ of WNW-ESE divergence from 17 to $16 \mathrm{Ma}$ until the present. If our reconstructions are reliable, they imply that the Africa Plate began fragmenting as early as $40 \mathrm{Ma}$ and further imply that structures outside of the present East African rift valleys have accommodated half or more of the estimated divergence. Alternatively, our reconstructions for times before 17 Ma may be significantly in error due to the sparsity of magnetic reversal identifications for seafloor older than $\approx 15 \mathrm{Ma}$ along the Nubia-Antarctic Plate boundary.

\section{ACKNOWLEDGEMENTS}

The magnetic reversal and fracture zone identifications used for our analysis are available as through the Marine Geoscience Data System (marine-geo.org) under the following doi: 10.26022/IEDA/330177. We thank Peter Molnar and an anonymous reviewer for their constructive comments and also thank Peter for suggesting that the arrival of the Afar hotspot plume beneath northern Somalia may have been the primary reason for the slowdown in Somalia's northward motion at that time. This work was supported by grant 1433323 from the National Science Foundation (usa). Figures were drafted using Generic Mapping Tools software (Wessel \& Smith 1991). 


\section{REFER EN CES}

Baines, A.G., Cheadle, M.J., Dick, H.J.B., Hosford-Scheirer, A., John, B.E., Kusznir, N.J. \& Matsumoto, T., 2007. Evolution of the Southwest Indian Ridge from $55^{\circ} 45^{\prime} \mathrm{E}$ to $62^{\circ} \mathrm{E}$ : changes in plate boundary geometry since $26 \mathrm{Ma}$, Geochem. Geophys. Geosyst., 8, Q06022, doi:10.1029/2006GC001559.

Balestrieri, M.L., Bonini, M., Corti, G., Sani, F. \& Philippon, M., 2016. A refinement of the chronology of rift-related faulting in the Broadly Rifted Zone, southern Ethiopia, through apatite fission-track analysis, Tectonophysics, 671, 42-55.

Bernard, A., Munschy, M., Rotstein, Y. \& Sauter, D., 2005. Refined spreading history at the Southwest Indian Ridge for the last $96 \mathrm{Ma}$, with the aid of satellite gravity data, Geophys. J. Int., 162, 765-778.

Boone, S.C., Balestrieri, M.-L., Kohn, B.P., Corti, G., Gleadow, A.J.W. \& Seiler, C., 2019b. Tectonothermal evolution of the Broadly Rifted Zone, Ethiopian Rift, Tectonics, 38, 1070-1100.

Boone, S.C., Kohn, B.P., Gleadow, A.J.W., Morley, C.K., Seiler, C. \& Foster, D.A., 2019a. Birth of the East African Rift system: nucleation of magmatism and strain in the Turkana Depression, Geology, 47, 886-890.

Bosworth, W., Huchon, P. \& McClay, K., 2005. The Red Sea and Gulf of Aden Basins, J. Afr. Earth Sci., 43, 334-378.

Cande, S.C. \& Patriat, P., 2015. The anticorrelated velocities of Africa and India in the Late Cretaceous and early Cenozoic, Geophys. J. Int., 200, 227-243.

Cande, S.C., Patriat, P. \& Dyment, J., 2010. Motion between the Indian, Antarctic, and African plates in the early Cenozoic, Geophys. J. Int., 183, $127-149$.

Cande, S.C. \& Stegman, D.R., 2011. Indian and African plate motions driven by the push force of the Reunion plume head, Nature, 475, 47-52.

Cannat, M., Sauter, D., Mendel, V., Ruellan, E., Okino, K., Escartin, J., Combier, V. \& Baala, M., 2006. Modes of seafloor generation at a meltpoor ultraslow-spreading ridge, Geology, 34, 605-608.

Carbotte, S.M. et al., 2004. New integrated data management system for Ridge2000 and MARGINS research, EOS, Trans. Am. geophys. Un., 85, $553,559$.

Copley, A., Avouac, J.-P. \& Royer, J.-Y., 2010. India-Asia collision and the Cenozoic slowdown of the Indian plate: implications for the forces driving plate motions, J. geophys. Res., 115, B03410, doi:10.1029/2009JB006634.

Cormier, M.-H. \& Sloan, H., 2018. Abyssal hills and abyssal plains, in Submarine Geomorphology, Springer Geology, pp. 389-408, eds Micallef, A., Krastel, S. \& Savini, A., Springer.

Corti, G., 2009. Continental rift evolution: from rift initiation to incipient break-up in the Main Ethiopian Rift, East Africa, Earth-Sci. Rev., 96, $1-53$.

DeMets, C., Calais, E. \& Merkouriev, S., 2017. Reconciling geologic and geodetic estimates of recent plate motion across the Southwest Indian Ridge, Geophys. J. Int., 208, 118-133.

DeMets, C., Gordon, R.G. \& Argus, D.F., 2010. Geologically current plate motions, Geophys. J. Int., 181, 1-80.

DeMets, C. \& Merkouriev, S., 2016. High-resolution estimates of NubiaSomalia plate motion since $20 \mathrm{Ma}$ from reconstructions of the Southwest Indian Ridge, Red Sea and Gulf of Aden, Geophys. J. Int., 207, 317-332.

DeMets, C. \& Merkouriev, S., 2019. High-resolution reconstructions of South America plate motion relative to Africa, Antarctica, and North America: 34 Ma to present, Geophys. J. Int., 217, 1821-1853.

DeMets, C., Merkouriev, S. \& Jade, S., 2020. High-resolution reconstructions and GPS estimates of India-Eurasia and India-Somalia plate motions: 20 Ma to the present, Geophys. J. Int., 220, 1149-1171.

DeMets, C., Merkouriev, S. \& Sauter, D., 2015. High-resolution estimates of Southwest Indian Ridge plate motions, 20 Ma to present, Geophys. J. Int., 203, 1495-1527.

DeMets, C. \& Wilson, D.S., 2008. Toward a minimum change model for recent plate motions: calibrating seafloor spreading rates for outward displacement, Geophys. J. Int., 174, 825-841.

Dick, H.J.B. et al., 1991. Tectonic evolution of the Atlantis II Fracture Zone, in Proceedings of the Ocean Drilling Program, Scientific Results, Vol. 118, eds Von Herzen, R.P., Robinson, P.T. et al., pp. 359-398.
Doubrovine, P.V., Steinberger, B. \& Torsvik, T.H., 2012. Absolute plate motions in a reference frame defined by moving hot spots in the Pacific, Atlantic, and Indian oceans, J. geophys. Res., 117, B09101, doi:10.1029/2011JB009072.

d'Acremont, E., Leroy, S., Maia, M., Patriat, P., Bselier, M.-O., Bellahsen, N., Fournier, M. \& Gente, P., 2006. Structure and evolution of the eastern Gulf of Aden: insights from magnetic and gravity data (Encens-Sheba MD117 cruise), Geophys. J. Int., 165, 786-803.

Fournier, M. et al., 2010. Arabia-Somalia plate kinematics, evolution of the Aden-Owen-Carlsberg triple junction, and opening of the Gulf of Aden, J. geophys. Res., 115, doi:10.1029/2008JB006257.

George, R., Rogers, N. \& Kelley, S., 1998. Earliest magmatism in Ethiopia: Evidence for two mantle plumes in one flood basalt province, Geology, 26, 923-926.

Granot, R. \& Dyment, J., 2018. Late Cenozoic unification of East and West Antarctica, Nature Communications, doi:10.1038/s41467-018-05270-w.

Hartnady, C.J.H., 2002. Earthquake hazard in Africa: perspectives on the Nubia-Somalia boundary, S. Afr. J. Sci., 98, 425-428.

Hassan, R., Williams, S.E., Gurnis, M. \& Muller, D., 2020. East African topography and volcanism explained by a single, migrating plume, Geosci. Front., 11, 1669-1680.

Hofmann, C., Courtillot, V., Feraud, G., Rochette, P., Yirgu, G., Ketefo, E. \& Pik, R., 1997. Timing of the Ethiopian flood basalt event and implications for plume birth and global change, Nature, 389, 838-841.

Horner-Johnson, B.C., Gordon, R.G. \& Argus, D.F., 2007. Plate kinematic evidence for the existence of a distinct plate between the Nubian and Somalian plates along the Southwest Indian Ridge, J. geophys. Res., 112, B05418, doi:10.1029/2006JB004519.

Hosford, A., Tivey, M., Matsumoto, T., Dick, H., Schouten, H. \& Kinoshita, H., 2003. Crustal magnetization and accretion at the Southwest Indian Ridge near the Atlantis II fracture zone, 0-25 Ma, J. geophys. Res., 108(B3), 2169.

Iaffaldano, G., Bodin, T. \& Sambridge, M., 2012. Reconstructing platemotion changes in the presence of finite-rotations noise, Nat. Commun., 3, 1048 .

Iaffaldano, G., Bodin, T. \& Sambridge, M., 2013. Slow-downs and speedups of India-Eurasia convergence since $\approx 20 \mathrm{Ma}$ : data-noise, uncertainties and dynamic implications, Earth planet. Sci. Lett., 367, 146-156.

Iaffaldano, G., Davies, D.R. \& DeMets, C., 2018. Indian Ocean floor deformation induced by the Reunion plume rather than the Tibetan Plateau, Nat. Geosci., 11, 362-366.

Iaffaldano, G., Hawkins, R., Bodin, T. \& Sambridge, M., 2014. REDBACK: open-source software for efficient noise-reduction in plate kinematic reconstructions, Geochem. Geophys. Geosyst., 15, 1663-1670.

Lawver, L.A. \& Scotese, C.R., 1987. A revised reconstruction of Gondwana, in Gondwana Six: Structure, Tectonics, and Geophysics, Vol. 40, AGU Monograph, ed. McKenzie, D.G., pp. 17-23, AGU.

Maher, S.M., Wessel, P., Muller, R.D., Williams, S.E. \& Harada, Y., 2015. Absolute plate motion of Africa around Hawaii-Emperor bend time, Geophys. J. Int., 201, 1743-1764.

Malinverno, A., Quigley, K.W., Staro, A. \& Dyment, J., 2020. A Late Cretaceous-Eocene geomagnetic polarity timescale (MQSD20) that steadies spreading rates on multiple mid-ocean ridge flanks, J. geophys. Res., 125, doi.org/10.1029/2020JB020034.

McQuarrie, N. \& van Hinsbergen, D.J.J., 2013. Retrodeforming the ArabiaEurasia collision zone: age of collision versus magnitude of continental subduction, Geology, 41, 315-318.

Mendel, V., Sauter, D., Parson, L.M. \& Vanney, J.R., 1997. Segmentation and morphotectonic variations along a super slow-spreading centre: the Southwest Indian Ridge $\left(57^{\circ} \mathrm{E}-70^{\circ} \mathrm{E}\right)$, Mar. Geophys. Res., 19, $503-531$.

Merkouriev, S. \& DeMets, C., 2006. Constraints on Indian plate motion since $20 \mathrm{Ma}$ from dense Russian magnetic data: implications for Indian plate dynamics, Geochem. Geophys. Geosyst., 7, Q02002, doi:10.1029/2005GC001079.

Merkouriev, S. \& DeMets, C., 2014a. High-resolution estimates of NubiaNorth America plate motion: 20 Ma to present, Geophys. J. Int., 196, $1281-1298$ 
Merkouriev, S. \& DeMets, C., 2014b. High-resolution Quaternary and Neogene reconstructions of Eurasia-North America plate motion, Geophys. J. Int., 198, 366-384.

Molnar, P. \& Stock, J.M., 2009. Slowing of India's convergence with Eurasia since $20 \mathrm{Ma}$ and its implications for Tibetan mantle dynamics, Tectonics, 28, TC3001, doi:10.1029/2008TC002271.

Ogg, J.G., 2012. Geomagnetic polarity time scale, in The Geologic Time Scale 2012, pp. 85-113, eds Gradstein, F.M., Ogg, J.G., Schmitz, M. \& Ogg, G., Elsevier.

Ogg, J.G., 2020. Geomagnetic polarity time scale, in Geologic Time Scale 2020, Chapter 5, pp. 159-192, eds Gradstein, F.M., Ogg, J.G., Schmitz, M.D. \& Ogg, G.M., Elsevier.

Patriat, P., Sauter, D., Munschy, M. \& Parson, L., 1997. A survey of the Southwest Indian ridge axis between Atlantis II fracture zone and the Indian Ocean triple junction: regional setting and large scale segmentation, Mar. Geophys. Res., 19, 457-480.

Patriat, P., Sloan, H. \& Sauter, D., 2008. From slow to ultraslow: a previously undetected event at the Southwest Indian Ridge at ca. $24 \mathrm{Ma}$, Geology, 36, 207-210.

Patriat, P.J., Segoufin, J. G. \& Beuzart, P., 1985. Relative positions of Africa and Antarctica in the Upper Cretaceous: evidence for non-stationary behavior of fracture zones, Earth planet. Sci. Lett., 75, 204-214.

Royer, J.Y., Patriat, P., Bergh, H.W. \& Scotese, C.R., 1988. Evolution of the Southwest Indian Ridge from the Late Cretaceous (anomaly 34) to the Middle Eocene (anomaly 20), Tectonophysics, 155, 235-260.

Sauter, D. et al., 2001. The Southwest Indian Ridge between $49^{\circ} 15^{\prime} \mathrm{E}$ and $57^{\circ} \mathrm{E}$ : focused accretion and magma redistribution, Earth planet. Sci. Lett., 192, 303-317.

Smith, W.H.F. \& Sandwell, D.T., 1997. Global sea floor topography from satellite altimetry and ship depth soundings, Science, 277, 1956-1962.

van Hinsbergen, D.J.J., Steinberger, B., Doubrovine, P.V. \& Gassmoller, R., 2011. Acceleration and deceleration of India-Asia convergence since the Cretaceous: roles of mantle plumes and continental collision, J. Geophys. Res., 116, B06101.

Wessel, P. \& Smith, W.H.F., 1991. Free software helps map and display data, EOS Trans. Amer. Geophys. U., 72, 441-446.

Westerhold, T., Rohl, U., Palike, H., Wilkens, R., Wilson, P.A. \& Acton, G., 2014. Orbitally tuned timescale and astronomical forcing in the middle Eocene to early Oligocene, Clim. Past, 10, 955-975.

\section{SUPPORTING INFORMATION}

Supplementary data are available at $G J I$ online.

Table S1. Nubia-Somalia rotations.

Figure S1. Magnetic reversal correlation points (labelled dotted lines) and magnetic block model used for the study. The synthetic magnetic profile, which is appropriate for correlating magnetic anomalies along much of the central Southwest Indian Ridge, was created using a $18 \mathrm{~mm} \mathrm{yr}^{-1}$ spreading rate, a ridge azimuth of $\mathrm{N} 86^{\circ} \mathrm{E}$, a $1.5-\mathrm{km}$-wide reversal transition zone, and ambient and palaeomagnetic inclinations and declinations for a point at $44.5^{\circ} \mathrm{S}$, $37^{\circ} \mathrm{E}$.

Figure S2. Comparative weighted root-mean-square (w.r.m.s.) misfits for reconstructed magnetic reversal and fracture zones by reversal age (panel a) and fracture zone age (panel b) per Southwest Indian Ridge plate pair and for the Nubia-South America Plate pair (DeMets \& Merkouriev 2019). All misfits are for reconstructions by the best-fitting rotations described in the text. The SWIR reconstruction misfits are comparable to those for the well-studied southern Mid- Atlantic Ridge, where seafloor spreading rates and the fidelities of the magnetic reversal sequences are approximately the same. The large misfit increase for the Nubia-Antarctic reversal crossings for 20-16 Ma is attributable to difficulties in identifying the sparsely surveyed magnetic anomalies for this period from the western third of the Southwest Indian Ridge (see text).
Figure S3. Observed (black) and predicted (coloured) NubiaAntarctic fracture zone traces. The red lines and lines that are colour coded by seafloor age show the flow lines determined respectively from the best-fitting and noise-reduced Nubia-Antarctica rotation sequences in Tables 2 and 3 of the main document. Vertical distances are exaggerated by $\approx 3$ times relative to horizontal distances to emphasize the misfits and noise in the digitized traces. Positive and negative distances on the horizontal axis indicate parts of the fracture zone that lie on the Africa or Antarctica sides of the SWIR, respectively. Distances are measured relative to the locations of the northern and southern ridge-transform fault intersections (RTI), where each fracture zone begins. Transform faults, which are located between the northern and southern RTIs, are omitted from this plot.

Figure S4. Observed (black) and predicted (coloured) LwandleAntarctic fracture zone traces. The red lines and lines that are colour coded by seafloor age show the flow lines determined respectively from the noise-mitigated and best-fitting Lwandle-Antarctica rotation sequences in Tables 5 and 6 of the main document. Vertical distances are exaggerated by five times relative to horizontal distances to emphasize the misfits and noise in the digitized traces. Positive and negative distances on the horizontal axis indicate parts of the fracture zone that lie on the Africa or Antarctica sides of the SWIR, respectively. Distances are measured relative to the locations of the northern and southern ridge-transform fault intersections (RTI), where each fracture zone begins. Transform faults, which are located between the northern and southern RTIs, are omitted from this plot.

Figure S5. Observed (black) and predicted (coloured) SomaliaAntarctic fracture zone traces. The red lines and lines that are colour coded by seafloor age show the flow lines determined, respectively from the best-fitting and noise-reduced Nubia-Antarctica rotation sequences in Tables 8 and 9 of the main document. Vertical distances are exaggerated by 2.6 times relative to horizontal distances to emphasize the misfits and noise in the digitized traces. Positive and negative distances on the horizontal axis indicate parts of the fracture zone that lie on the Africa or Antarctica sides of the SWIR, respectively. Distances are measured relative to the locations of the northern and southern ridge-transform fault intersections (RTI), where each fracture zone begins. Transform faults, which are located between the northern and southern RTIs, are omitted from this plot.

Figure S6. Individual and average abyssal hill azimuths (circles and blue line respectively) versus seafloor age for a multibeam transect at $51^{\circ} \mathrm{E}$ north of the Lwandle-Antarctic portion of the Southwest Indian Ridge. The blue lines in the inset map show the abyssal hill lineations we digitized from the R/V Gallieni multibeam data. The average abyssal hill azimuths were determined at 0.5 -Myr intervals for 5-Myr-long periods centred on each time. The bold red line shows directions that are orthogonal to Lwandle-Antarctic Plate slip directions predicted by noise-reduced rotations from Table 7 of the main document.

Figure S7. Nubia Plate seafloor bathymetry and reconstructed magnetic lineations, Chrons 23 to 13, for the region identified in the inset map in Fig. 4 of the main document. Any rotation of the abyssal hill fabric between $\mathrm{C} 19 \mathrm{c}$ and $\mathrm{C} 18 \mathrm{y}(41.1-38.4 \mathrm{Ma})$ is modest (less than 10 degrees), in contrast to a much larger change in the SomaliaAntarctic abyssal hill fabric during this period (Fig. 14 of the main document). The circles show our magnetic reversal identifications in place (filled) or rotated from the Antarctic Plate (open). Black lines are the great circles that best fit each ensemble of stationary and rotated reversal crossings. 
Figure S8. Comparisons of Nubia-Antarctic (Nb-An), LwandleAntarctic (Lw-An) and Somalia-Antarctic (Sm-An) noise-reduced finite rotation poles (a) and opening angles (b), C1n to C23o. Confidence ellipses are omitted for clarity. All the opening angles are reduced by a slope of $0.170^{\circ} \mathrm{Myr}^{-1}$ to facilitate a comparison of their angular rate changes. The same pole and angle sequences are shown in more detail in Figs 3, 7 and 11 of the main document.

Figure S9. Blended bathymetric grids with French and other multibeam observations that were used in our analysis. Circles identify the digitized fracture zone crossings that constrain our rotations and red lines show abyssal hill lineations used in part of our analysis. The resolutions of the underlying multibeam grids included in this map range from 150 to $500 \mathrm{~m}$.

Figure S10. Along-track magnetic anomaly observations, magnetic reversal identifications, and reconstructed magnetic lineations for the magnetic reversals identified in the legend above the figure. The map base is 1-min seafloor bathymetry from topex.ucsd.edu/WWW_html/mar_topo.html (Smith \& Sandwell 1997). Fracture zone flow lines digitized from GeoMapApp are indicated by the tiny white circles. Flow lines predicted with the bestfitting and noise-mitigated Nubia-Antarctic rotations (Tables 2 and 3 ) are indicated by the coloured circles and red lines, respectively. The symbols that are filled with yellow show magnetic reversal crossings rotated onto their same-age counterparts across the ridge. The solid symbols and white-filled symbols are magnetic reversal crossings in their original locations. The coloured lines are the great circles that best fit the stationary and rotated reversal crossings for each palaeo-spreading segment. Digitized transform faults are indicated by circles with black rims and yellow cores. Transform fault small circles that are predicted by the Chron $1 \mathrm{n}$ pole are shown by the thin black lines.

Figure S11. Along-track magnetic anomaly observations, magnetic reversal identifications, and reconstructed magnetic lineations for the magnetic reversals identified in the legend above the figure. The map base is 1-min seafloor bathymetry from topex.ucsd.edu/WWW_html/mar_topo.html (Smith \& Sandwell 1997). Fracture zone flow lines digitized from GeoMapApp are indicated by the tiny white circles. Flow lines predicted with the bestfitting and noise-mitigated Nubia-Antarctic rotations (Tables 2 and 3 ) are indicated by the coloured circles and red lines, respectively. The symbols that are filled with yellow show magnetic reversal crossings rotated onto their same-age counterparts across the ridge. The solid symbols and white-filled symbols are magnetic reversal crossings in their original locations. The coloured lines are the great circles that best fit the stationary and rotated reversal crossings for each palaeo-spreading segment. Digitized transform faults are indicated by circles with black rims and yellow cores. Transform fault small circles that are predicted by the Chron $1 \mathrm{n}$ pole are shown by the thin black lines.

Figure S12. Along-track magnetic anomaly observations, magnetic reversal identifications and reconstructed magnetic lineations for the magnetic reversals identified in the legend above the figure. The map base is 1-min seafloor bathymetry from topex.ucsd.edu/WWW_html/mar_topo.html (Smith \& Sandwell 1997). Fracture zone flow lines digitized from GeoMapApp are indicated by the tiny white circles. Flow lines predicted with the bestfitting and noise-mitigated Nubia-Antarctic rotations (Tables 2 and 3 ) are indicated by the coloured circles and red lines, respectively. The symbols that are filled with yellow show magnetic reversal crossings rotated onto their same-age counterparts across the ridge. The solid symbols and white-filled symbols are magnetic reversal crossings in their original locations. The coloured lines are the great circles that best fit the stationary and rotated reversal crossings for each palaeo-spreading segment. Digitized transform faults are indicated by circles with black rims and yellow cores. Transform fault small circles that are predicted by the Chron $1 \mathrm{n}$ pole are shown by the thin black lines.

Figure S13. Along-track magnetic anomaly observations, magnetic reversal identifications, and reconstructed magnetic lineations for the magnetic reversals identified in the legend above the figure. The map base is 1-min seafloor bathymetry from topex.ucsd.edu/WWW_html/mar_topo.html (Smith \& Sandwell 1997). Fracture zone flow lines digitized from GeoMapApp are indicated by the tiny white circles. Flow lines predicted with the bestfitting and noise-mitigated Nubia-Antarctic rotations (Tables 2 and 3 ) are indicated by the coloured circles and red lines, respectively. The symbols that are filled with yellow show magnetic reversal crossings rotated onto their same-age counterparts across the ridge. The solid symbols and white-filled symbols are magnetic reversal crossings in their original locations. The coloured lines are the great circles that best fit the stationary and rotated reversal crossings for each palaeo-spreading segment. Digitized transform faults are indicated by circles with black rims and yellow cores. Transform fault small circles that are predicted by the Chron $1 \mathrm{n}$ pole are shown by the thin black lines.

Figure S14. Along-track magnetic anomaly observations, magnetic reversal identifications and reconstructed magnetic lineations for the magnetic reversals identified in the legend above the figure. The map base is 1-min seafloor bathymetry from topex.ucsd.edu/WWW_html/mar_topo.html (Smith \& Sandwell 1997). Fracture zone flow lines digitized from GeoMapApp are indicated by the tiny white circles. Flow lines predicted with the best-fitting and noise-mitigated Lwandle-Antarctic rotations (Tables 5 and 6 ) are indicated by the coloured circles and red lines, respectively. The symbols that are filled with yellow show magnetic reversal crossings rotated onto their same-age counterparts across the ridge. The solid symbols and white-filled symbols are magnetic reversal crossings in their original locations. The coloured lines are the great circles that best fit the stationary and rotated reversal crossings for each palaeo-spreading segment. Digitized transform faults are indicated by circles with black rims and yellow cores. Transform fault small circles that are predicted by the Chron $1 \mathrm{n}$ pole are shown by the thin black lines.

Figure S15. Along-track magnetic anomaly observations, magnetic reversal identifications, and reconstructed magnetic lineations for the magnetic reversals identified in the legend above the figure. The map base is 1-min seafloor bathymetry from topex.ucsd.edu/WWW_html/mar_topo.html (Smith \& Sandwell 1997). Fracture zone flow lines digitized from GeoMapApp are indicated by the tiny white circles. Flow lines predicted with the best-fitting and noise-mitigated Lwandle-Antarctic rotations (Tables 5 and 6) are indicated by the coloured circles and red lines, respectively. The symbols that are filled with yellow show magnetic reversal crossings rotated onto their same-age counterparts across the ridge. The solid symbols and white-filled symbols are magnetic reversal crossings in their original locations. The coloured lines are the great circles that best fit the stationary and rotated reversal crossings for each palaeo-spreading segment. Digitized transform faults are indicated by circles with black rims and yellow cores. Transform fault small circles that are predicted by the Chron $1 \mathrm{n}$ pole are shown by the thin black lines.

Figure S16. Along-track magnetic anomaly observations, magnetic reversal identifications, and reconstructed magnetic lineations for the magnetic reversals identified in the legend above 
the figure. The map base is 1-min seafloor bathymetry from topex.ucsd.edu/WWW_html/mar_topo.html (Smith \& Sandwell 1997). Fracture zone flow lines digitized from GeoMapApp are indicated by the tiny white circles. Flow lines predicted with the best-fitting and noise-mitigated Lwandle-Antarctic rotations (Tables 5 and 6) are indicated by the coloured circles and red lines, respectively. The symbols that are filled with yellow show magnetic reversal crossings rotated onto their same-age counterparts across the ridge. The solid symbols and white-filled symbols are magnetic reversal crossings in their original locations. The coloured lines are the great circles that best fit the stationary and rotated reversal crossings for each palaeo-spreading segment. Digitized transform faults are indicated by circles with black rims and yellow cores. Transform fault small circles that are predicted by the Chron $1 \mathrm{n}$ pole are shown by the thin black lines.

Figure S17. Along-track magnetic anomaly observations, magnetic reversal identifications, and reconstructed magnetic lineations for the magnetic reversals identified in the legend above the figure. The map base is 1-min seafloor bathymetry from topex.ucsd.edu/WWW_html/mar_topo.html (Smith \& Sandwell 1997). Fracture zone flow lines digitized from GeoMapApp are indicated by the tiny white circles. Flow lines predicted with the best-fitting and noise-mitigated Lwandle-Antarctic rotations (Tables 5 and 6) are indicated by the coloured circles and red lines, respectively. The symbols that are filled with yellow show magnetic reversal crossings rotated onto their same-age counterparts across the ridge. The solid symbols and white-filled symbols are magnetic reversal crossings in their original locations. The coloured lines are the great circles that best fit the stationary and rotated reversal crossings for each palaeo-spreading segment. Digitized transform faults are indicated by circles with black rims and yellow cores. Transform fault small circles that are predicted by the Chron $1 \mathrm{n}$ pole are shown by the thin black lines.

Figure S18. Along-track magnetic anomaly observations, magnetic reversal identifications and reconstructed magnetic lineations for the magnetic reversals identified in the legend above the figure. The map base is 1-min seafloor bathymetry from topex.ucsd.edu/WWW_html/mar_topo.html (Smith \& Sandwell 1997). Fracture zone flow lines digitized from GeoMapApp are indicated by the tiny white circles. The small coloured circles show the predicted fracture zone flow lines created with the LwandleAntarctic rotations west of $52^{\circ} \mathrm{E}$ (Table 5) and Somalia-Antarctic rotations east of $52^{\circ} \mathrm{E}$ (Table 8 ). Flow lines predicted with the Lwandle-Antarctic and Somalia-Antarctic noise-mitigated rotations (Tables 6 and 9, respectively) are indicated by the red lines. The symbols that are filled with yellow show magnetic reversal crossings rotated onto their same-age counterparts across the ridge. The solid symbols and white-filled symbols are magnetic reversal crossings in their original locations. The coloured lines are the great circles that best fit the stationary and rotated reversal crossings for each palaeo-spreading segment. Digitized transform faults are indicated by circles with black rims and yellow cores. Transform fault small circles that are predicted by the Chron $1 \mathrm{n}$ pole are shown by the thin black lines. The olive-coloured lines show abyssal hill lineations digitized from multibeam tracks and discussed in the text. Figure S19. Along-track magnetic anomaly observations, magnetic reversal identifications, and reconstructed magnetic lineations for the magnetic reversals identified in the legend above the figure. The map base is 1-min seafloor bathymetry from topex.ucsd.edu/WWW_html/mar_topo.html (Smith \& Sandwell 1997). The small coloured circles show the predicted fracture zone flow lines created with the Lwandle-Antarctic rotations west of $52^{\circ} \mathrm{E}$ (Table 5) and Somalia-Antarctic rotations east of $52^{\circ} \mathrm{E}$ (Table 8). Flow lines predicted with the Lwandle-Antarctic and Somalia-Antarctic noise-mitigated rotations (Tables 6 and 9, respectively) are indicated by the red lines. The symbols that are filled with yellow show magnetic reversal crossings rotated onto their same-age counterparts across the ridge. The solid symbols and white-filled symbols are magnetic reversal crossings in their original locations. The coloured lines are the great circles that best fit the stationary and rotated reversal crossings for each palaeo-spreading segment. Digitized transform faults are indicated by circles with black rims and yellow cores. Transform fault small circles that are predicted by the Chron $1 \mathrm{n}$ pole are shown by the thin black lines. The olive-coloured lines show abyssal hill lineations digitized from multibeam tracks and discussed in the text.

Figure S20. Along-track magnetic anomaly observations, magnetic reversal identifications and reconstructed magnetic lineations for the magnetic reversals identified in the legend above the figure. The map base is 1-min seafloor bathymetry from topex.ucsd.edu/WWW_html/mar_topo.html (Smith \& Sandwell 1997). The magnetic reversals shown in the figure are reconstructed with best-fitting Somalia-Antarctic rotations from Table 8. The symbols that are filled with yellow show magnetic reversal crossings rotated onto their same-age counterparts across the ridge. The solid symbols and white-filled symbols are magnetic reversal crossings in their original locations. The coloured lines are the great circles that best fit the stationary and rotated reversal crossings for each palaeo-spreading segment.

Figure S21. Along-track magnetic anomaly observations, magnetic reversal identifications, and reconstructed magnetic lineations for the magnetic reversals identified in the legend above the figure. The map base is 1-min seafloor bathymetry from topex.ucsd.edu/WWW_html/mar_topo.html (Smith \& Sandwell 1997). The magnetic reversals shown in the figure are reconstructed with best-fitting Somalia-Antarctic rotations from Table 8. The symbols that are filled with yellow show magnetic reversal crossings rotated onto their same-age counterparts across the ridge. The solid symbols and white-filled symbols are magnetic reversal crossings in their original locations. The coloured lines are the great circles that best fit the stationary and rotated reversal crossings for each palaeo-spreading segment.

Please note: Oxford University Press is not responsible for the content or functionality of any supporting materials supplied by the authors. Any queries (other than missing material) should be directed to the corresponding author for the paper. 